\title{
الدلالة الإشارية والإعلان المعاصر
}

\author{
اعتوالو

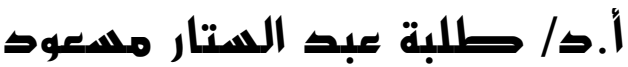 \\ معهد اللغة العربية - جامعة أم القرى البه \\ القبول : 7r/r/r / \\ الاستلام: 19/r/0
}

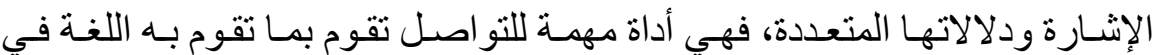

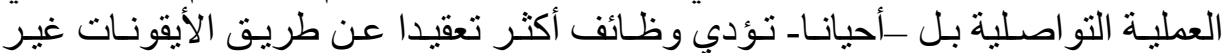

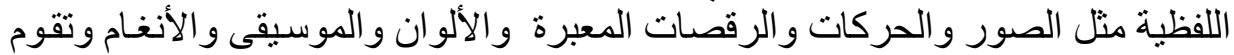

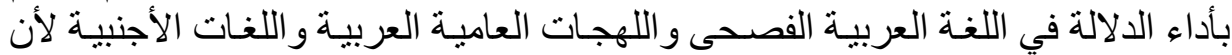

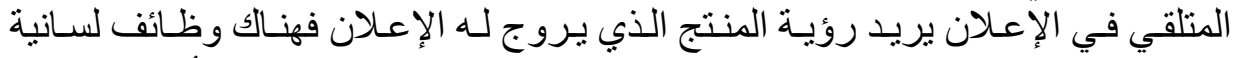

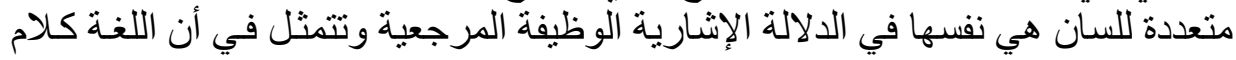

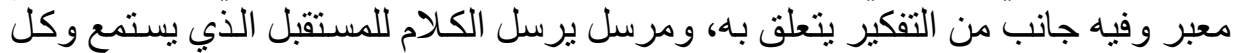

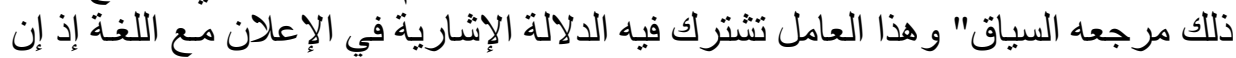

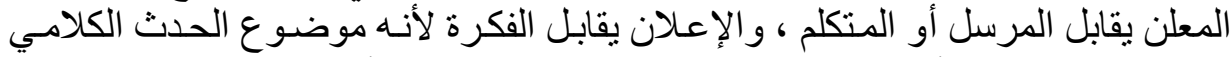

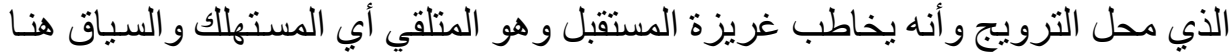

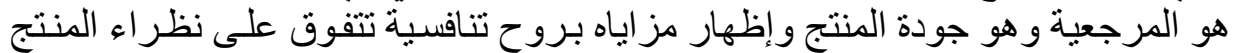

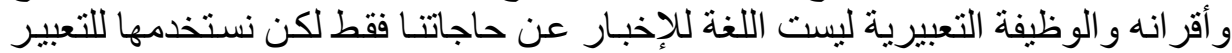

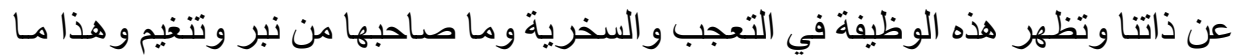

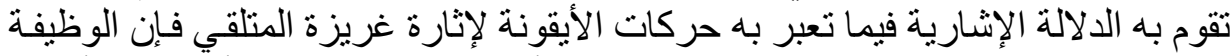

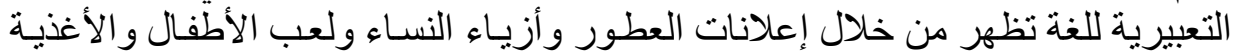

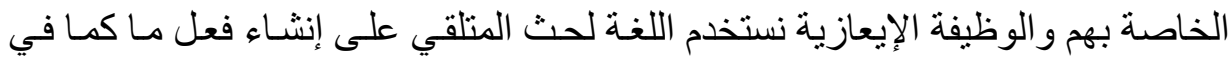

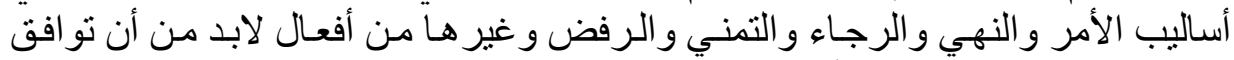

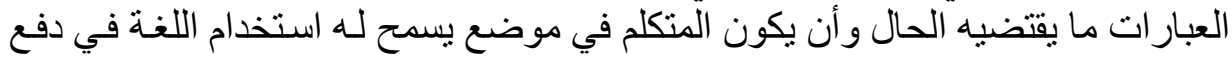

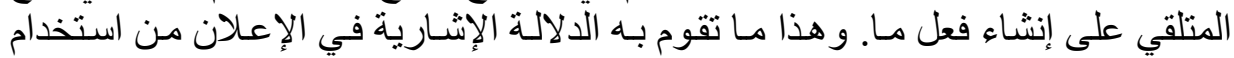

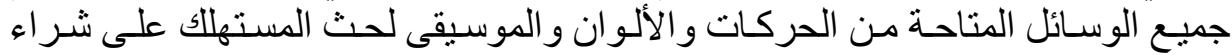

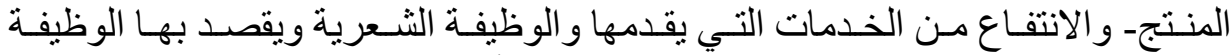

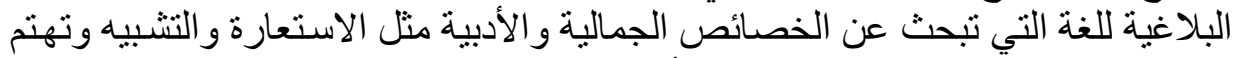

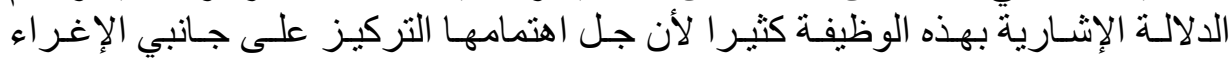




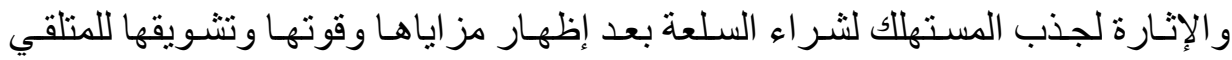

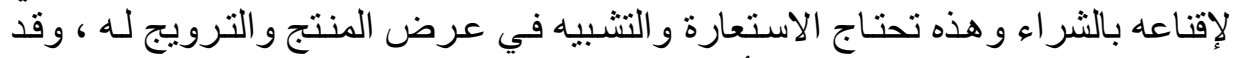

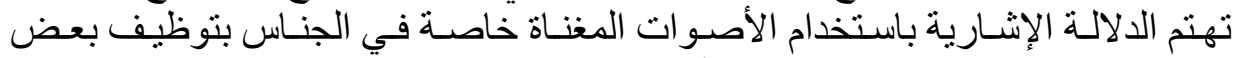

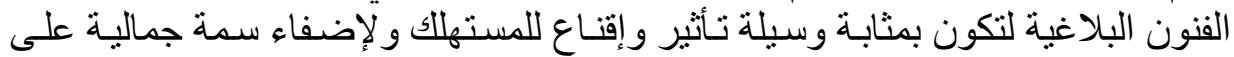

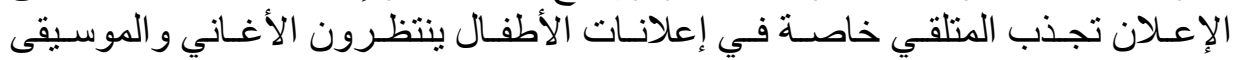

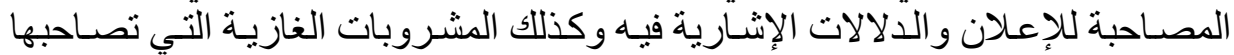

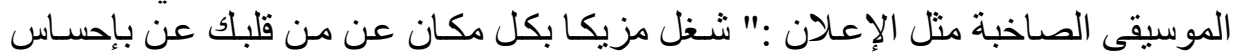

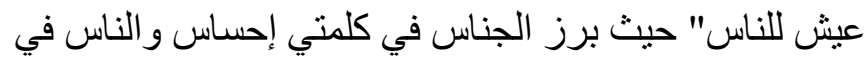

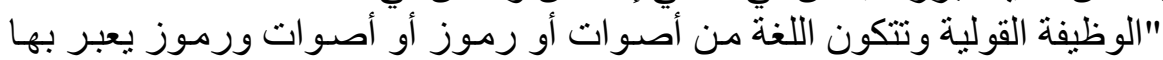

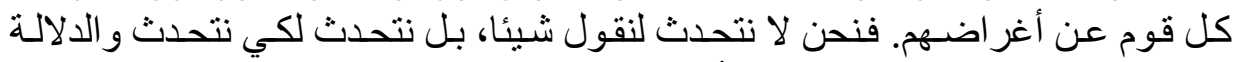

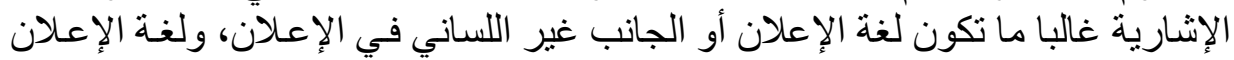

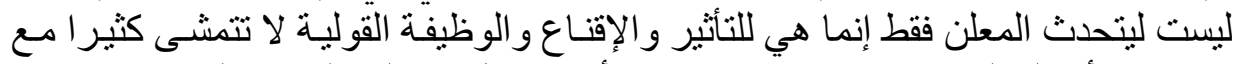

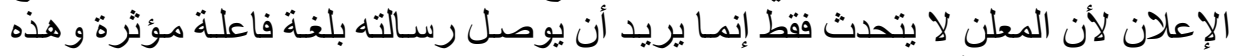

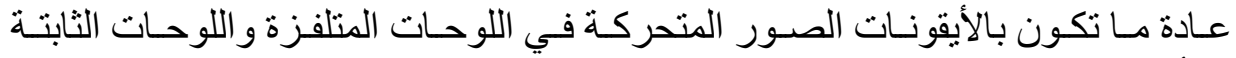

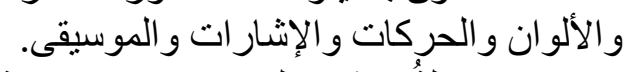

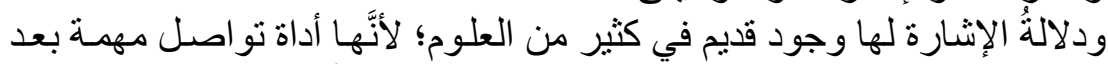

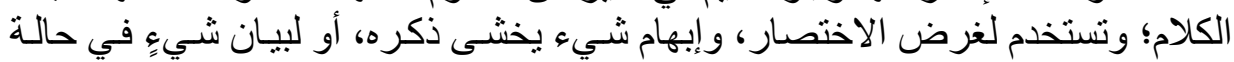

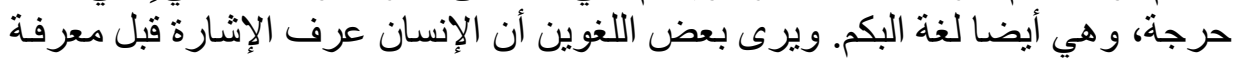

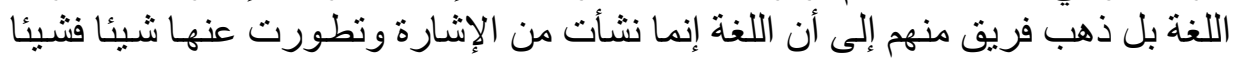

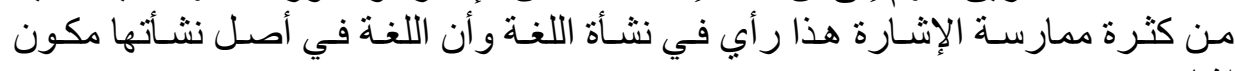

فالإشارة تتحصر في إطار محدود لا يتغير، إذ بعبر بـه الفهم دون أنْ بلاحظها إثناري.

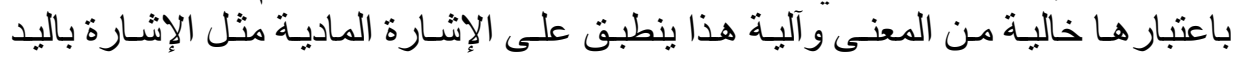

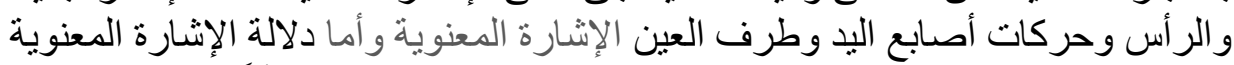

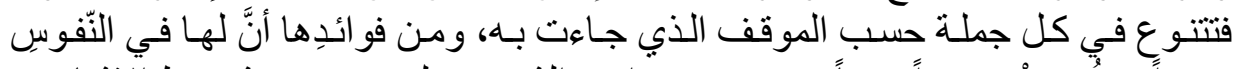

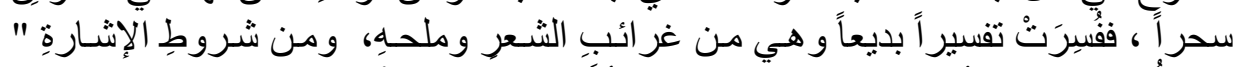

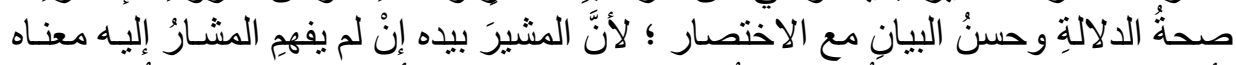

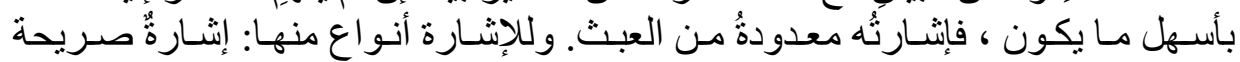

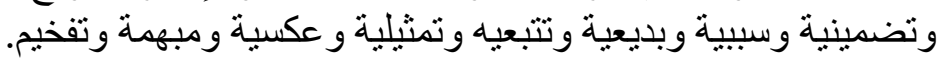




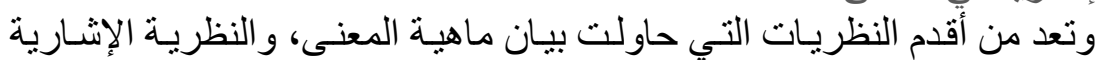

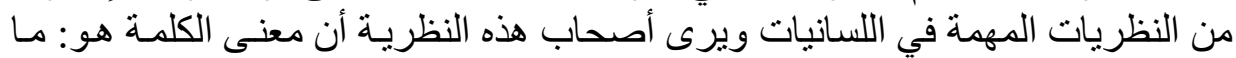

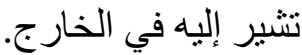
الكلمات الدالة : ( النظرية الإثناريةـ الدلالة_ الإعلان المعاصر - السيمياء)

Abstract :

The signal and its multiple meanings are an important communication tool that performs the language in the communicative process, but sometimes performs more complex functions through nonverbal icons such as pictures, movements, dances, colors, music, and melodies and performs the significance in standard Arabic, dialects and foreign languages. In the ad wants to see the product promoted by the ad there are multiple language functions for the same are in the reference signal reference function is that the language. sometimes performs more complex functions through nonverbal icons such as pictures, movements, dances, colors, music, and melodies and performs the significance in standard Arabic, dialects and foreign languages. In the ad he wants to see the product promoted by the ad, there are multiple linguistic functions of the Sun are the same in the reference signal reference function is that language is a word of expression and a part of thinking related to him, This factor shares the indicative significance of the declaration with the language, since the advertiser meets the sender or the speaker, the advertisement corresponds to the idea because it is the subject of the speech event that is in the promotion and it addresses the instinct of the future which is the receiver ie the consumer and the context here is the reference is the quality of the product and show Its advantages in a competitive spirit that surpass the product counterparts and peers and expressive function is not the language to tell us about our needs, but we use them to express ourselves and show this function in the exclamation and ridicule and associated with the tone and toning and this is what sign indicative sign as the movements icon 


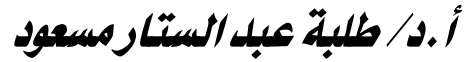

icon to stir The instinct of the recipient The expressive function of the language is manifested through advertisements for perfumes, women's fashion, toys, their food, and the instructional function. We use language to induce the recipient to create an act as in the methods of command, prohibition, hope, wish, refusal and other actions. In a position that allows him to use the language in pushing the receiver to create an act. This is what the indicative sign in the Declaration makes of using all available means of movement, color and music to induce the consumer to purchase the product - and to benefit from the services it provides and the poetic function. It is meant by the rhetorical function of the language that is looking for aesthetic and literary characteristics such as metaphor and metaphor. Because most interest focus on both sides of the temptation and excitement to attract the consumer to buy the product after showing the advantages and strength and marketing to the recipient to persuade him to buy and this requires metaphor and analogy in the presentation of the product and promotion, and may be indicative signal Using singing voices especially in the genre by employing some rhetorical arts to serve as a means of influencing and persuading the consumer and to impart an aesthetic feature to the advertisement that attracts the recipient especially in the children's ads waiting for the songs and music associated with the advertisement and its signifiers as well as soft drinks accompanied by loud music such as the announcement: From your heart about the sense of life for people "where the emergence of anaphylaxis in the words sense and people in "We are not talking to say anything, but talking to speak and indicative sign is often the language of the ad or the non-language aspect of the declaration, and the language of the declaration is not to speak only the advertiser but Is for influence and persuasion and the function of the colloquial is not very much in line with the declaration because the advertiser not only speaks but wants to deliver his message in 
effective language influential and these are usually icons animated images in televised paintings and paintings fixed colors and movements and signals and music.

The significance of the sign has an old presence in many sciences; it is a useful communication tool after speech; it is used for the purpose of abbreviation, the thumb of something that is feared to be mentioned, or to indicate something in a critical state, which is also dumb. Some linguists believe that man knew the sign before learning the language, but a group of them went on to say that the language originated from the reference and gradually evolved from the great practice of this reference in the origin of the language and that the language of origin is an indicative component .The signal is confined to a limited framework does not change, as it expresses the understanding without noticing it as free of meaning and mechanism This applies to physical reference such as hand and head signal and movements of fingers and the side of the eye Moral signal and the significance of the moral signal vary in each sentence according to the position it came, And it is beneficial for her to have magic in her soul, so she explained an excellent explanation which is one of the oddities of poetry and its salutation, and one of the conditions of the reference is "the validity of the meaning and the good statement with the abbreviation; because the guide is in his hand if he does not understand what is meant by the easiest thing. A: A clear, inclusive, causal, intelligent, follow-up, representative, inverse, opaque and exaggerated Indicative theory in meaning It is one of the oldest theories that tried to define the meaning of the meaning, and the theory of the theory of important theories in linguistics and the owners of this theory that the meaning of the word is: what refers to abroad.

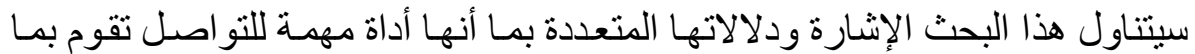

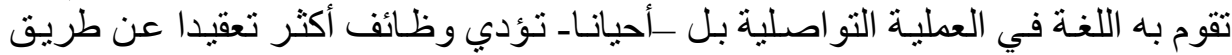

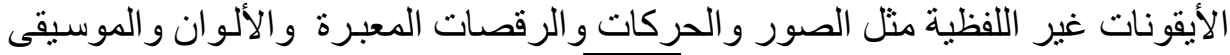




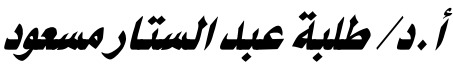

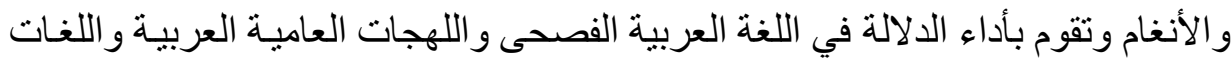

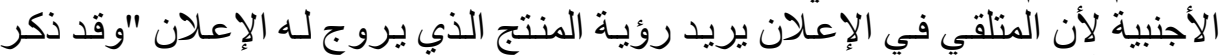

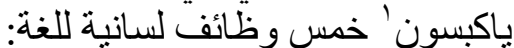

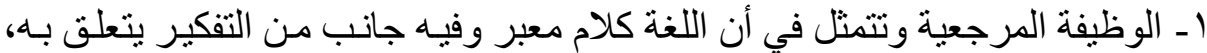

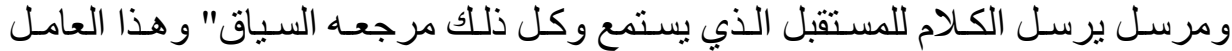

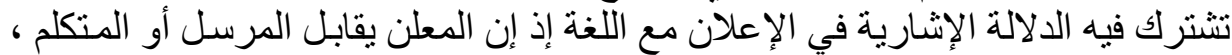

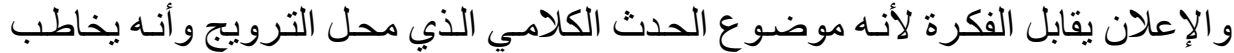

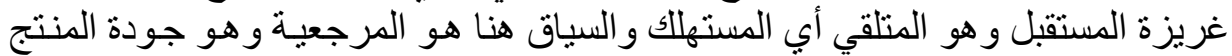

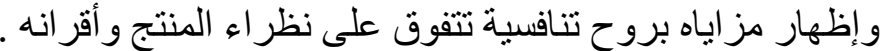

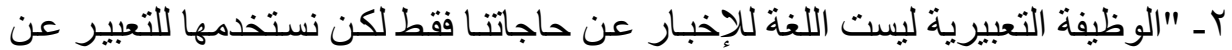

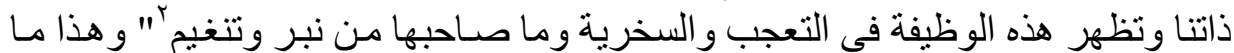

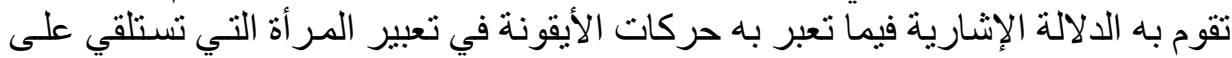

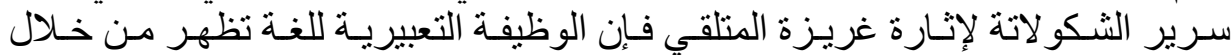

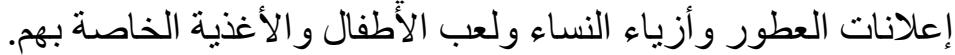

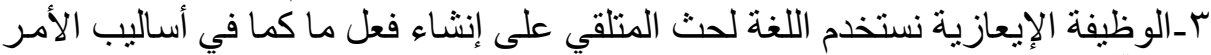

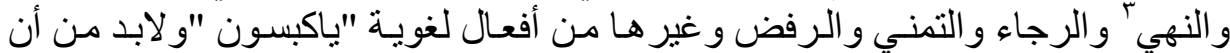

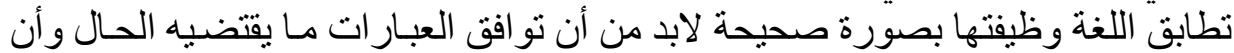

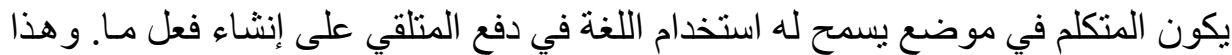

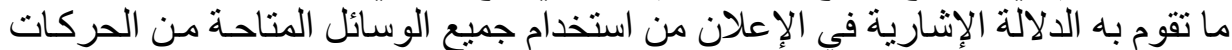

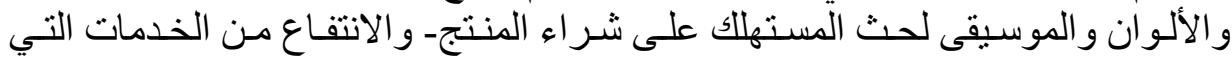

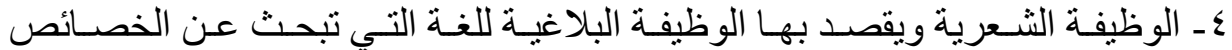

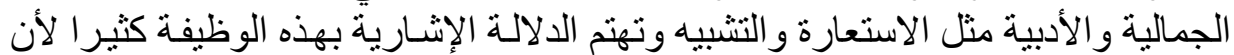

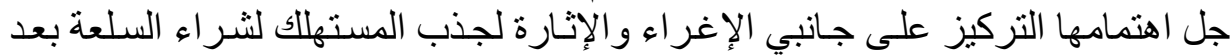

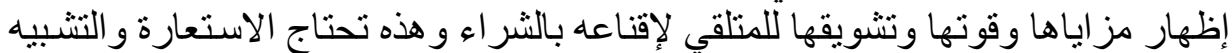

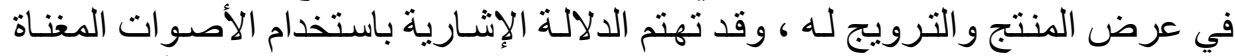

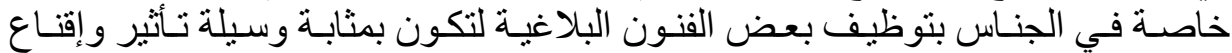
للمستهلك و لإضفاء سمة جمالية على الإعلان تجذب المتلقي خاصة في إعلانات الأطفال

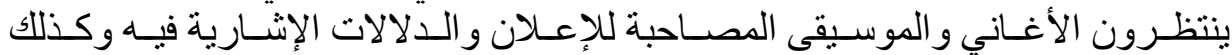

- باكبسون، اللغة دفاتر فلسفية ص10

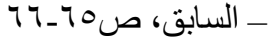

ـ ع عيسى عودة بر هومة التحليل اللغوي للخطاب الإعلاني صل ح "بتصرف" 
المشروبات الغازية التي تصاحبها الموسيقى الصاخبة مثل الإعلان :" شــل مزيكا بكل فئل

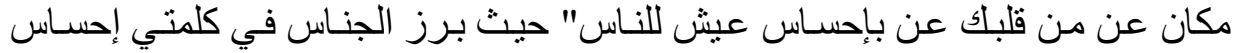

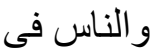
"الوظيفة القولية' " وتتكون اللغة من أصوات أو رموز أو أصوات ورموز يعبر بها كل

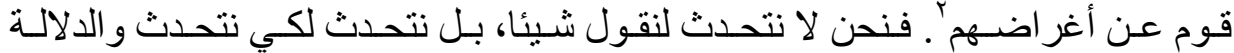

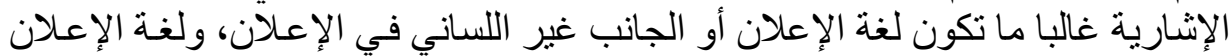

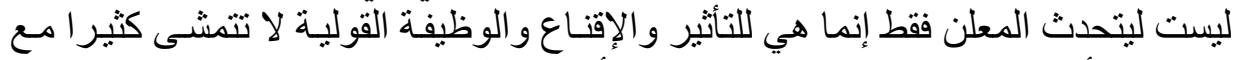

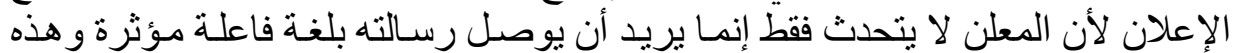

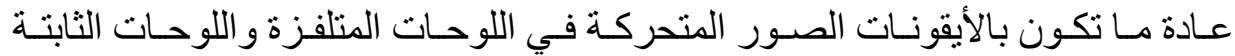

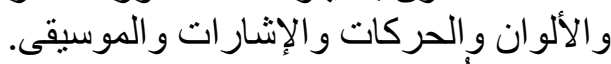

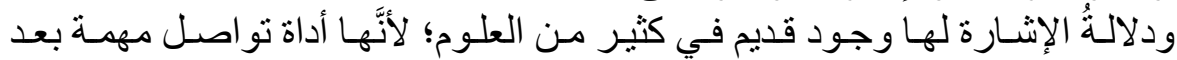

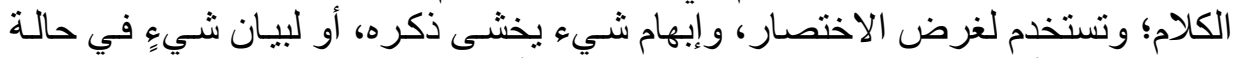

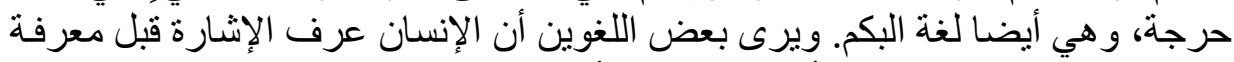

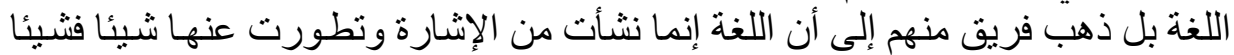

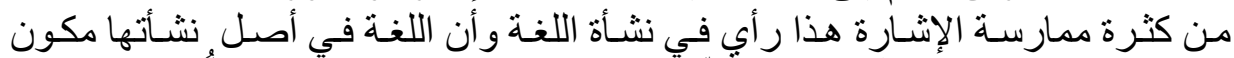

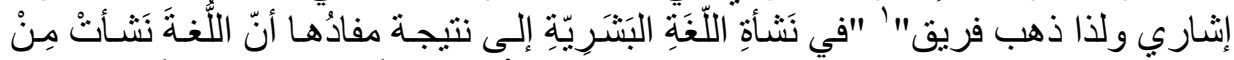

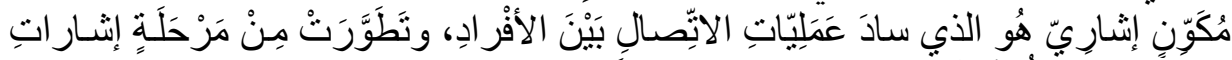

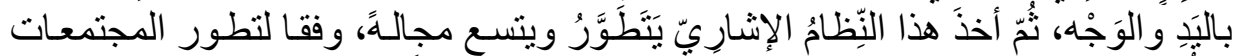

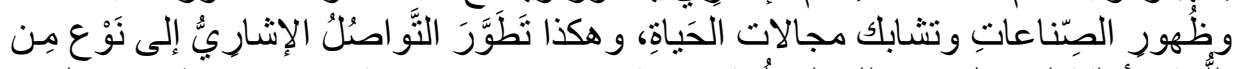

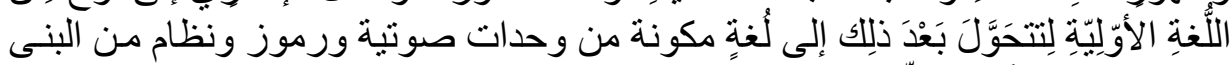

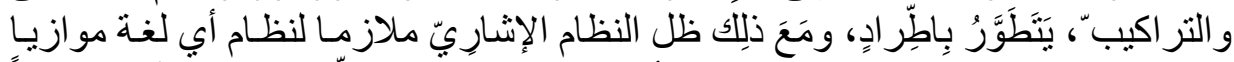

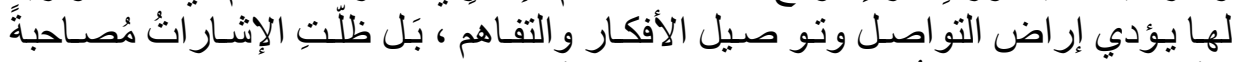

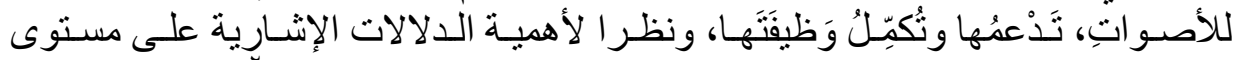

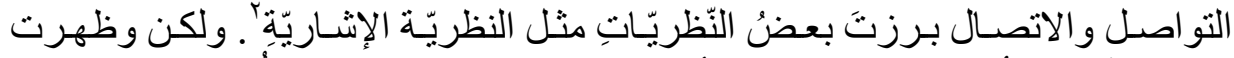

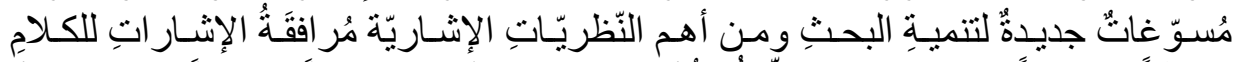

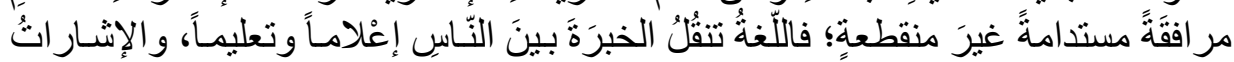

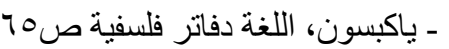

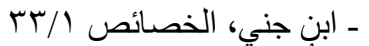

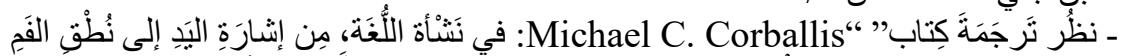

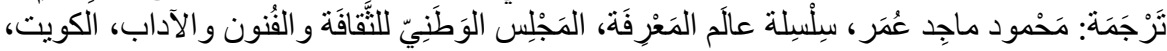

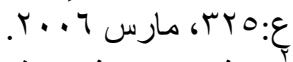
- غدوبس، وغروست، لغنة الجسد ترجمة هيلانة صالح شقير نشر دار علاء الدين للطباعة والتوزيع 


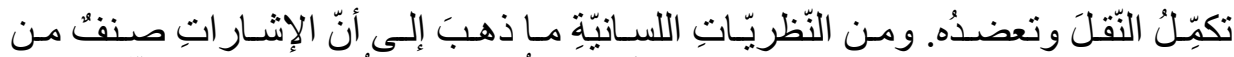

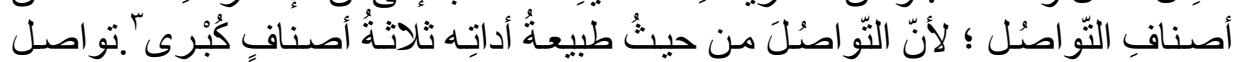

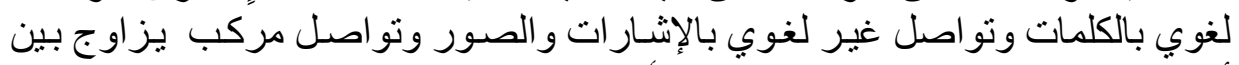

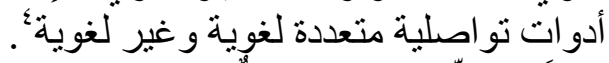

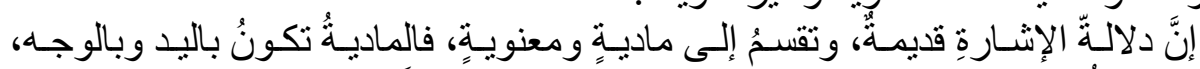

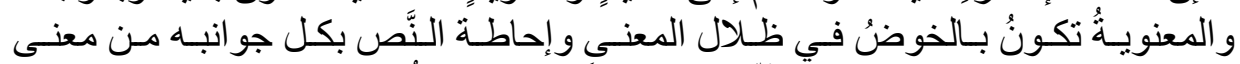

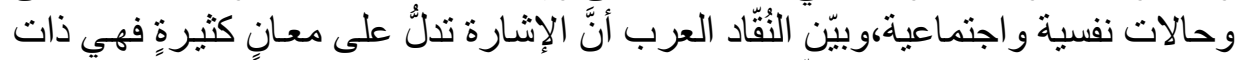

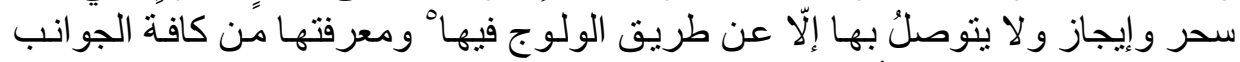

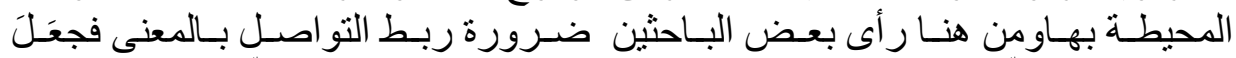

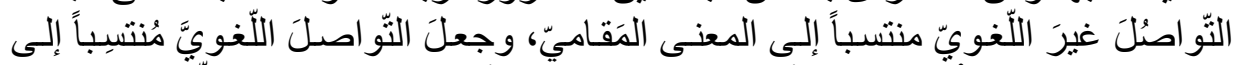

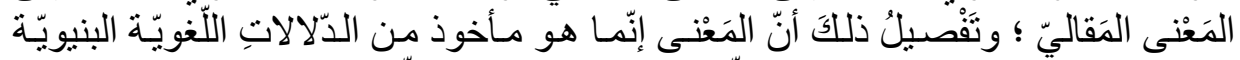

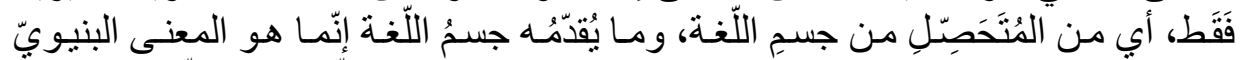

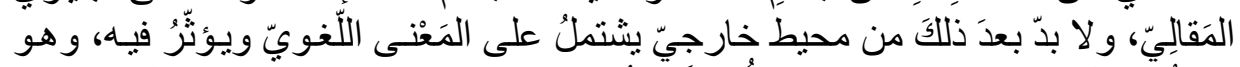

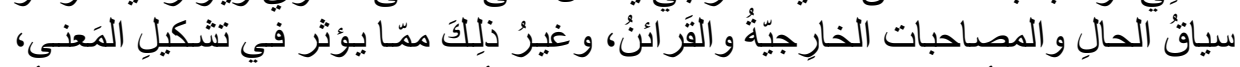

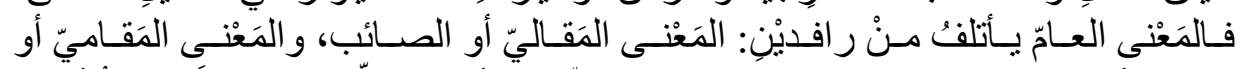

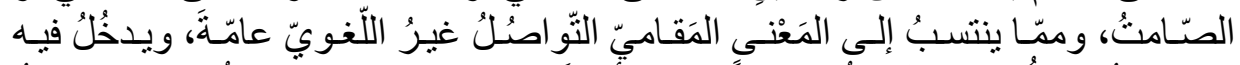

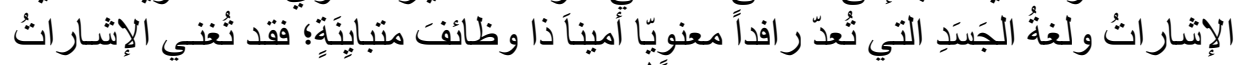

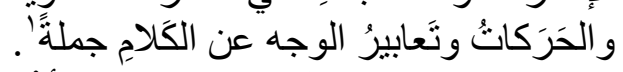

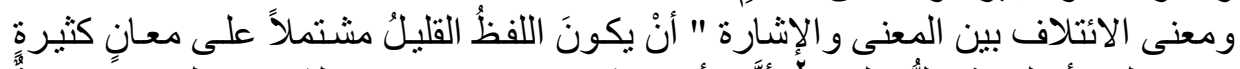

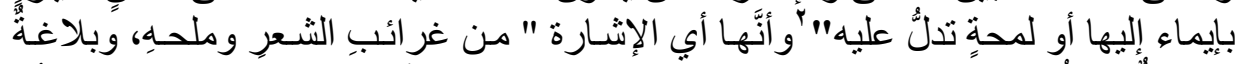

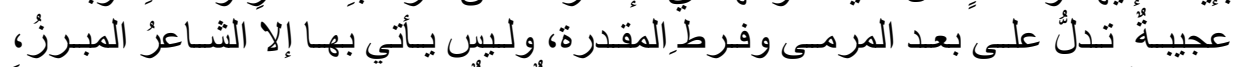

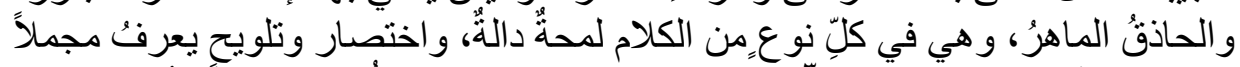

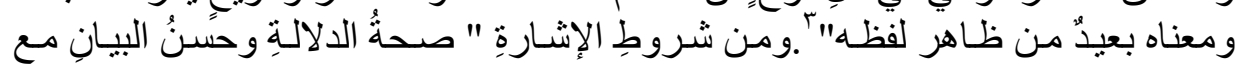

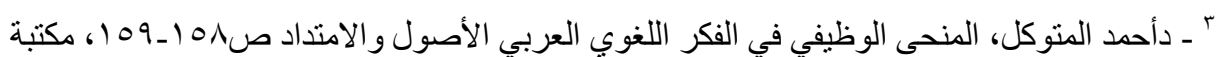

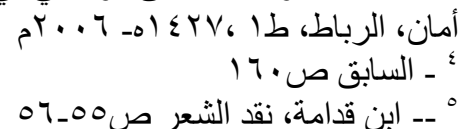

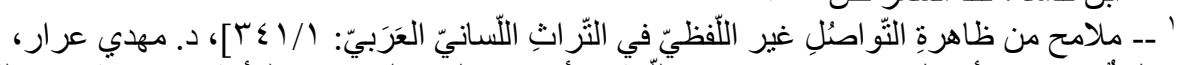

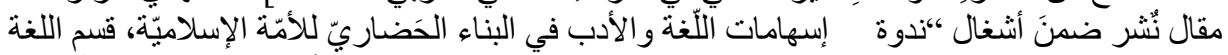

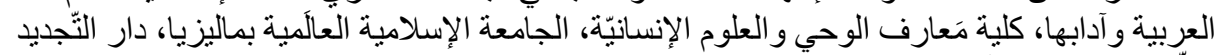

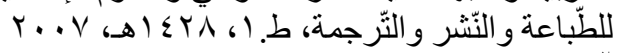

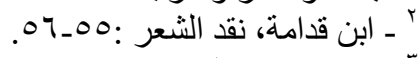


الاختصار ؛ لأنَّ المشيرَ بيده إنْ لم يفهرٍ المشارُ إليه معناه فلا قيمه للإشارة.

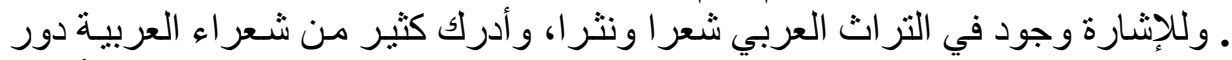

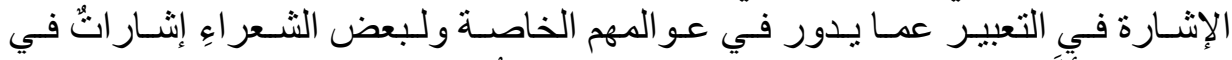

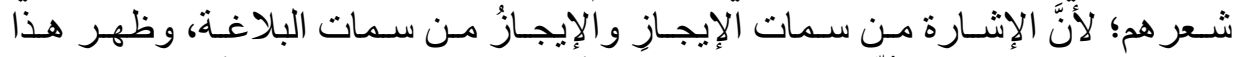

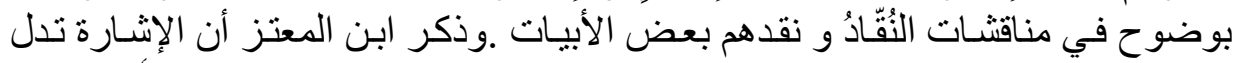

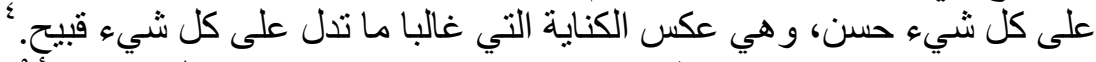

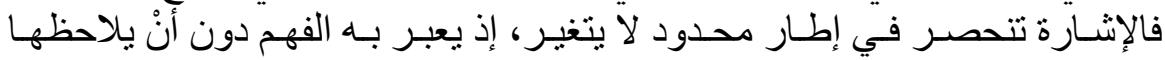

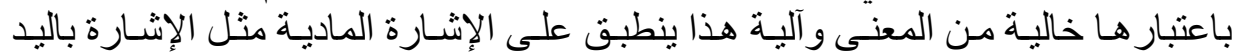

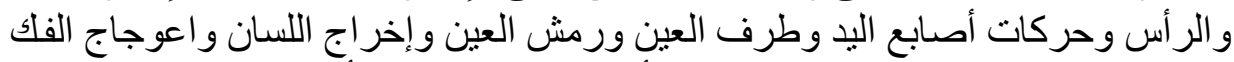

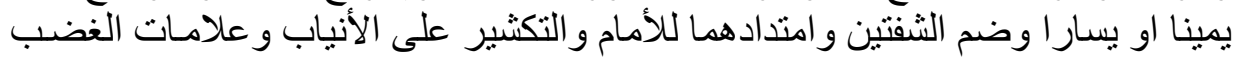

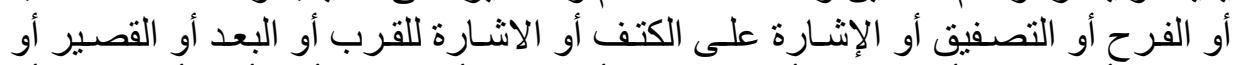

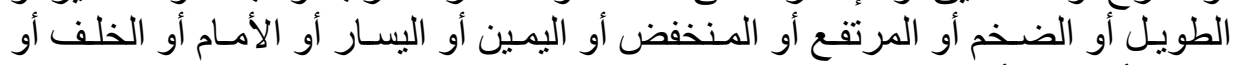

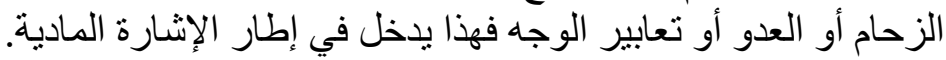
الإشارة المعنوية:

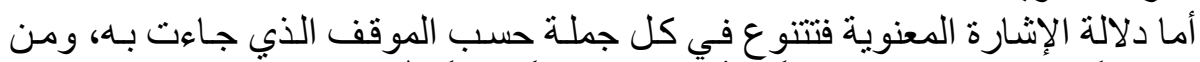

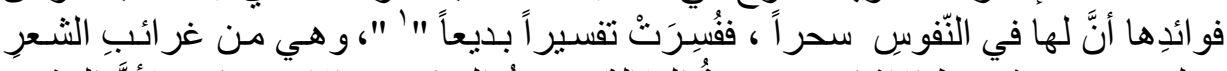

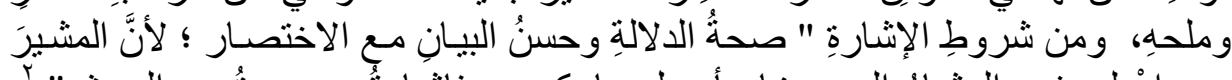

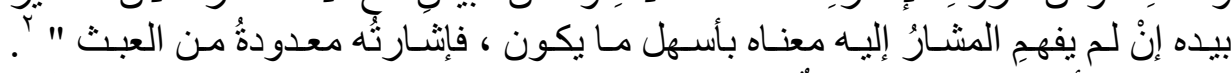

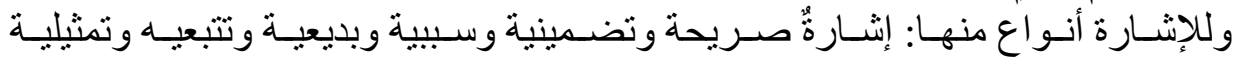
و وكسية ومبهمة وتفخيم وتلويح عن طريق الخهارة الخوض في ضباب المعنى و الربط بينَ الاسم و الفكرة و المشار إليه. أمَّا الفرق بين الإشـارة و الرمز فـ " فالإشـارة تتحصر في إطار محدود لا يتغير ، إذ يعبر

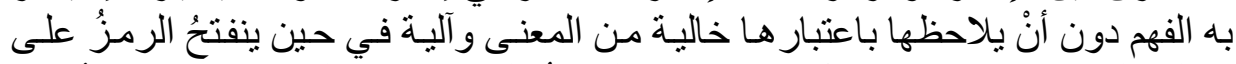

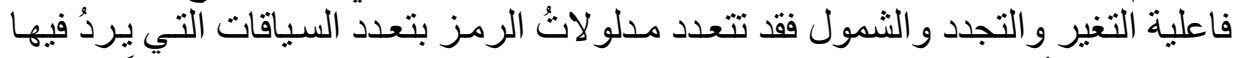

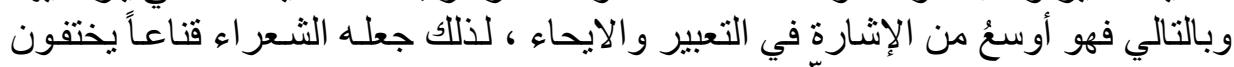

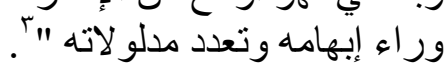
النظرية الإشارية في المعنى مدنى وتعد من أقدم النظريـات التي حاولت بيـان ماهية المعنى، والنظريـة الإشـارية من

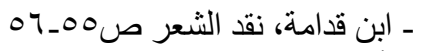

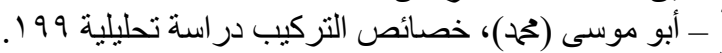

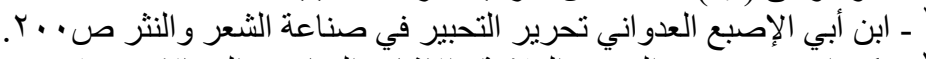

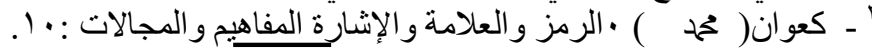




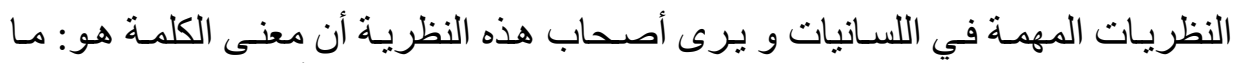

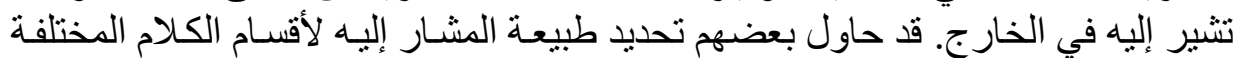

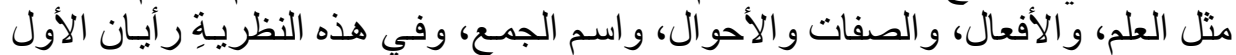

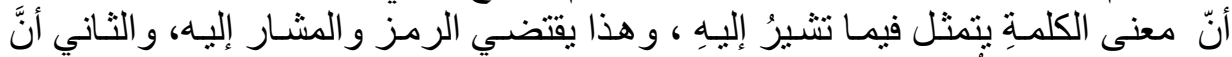

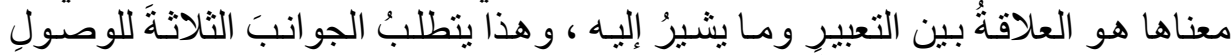

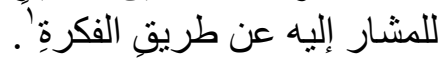

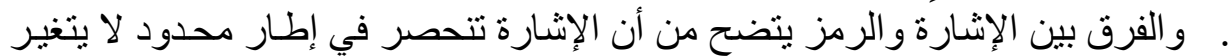

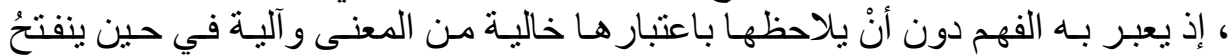

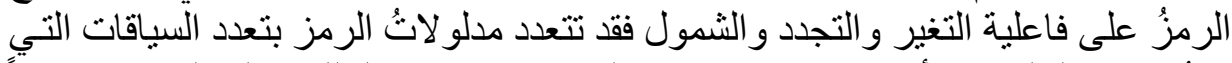

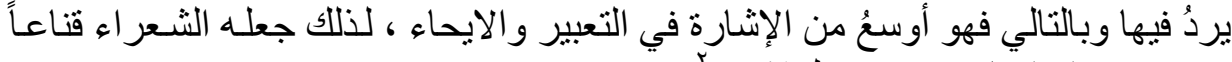

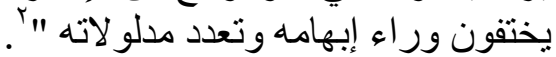

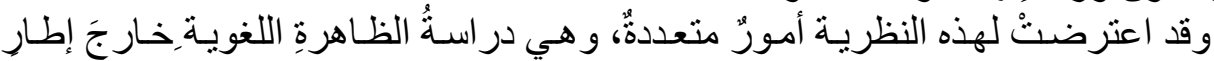

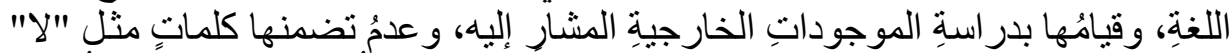

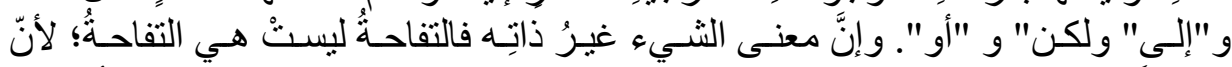
.

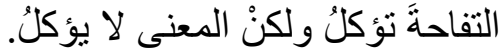

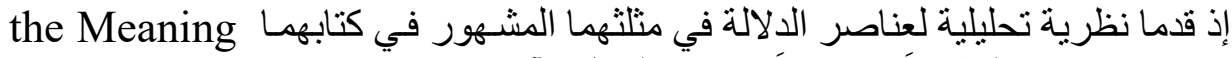
of Meaning

$$
\text { الفكرة - المرجع - المدلول }
$$

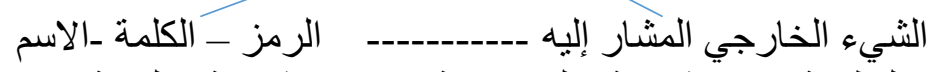

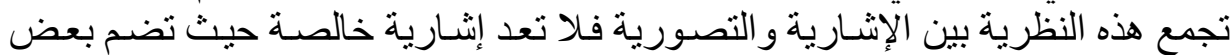

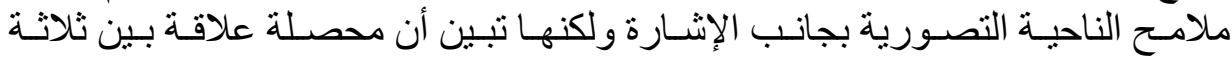

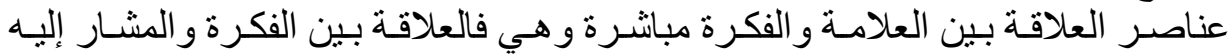

$$
\text { إنشارية وقد تكون شبه إيقونية. }
$$

و العلاقـة بين الرمـز و المشـار إلبـه غيرة مباشـرة و لا تكـون إلا عن طريق الفكرة

لذارسم خطا متقطعا بين العلامة و المشار إلئه اليها

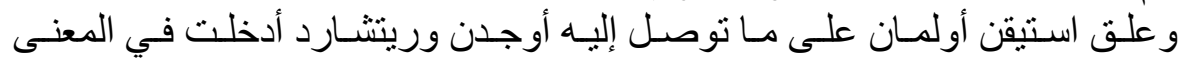




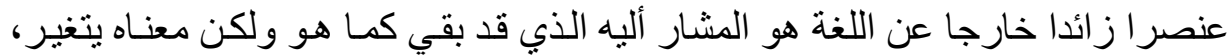

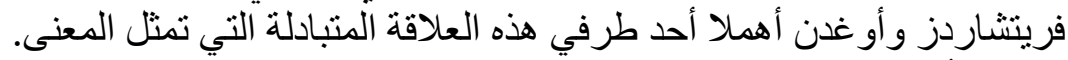

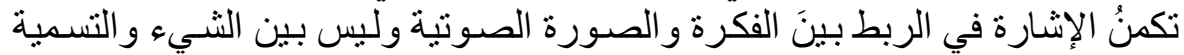

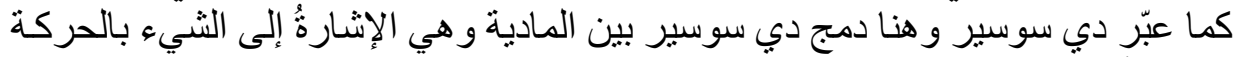

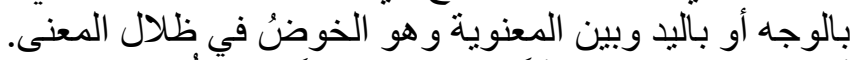

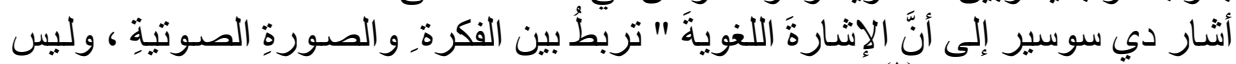

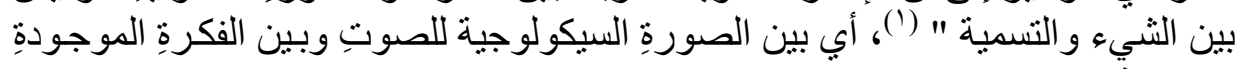
و هذا يعني أنَّ لفظةَ الإشـارةِ تدل على الفكرةِ بأكملها ، و الصورةِ الصونية ، وقد

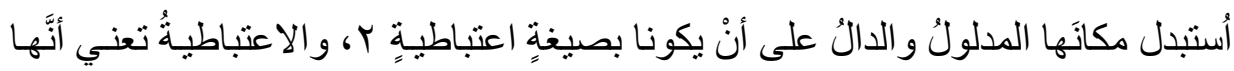

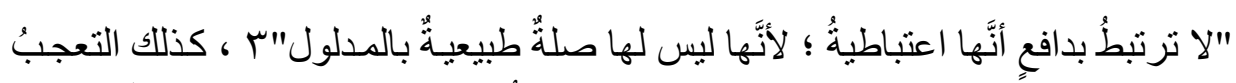

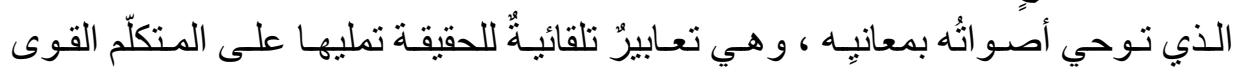

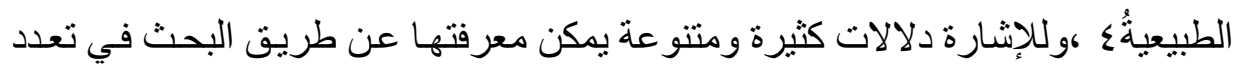

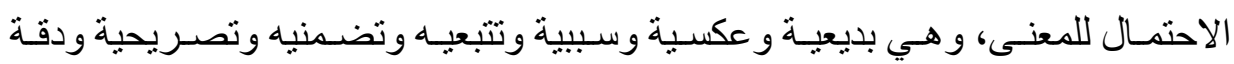

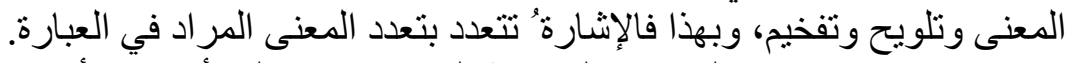

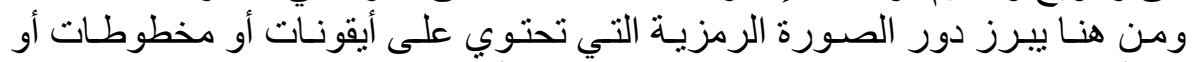

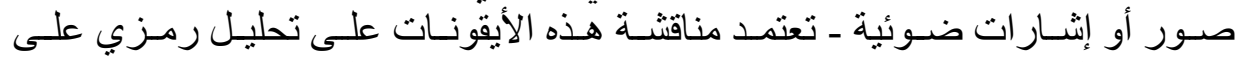

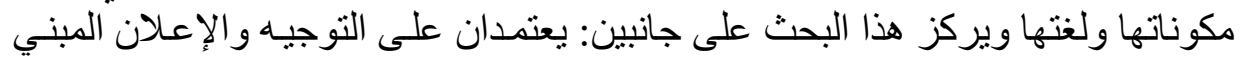

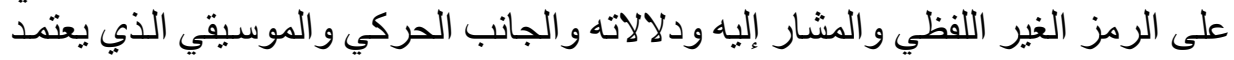

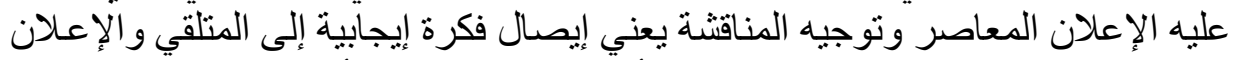

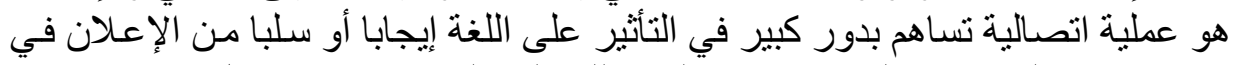

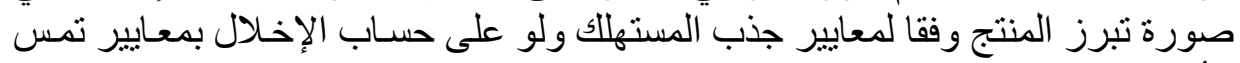

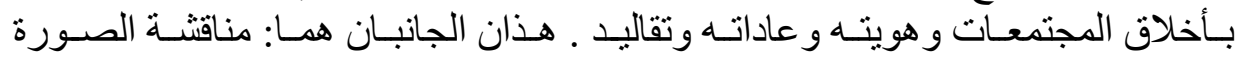

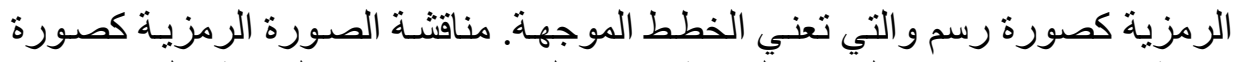
رقمية مما يعني استخدام الصور الرّفية لإنشية لإنشاء الصور في عصر الرقمنة والحاسوب.

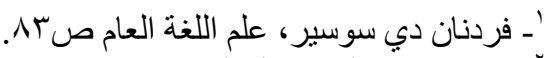

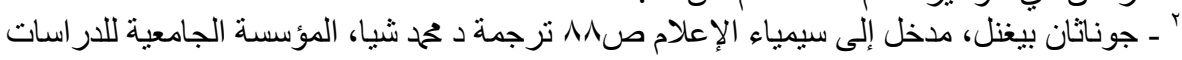

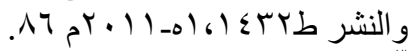

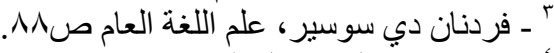

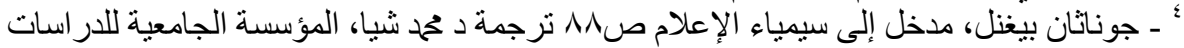




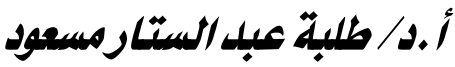

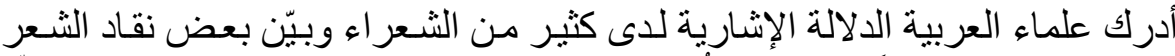

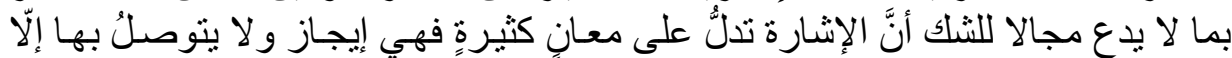

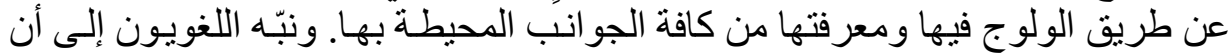

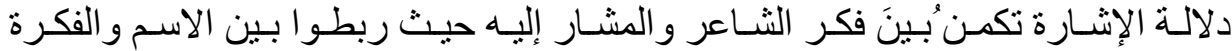

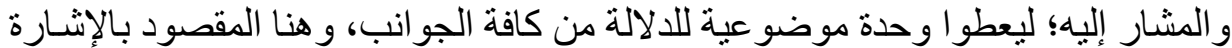

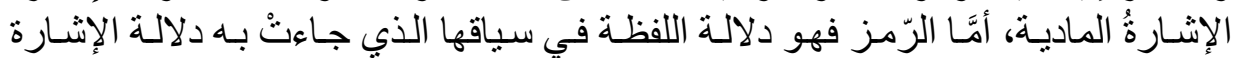

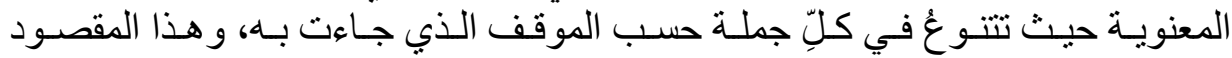

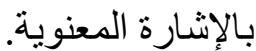

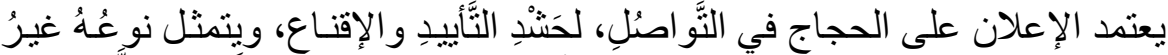

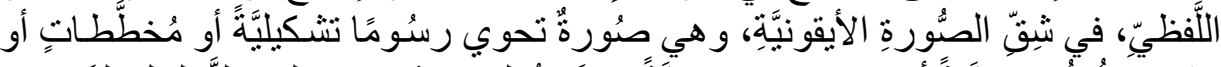

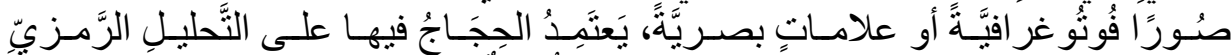

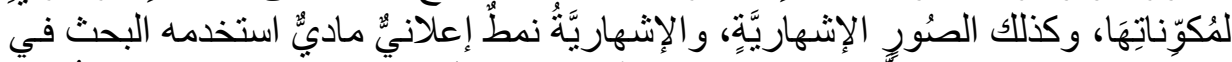

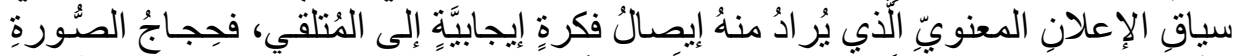

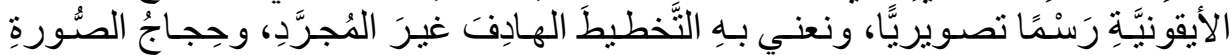

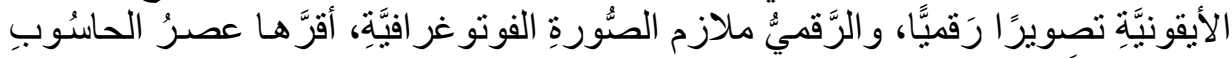

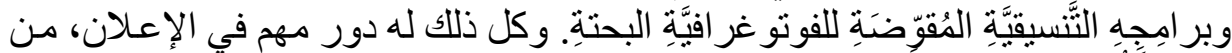

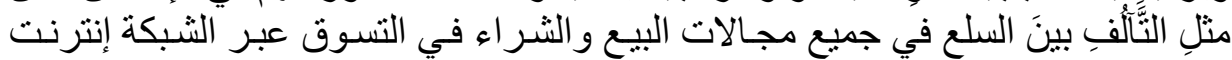

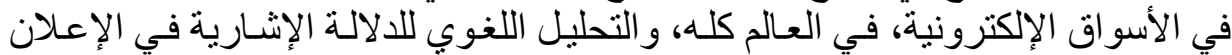

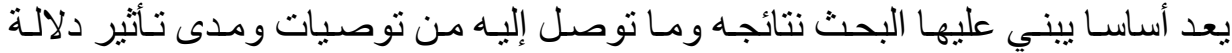

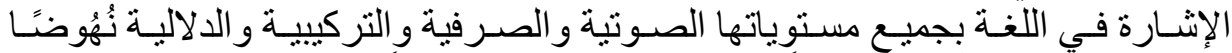

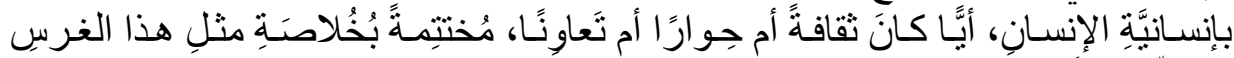

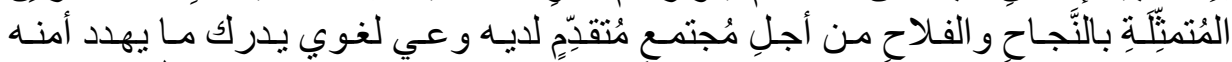

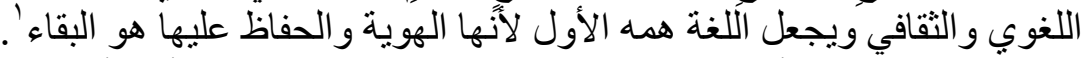

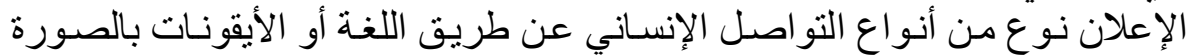

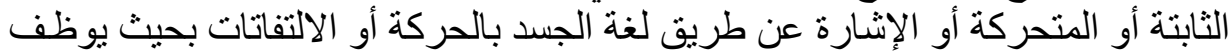

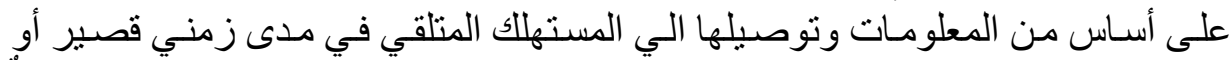

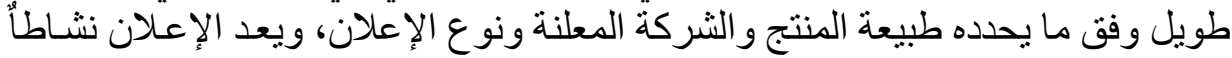

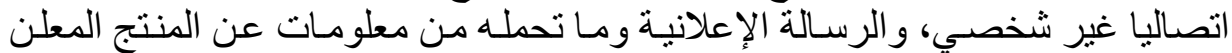

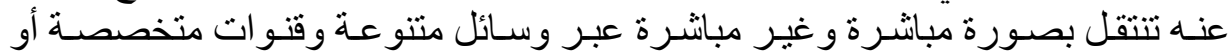

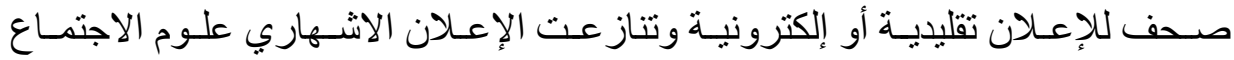

' - إسر اء عامر شمس الدين السعدي، الحجاج في الصورة الأيقونية، مجلة سيمائيات، المجلد7، العددّ/

https://www.asjp.cerist.dz/en/article/56740 


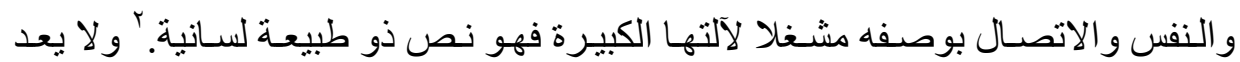

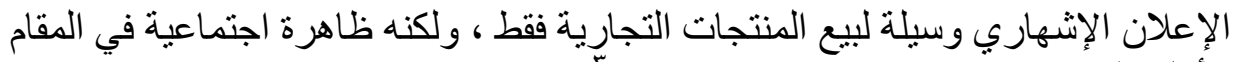

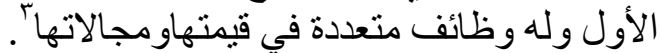

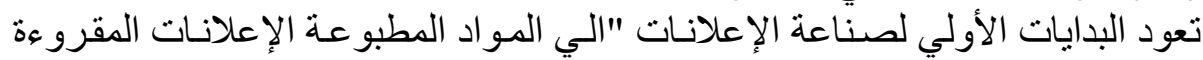

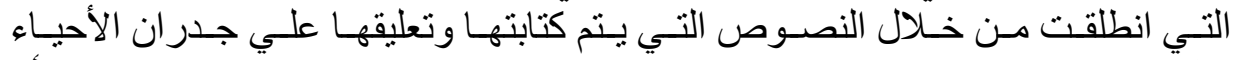

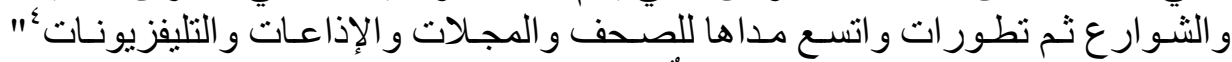

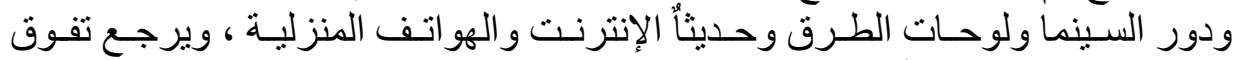

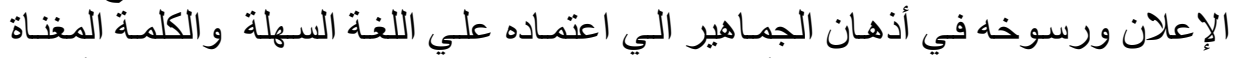

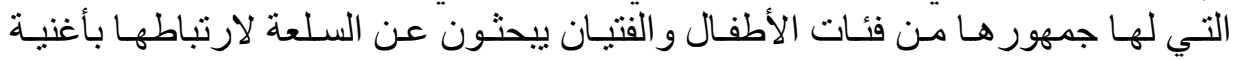

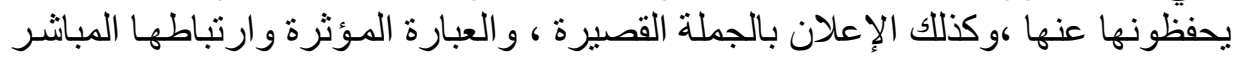

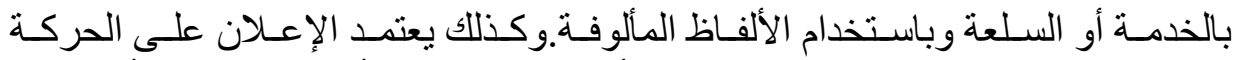

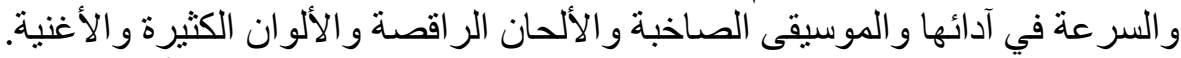

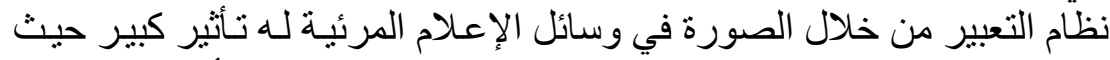

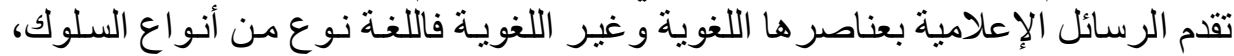

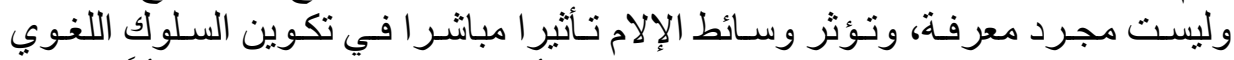

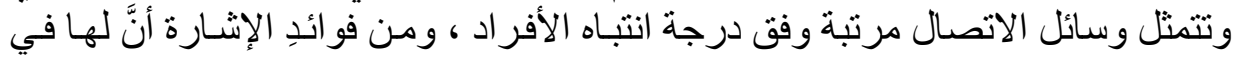

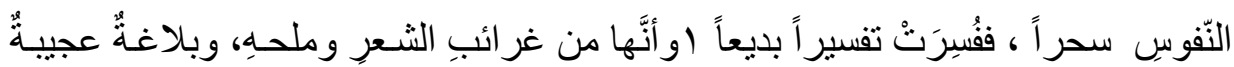

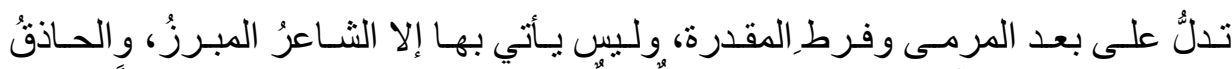

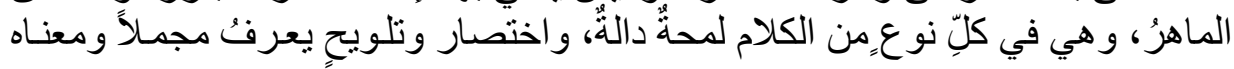

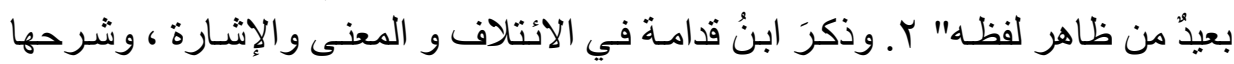

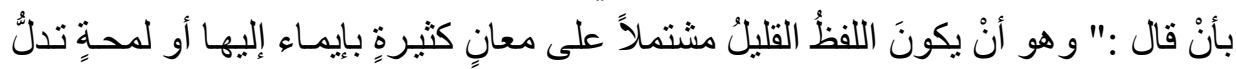
عليهץ" بان : اعلان

\section{الإعلان المعاصر وتأثيره في اللغة الإنة}

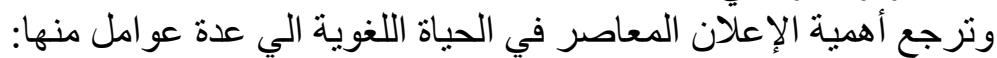

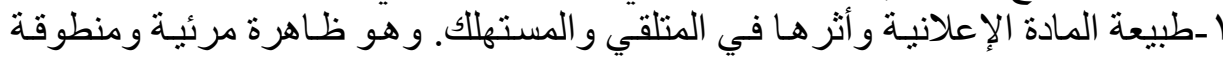

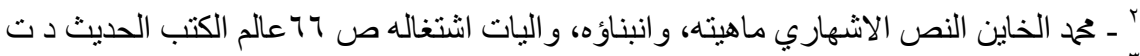

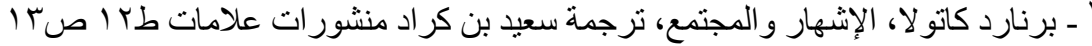

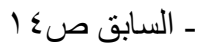

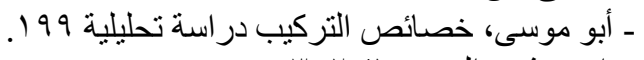

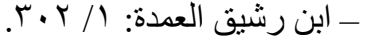

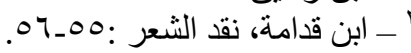




\section{أ اد طلبة عبل الستارمسعود}

$$
\begin{aligned}
& \text { و ومسمو عة والحوار و الإقناع في عرض المنتج. }
\end{aligned}
$$

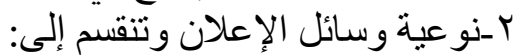

$$
\begin{aligned}
& \text { ا _المرناة "التلفاز . }
\end{aligned}
$$

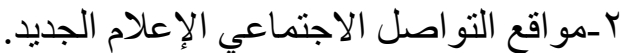

$$
\begin{aligned}
& \text { بـ ـالإعلان في الصحف التول التقليدية الإلكترونية. } \\
& \text { ـ ـ الإذاعة. } \\
& \text { بـ ـلوحات الإذاعة الإنلان المتلفزة و العادية على الطرق و الحو ائط و الحافلات و القطار ات } \\
& \text { عـ السينما الناطقة و الإعلان الخطابات الرسمية. }
\end{aligned}
$$

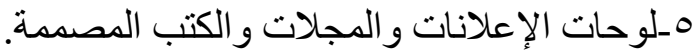

$$
\begin{aligned}
& \text { أنواع الإعلانات ـمقرو عة - مرئية - مسمو عة. }
\end{aligned}
$$

وتتضمن هذه الأنو اع الدلالة الإشارية و يميل بعض المعلنين لاستخدام الأطفال

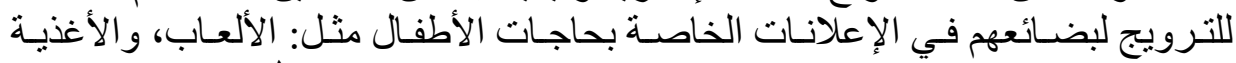

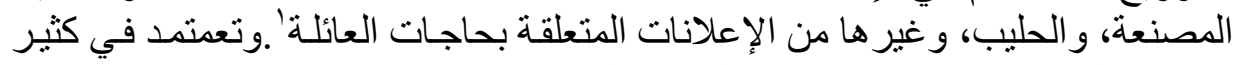
منها الدلالة الإشارية كما يتضح من النهايبة النماذج التطبيقية.

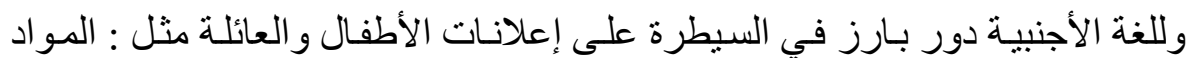

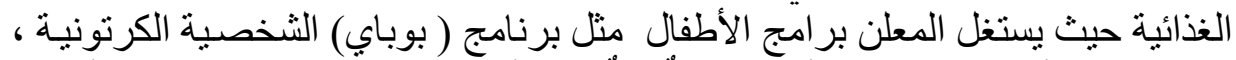

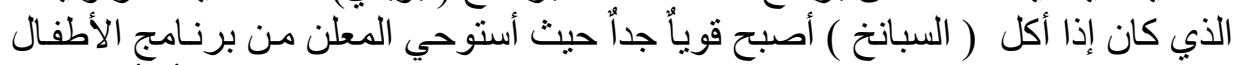

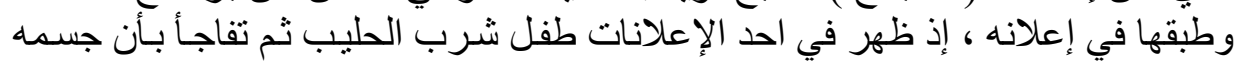

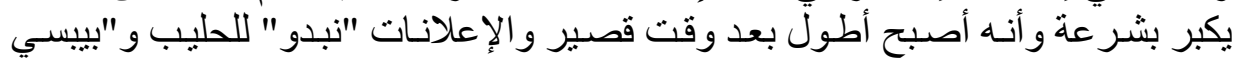

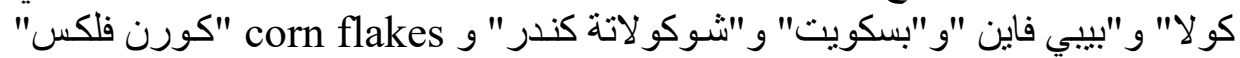

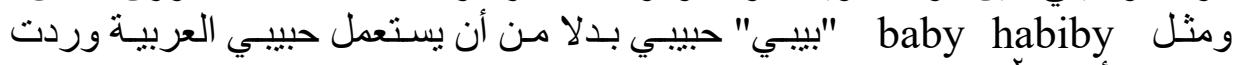
بحروف أجنبية

وتقوم عملية الاتصال الإعلاني على العناصر الآتية: اـلفت الانتباه نحو السلعة باللجوء إلى الأيقونة والموسيقى والحركة و اللون. r-تحفيز الرغبة عن طريق الدلالة الإشارية.

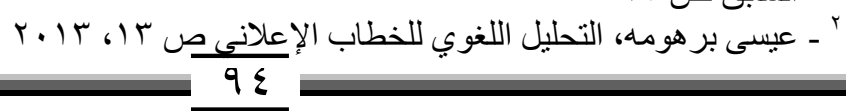


r- مخاطبة الأحاسيس وجذب المشاهد

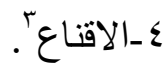

\section{من خصائص الدلالة الإشارية في الإعلان:}

1 - حضور ها على شاثات التلفزة و الإذاعات و الصحف.

ץ ـ اعتمادها على جذب المشاهد و اقناعه بوسائل متنو عة الصـورة الحركة اللون الأغنية القصيرة الموسيقى المصاحبة للجمل المغناة.

\section{الدلالة الإشارية الأيقونية في الإعلان:}

تصف المنتج و لا تنقله، تبين مميز اته، تتجاوز حدوده المرئية.ـ- ترستخ في ذهن الإنس

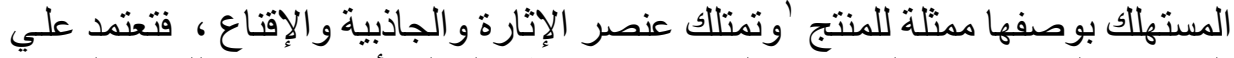

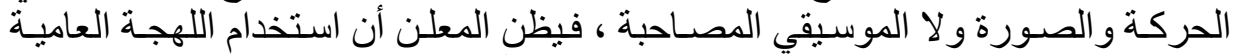

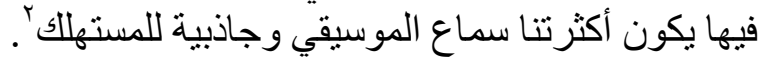

و الايقونات الملونة وبعض العلامـات السيمائية والصـورة الرمزيـة تدفع بشهية

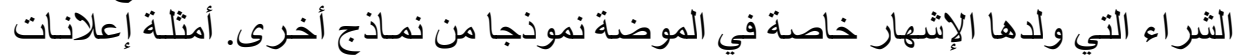

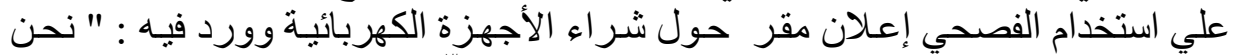

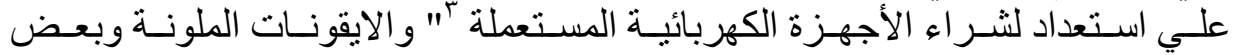

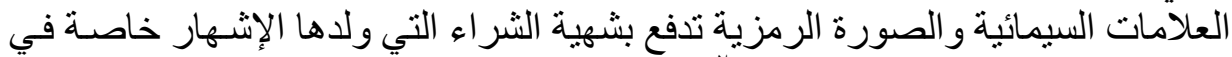

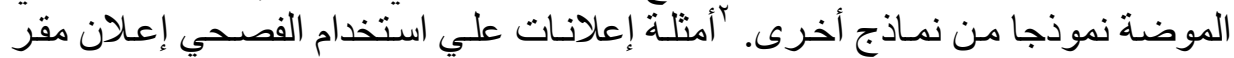

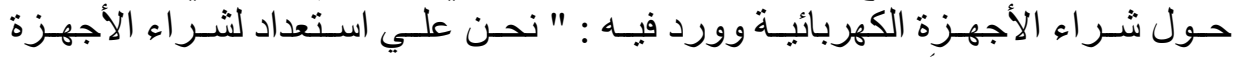

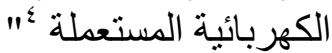

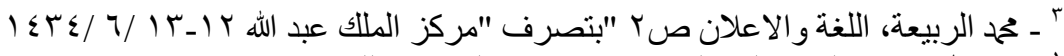

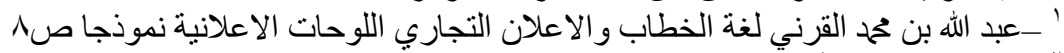

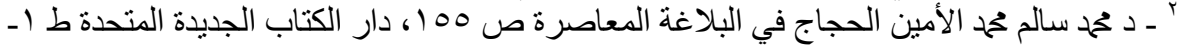
r.. 1

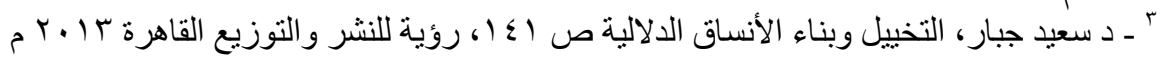
؛ -- د عبسى برهومه التحليل اللغوي للخطاب الاعلاني صبا 90 


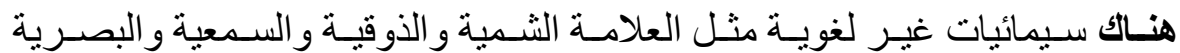

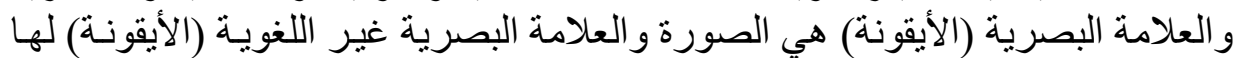

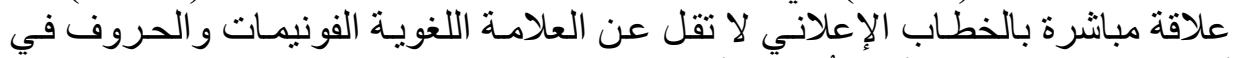

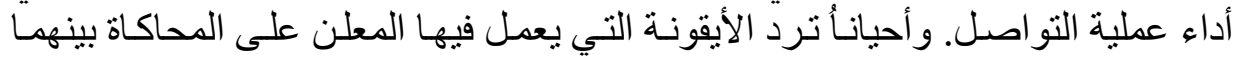

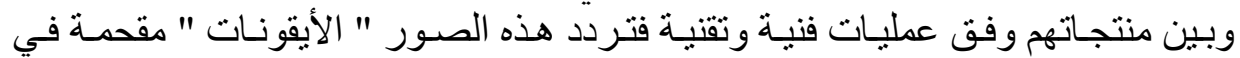

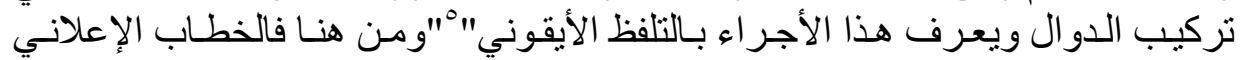

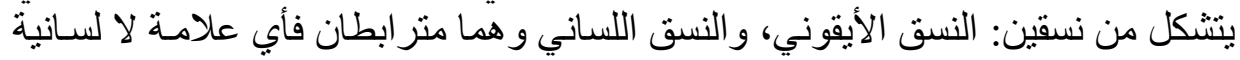

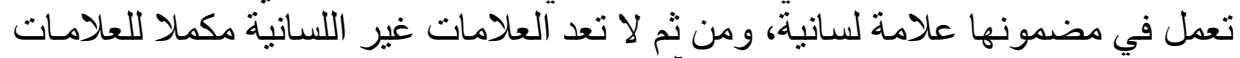

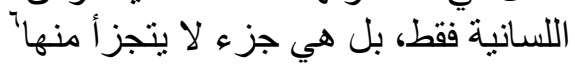

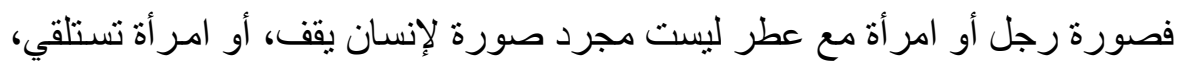

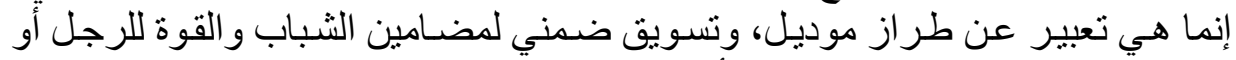

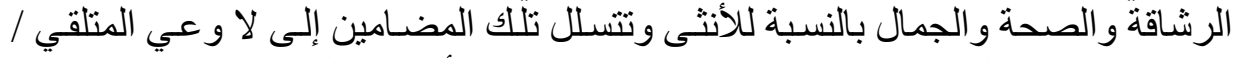

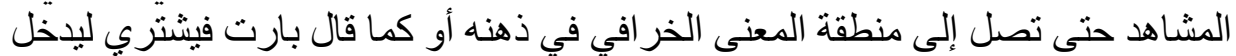

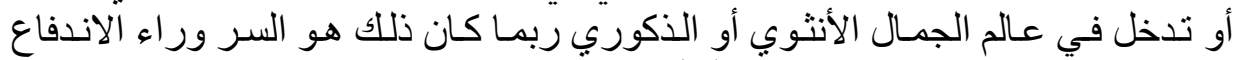

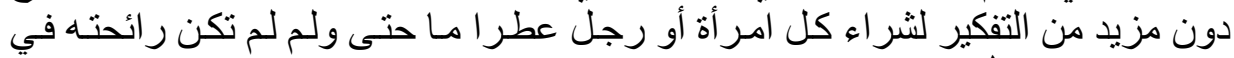

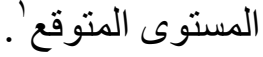

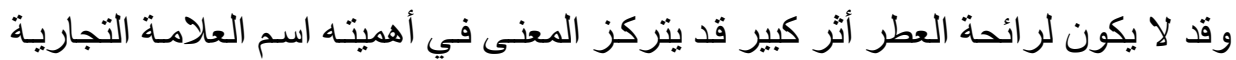

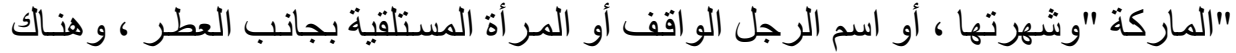

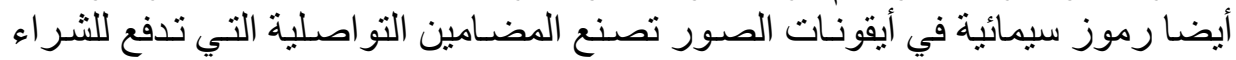

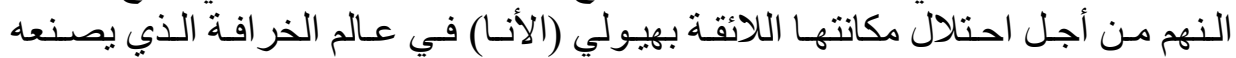

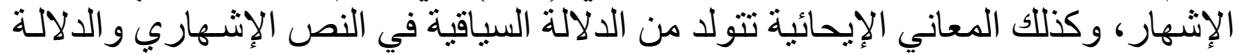

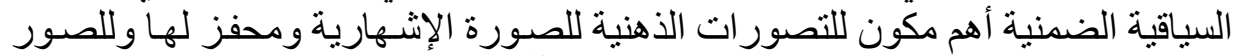

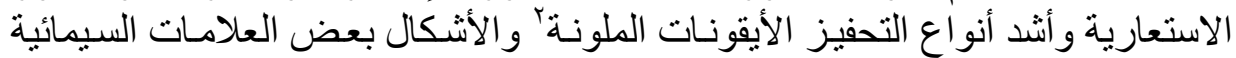

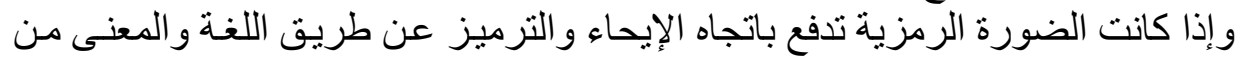

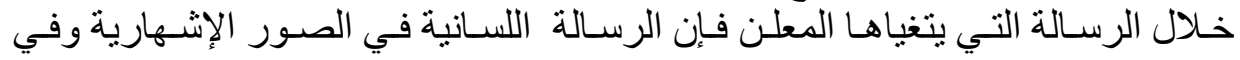

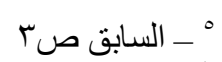
" ـ مرتاض عبد الجليل، المقارنة السيمائية، مجلة الأدوات و اللغات ع لأياد 1 ـ ك ص ص جامعة قاصدي مرباح، الجزائر ' ـ ـ عبد الله بن محمد القرني لغة الخطاب و الاعلان التجاري اللوحات الاعلانية نموذجاصى 
مقارنتها بالرسالة الرمزية تقوم على وظيفتين وظيفة الإرساء ووظيفة الإبدال ونتكلان

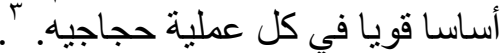

من أنو اع الدلالة الإشارية الإشارة الصريحة وتللك التي تكون فيها الإشـارة صريحة فيما

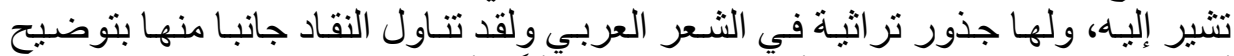

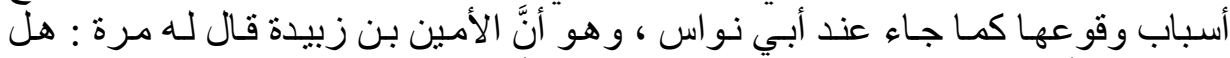

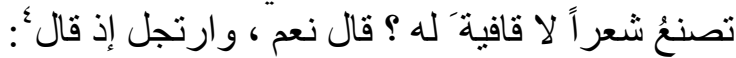

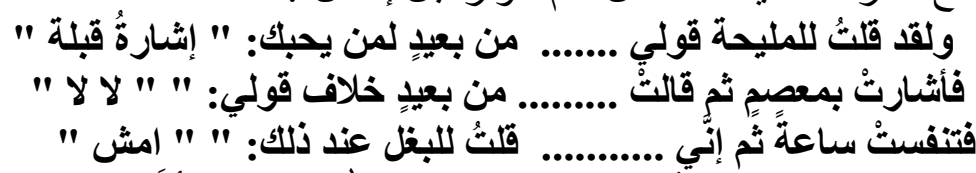

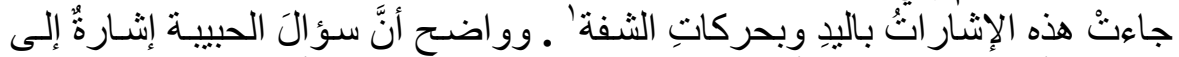

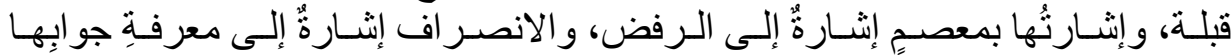
و القناعِة بـه.

ثم تطور الأمر في دلالة الإشارة ووظفها اللغويون في صناعة لغة للصدم و البكم

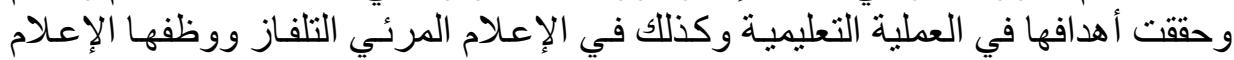

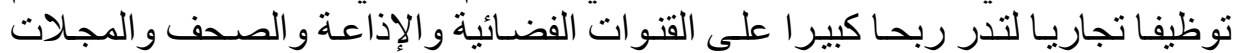

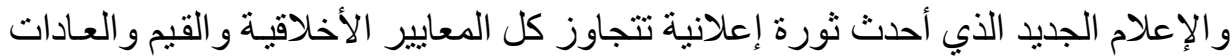

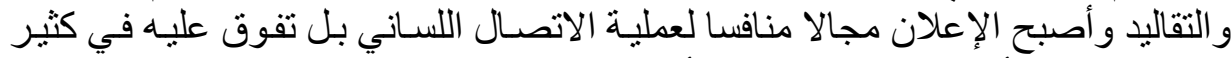

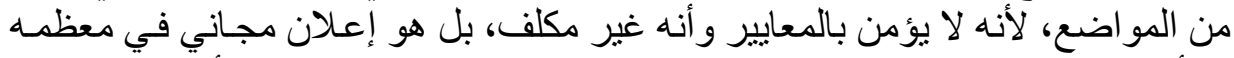

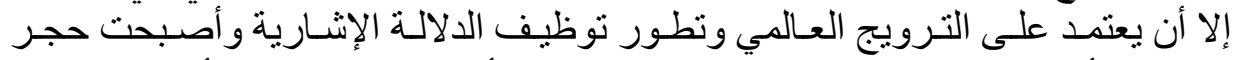

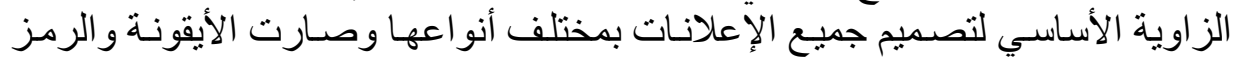

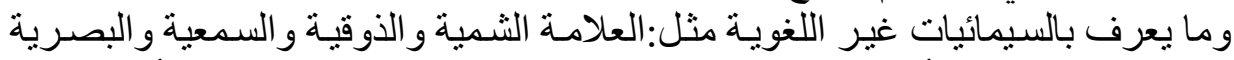

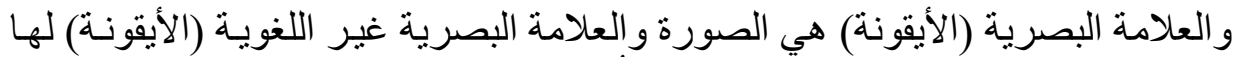

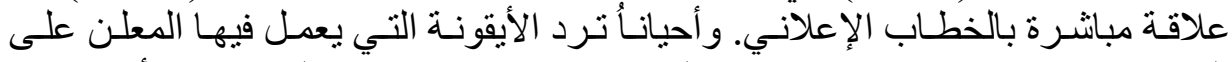

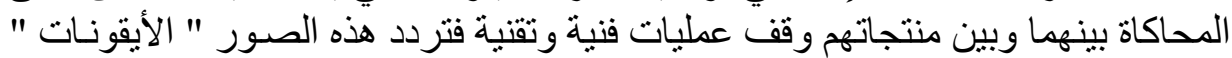
مقحمة في تركيب الدوال ويعرف هذا الأجر اء بالتلفظ الأيقوني فئن

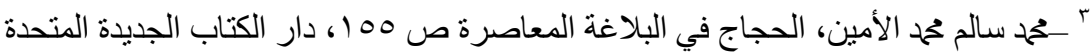

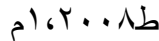

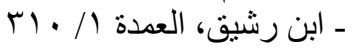

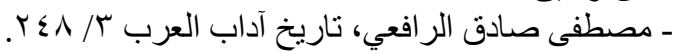

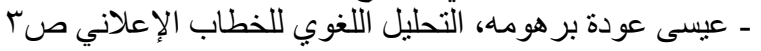




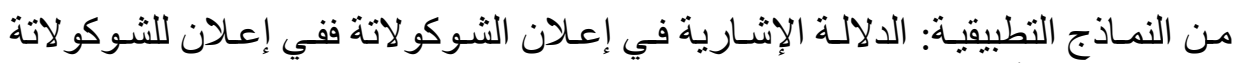

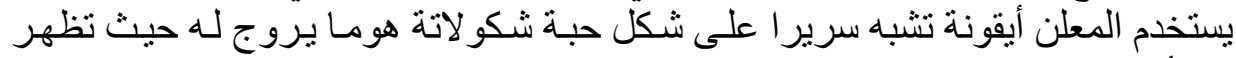

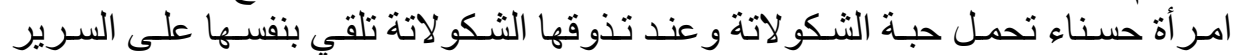

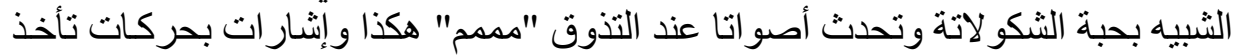

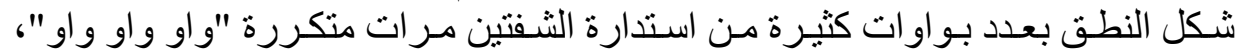

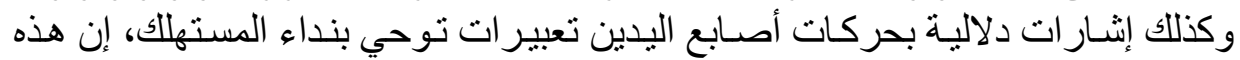

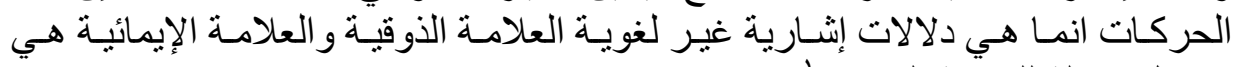

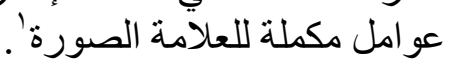

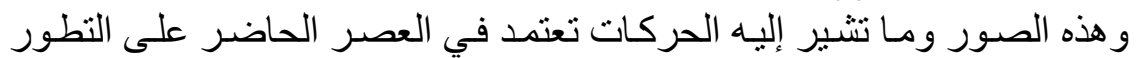

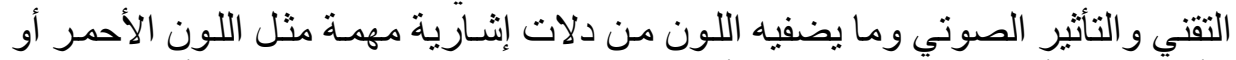

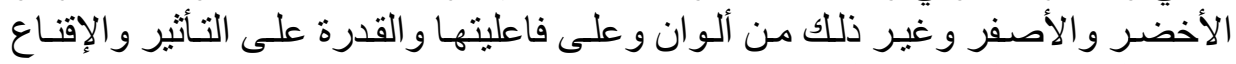

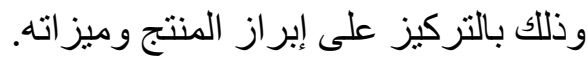

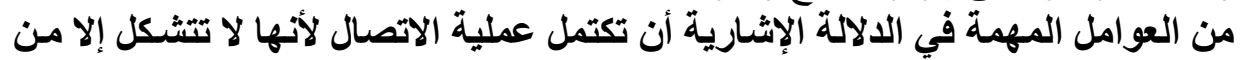
خلال هذه العوامل وتتككون من:

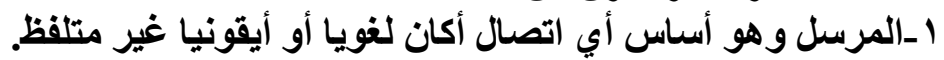

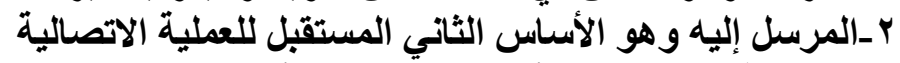

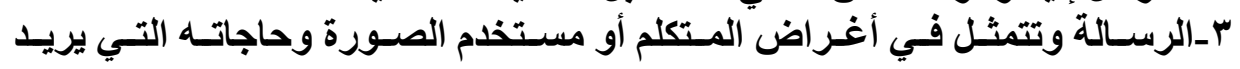
تحقيقها. ع ـالثفرة أي الرمز ويشترك في جزء منها أو في الرسالة كلها المرسل والمرسل إليهايه.

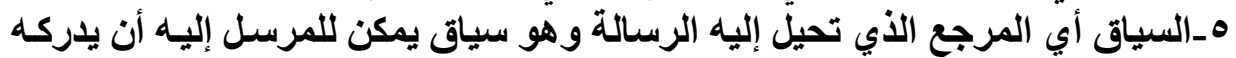

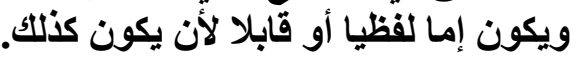

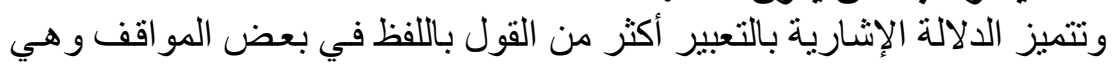

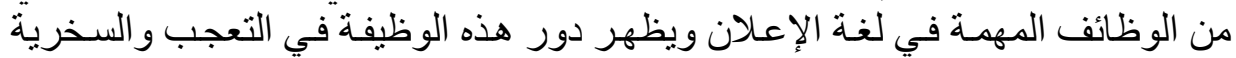

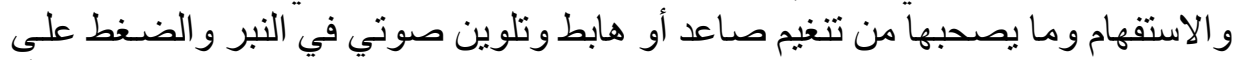

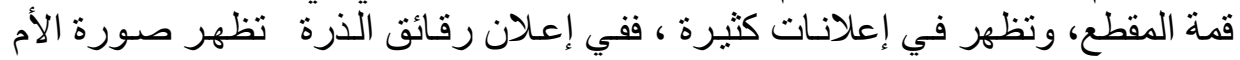

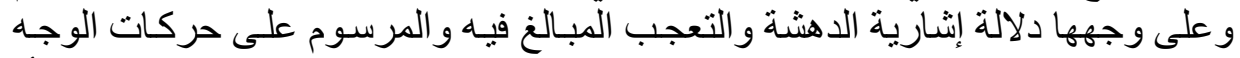

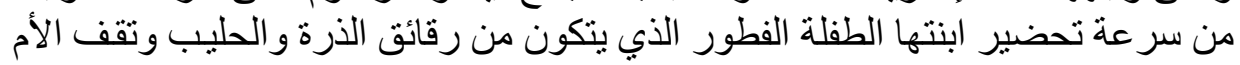

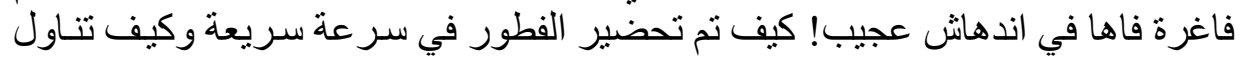

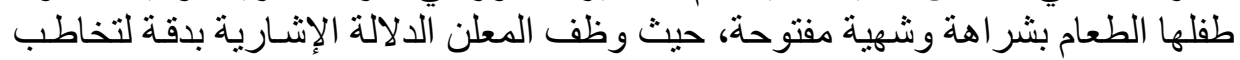

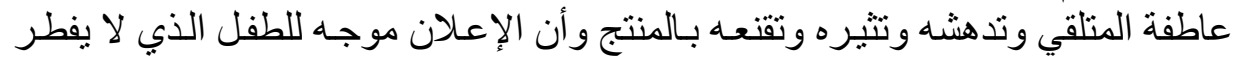

' - عيسى عودة بر هو مه، التحليل اللغوي للخطاب الإعلاني ص؟ 


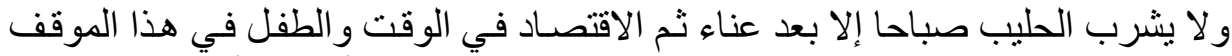

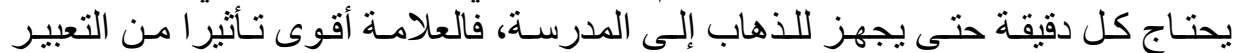
باللغة، في هذه الحال.

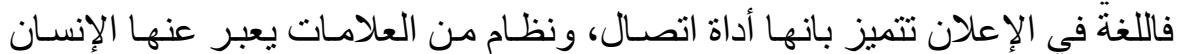

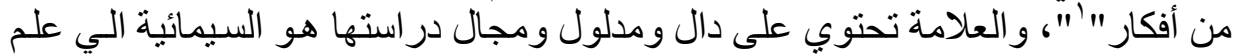

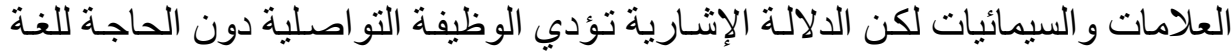

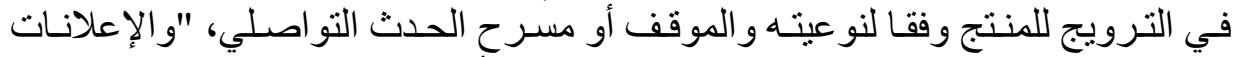

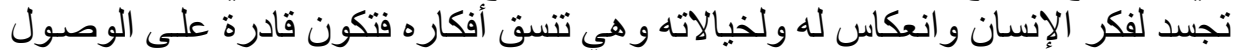

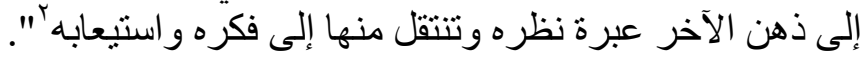

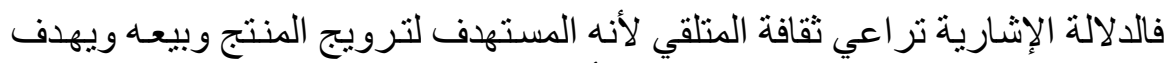

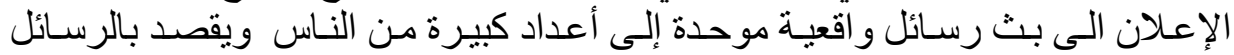

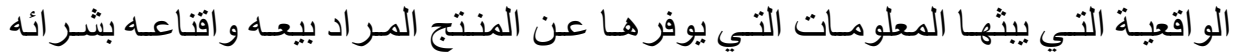

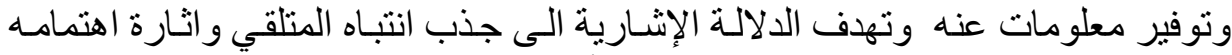

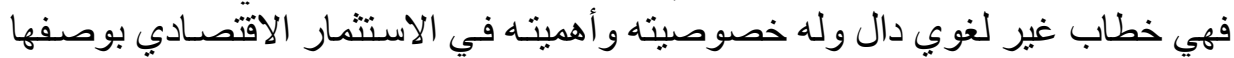

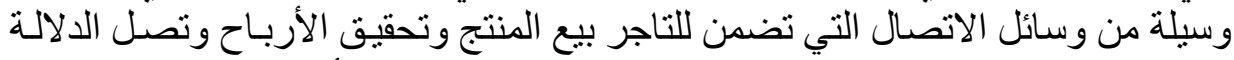

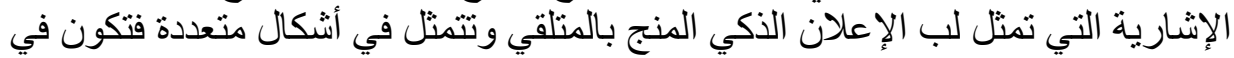

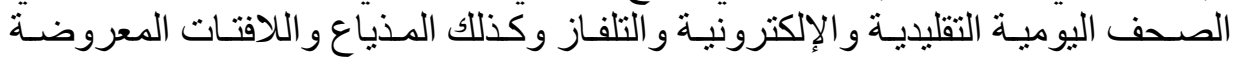

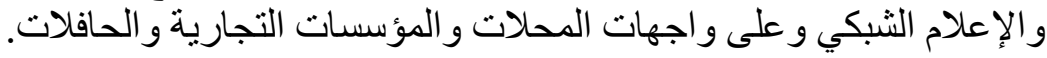

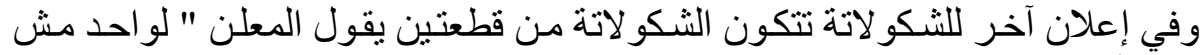

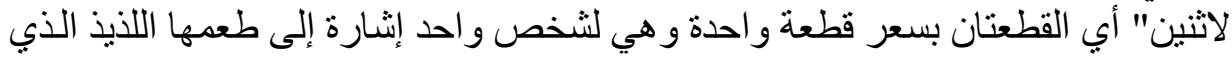

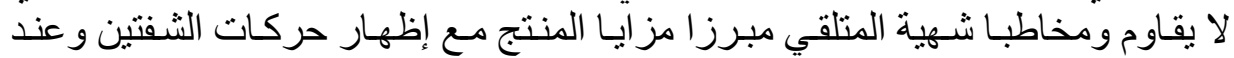

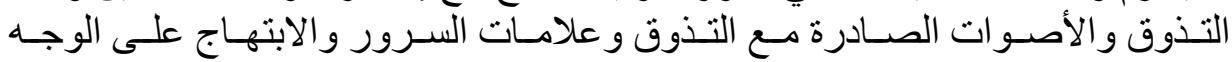

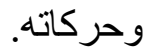

إذ تلعب الدلالة الإشارية دور ا مهما في الإعلانـات الخاصـة بالأزياء و أدوات الزئات الزينة

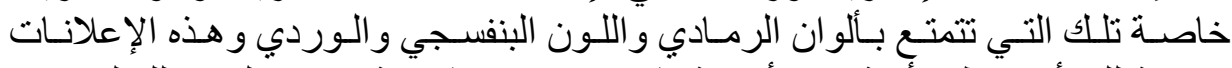

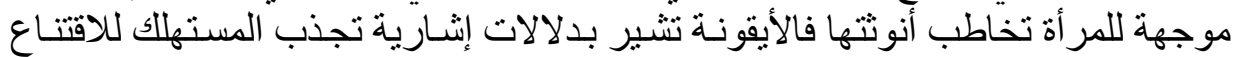

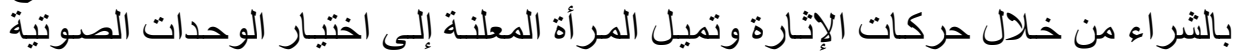

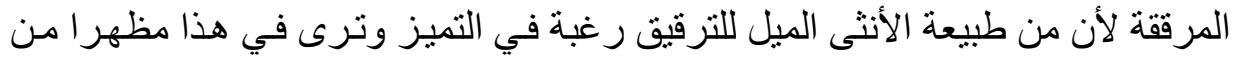

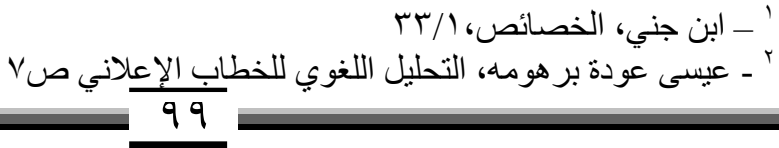




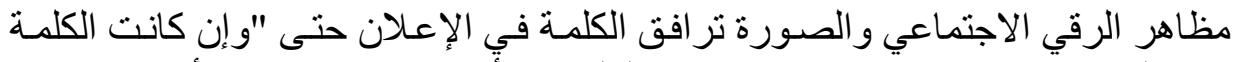

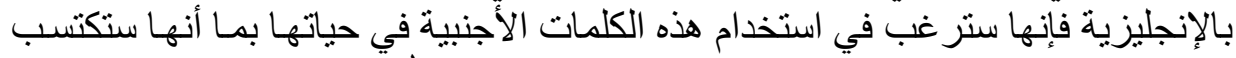

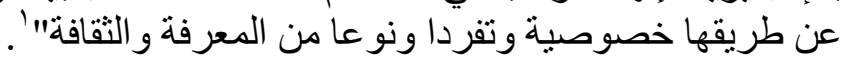

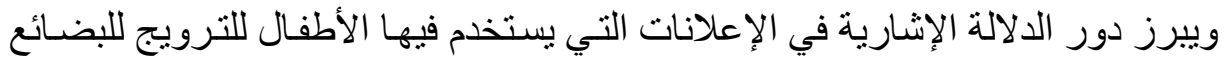

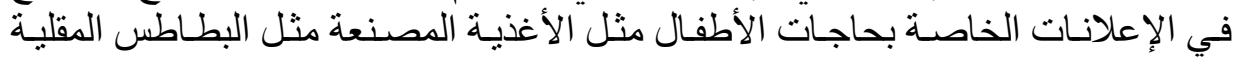

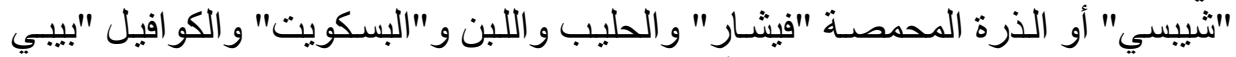

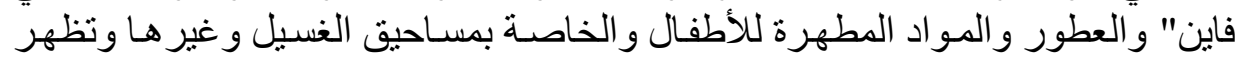

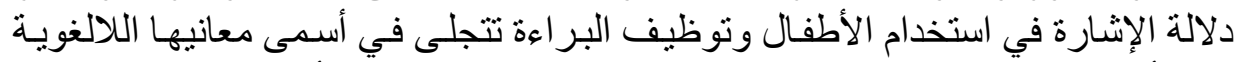

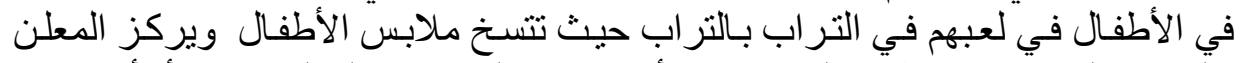

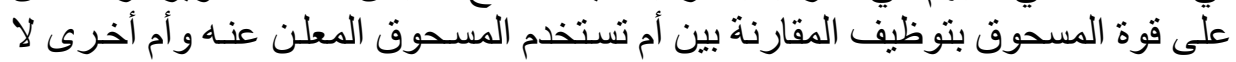

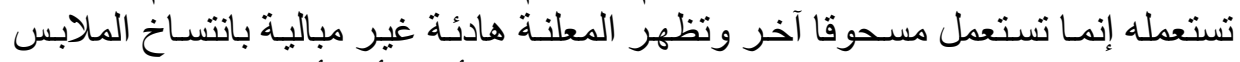

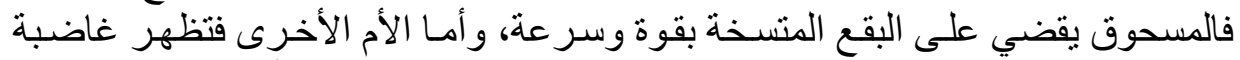

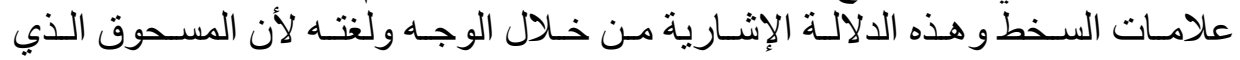

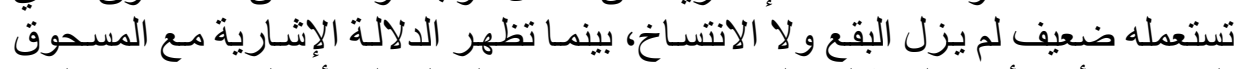

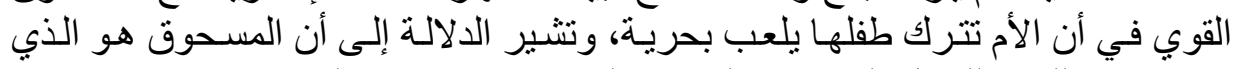

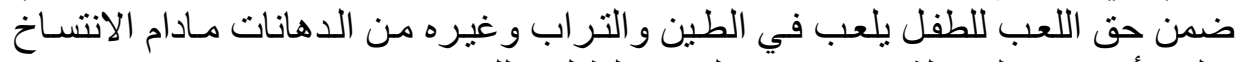

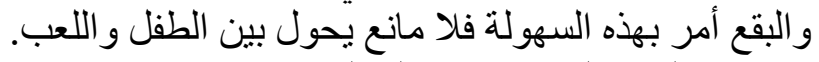

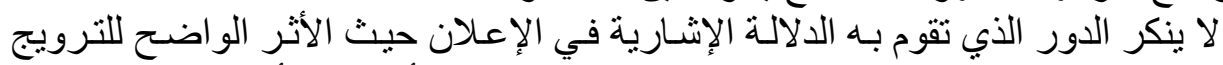

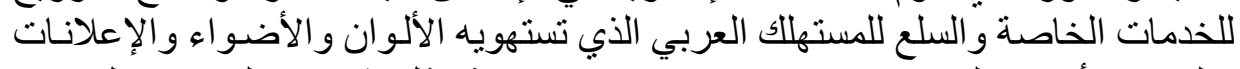

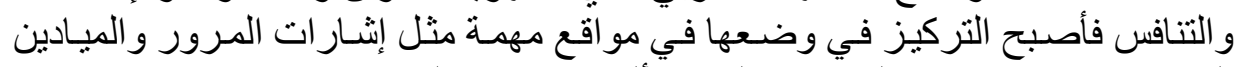

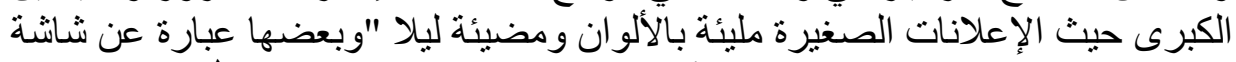

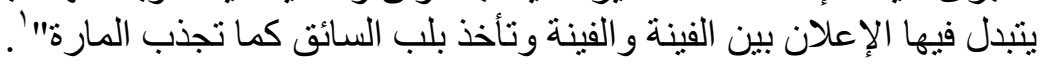
استخدام الالالة الإشارية في غير الإنانة موضعها:

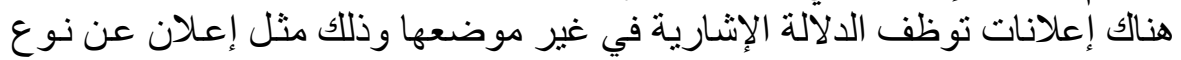

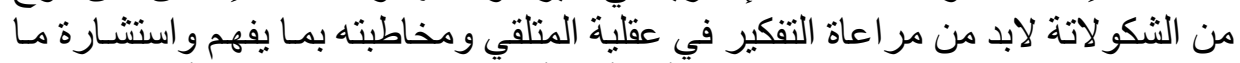

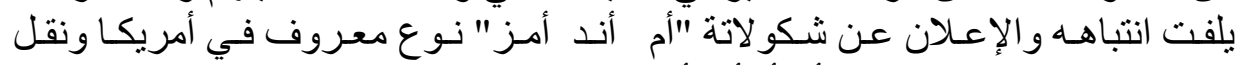

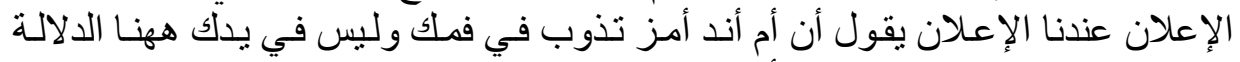

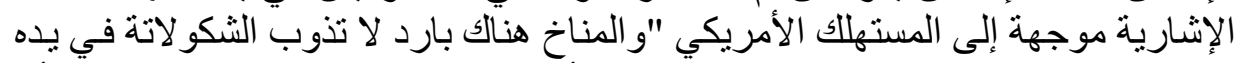

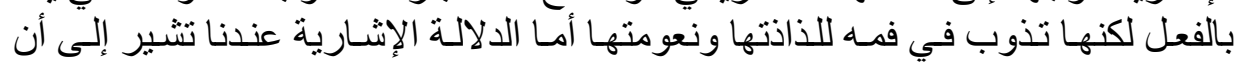


الثكو لاتة تذوب في يد المستهلك قبل أن تصل إلى فمـه لحر ارة الجو وسخونته"'"في

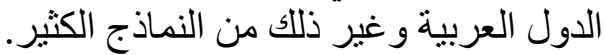

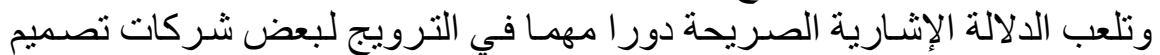

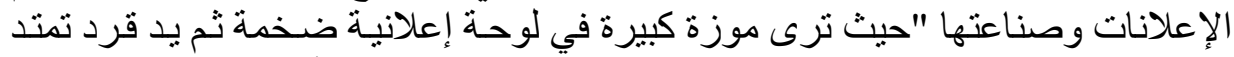

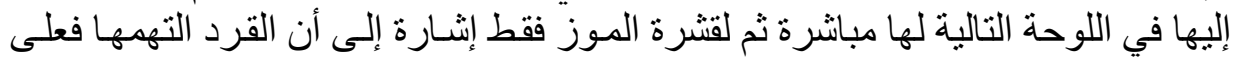

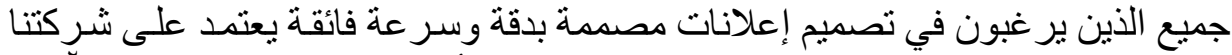

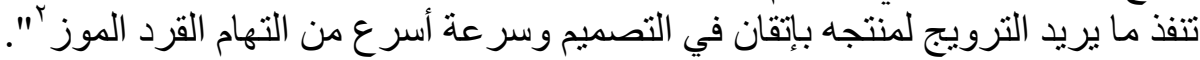

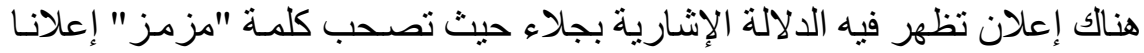

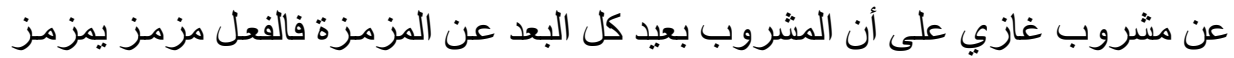

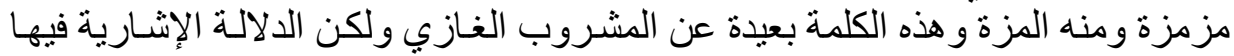

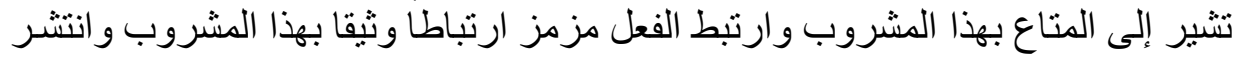

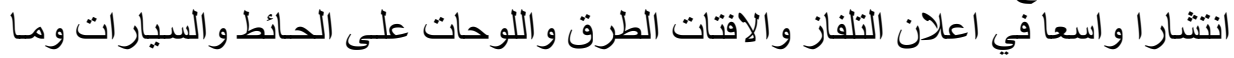

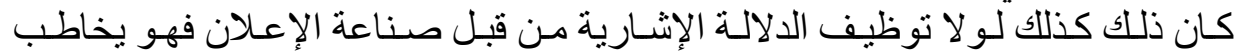

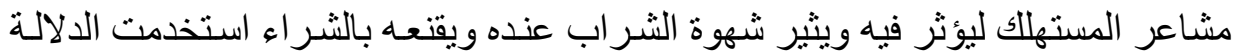
الإشارية هنا في غير موضعها.

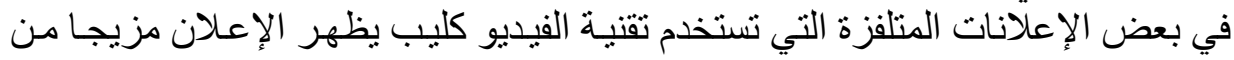

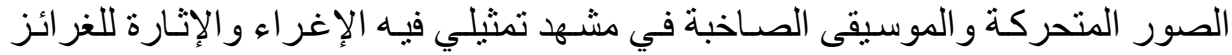

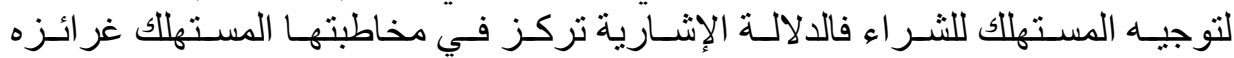

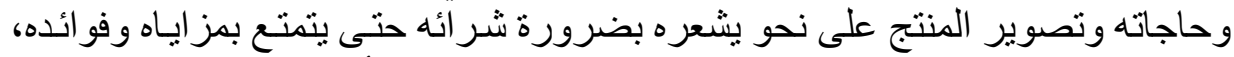

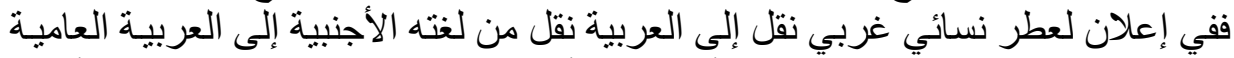

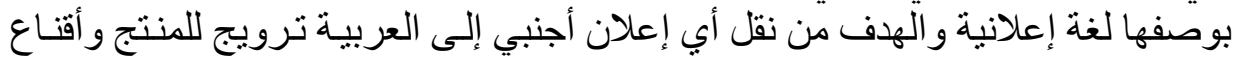

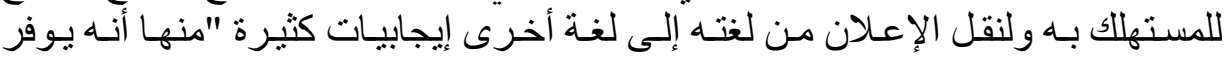

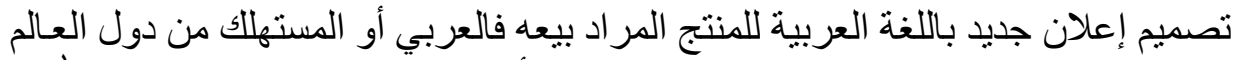

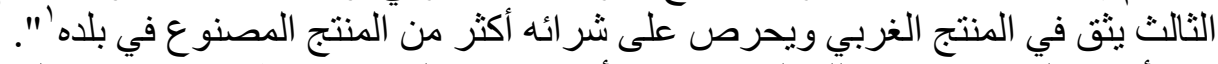

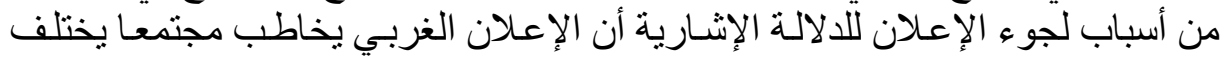

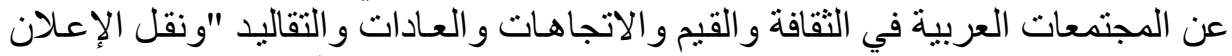

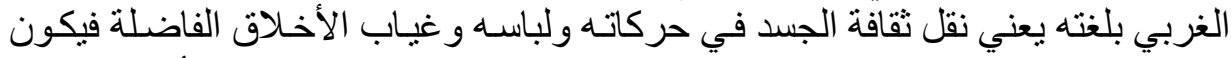

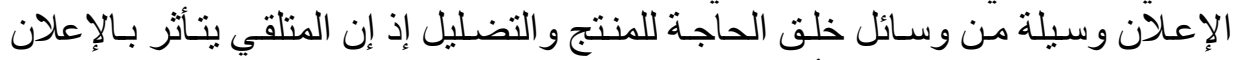

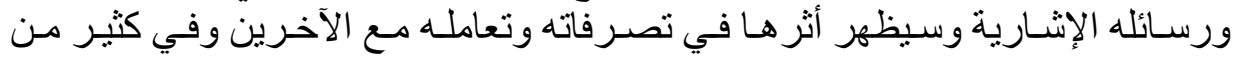

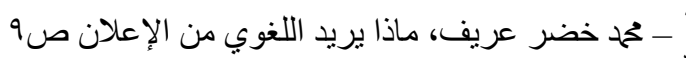

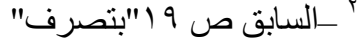

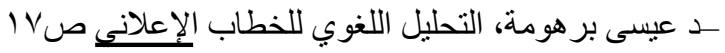




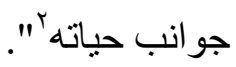

الالالة الإشارية السبية ودية ودورها في الإعلان:

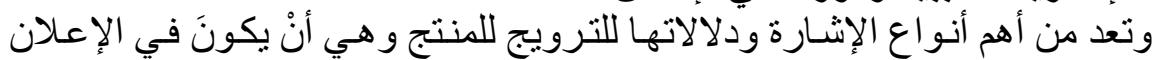

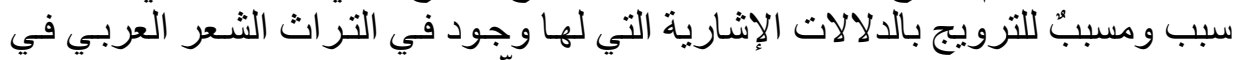

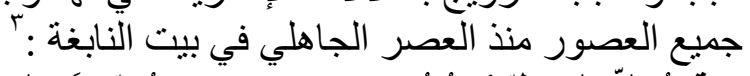

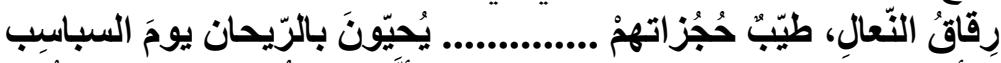

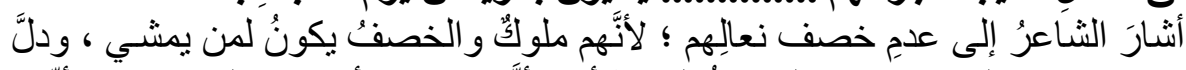

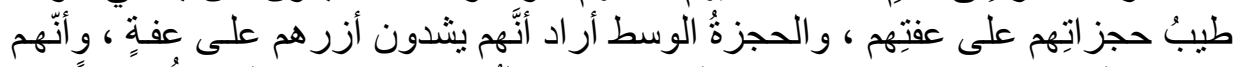

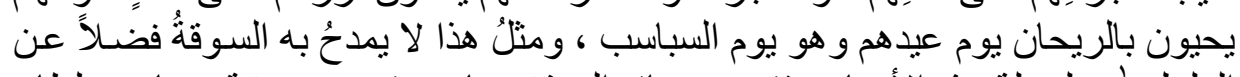

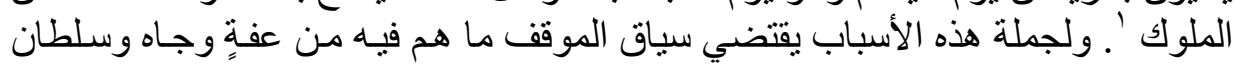

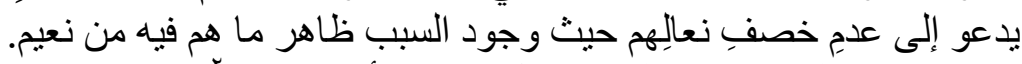

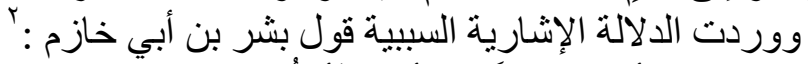

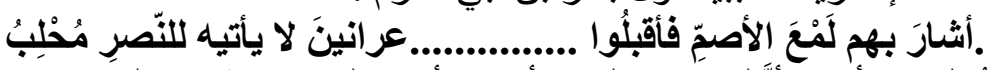

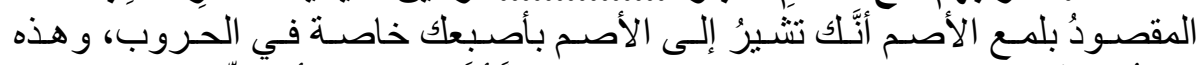

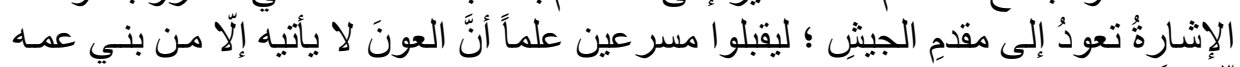

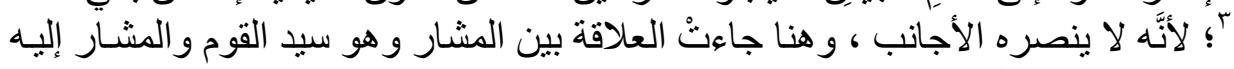

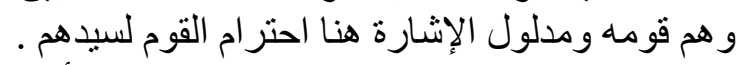

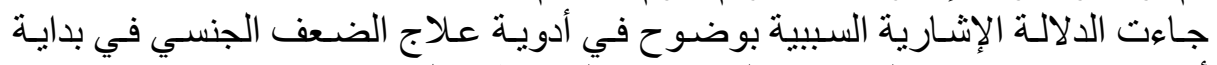

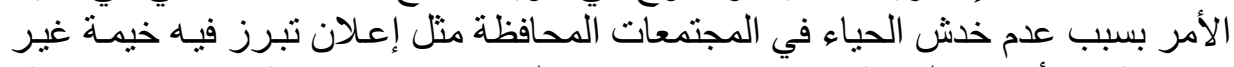

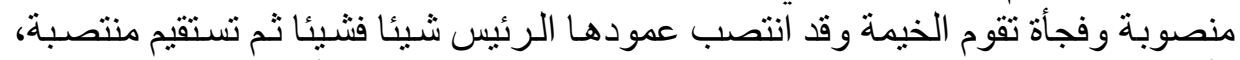

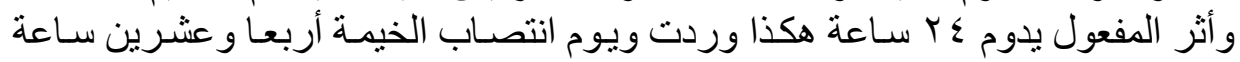

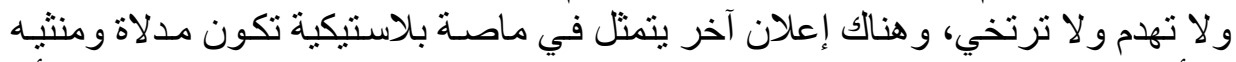

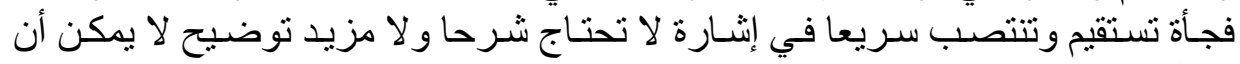

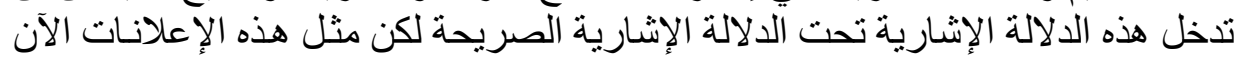

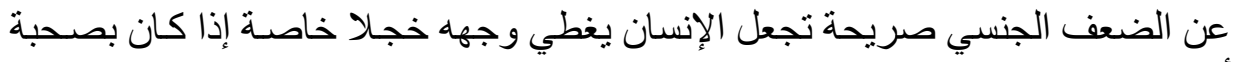

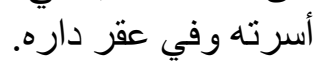
كما يظهر دور الدلالة الإشـارية في إعلانـات الأزياء لكن باللاجهة العامية كما في هذا

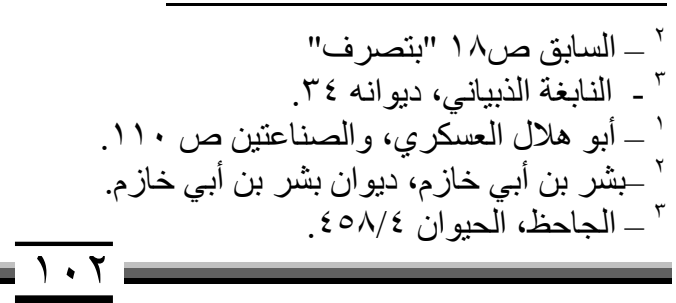


الإعلان الكبير وفيه تظهر فتاة عارضة أزياء تقول " هنا شياكتي" وآخر "للك أنتي" وفي الإني

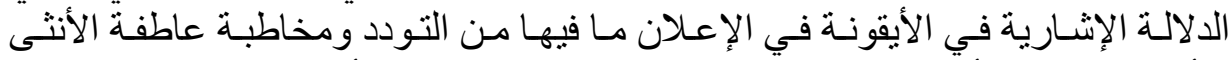

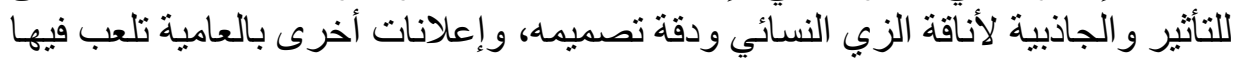

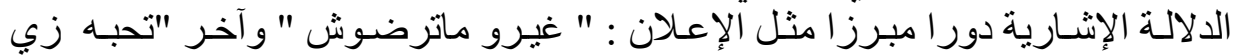

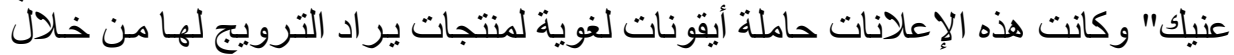

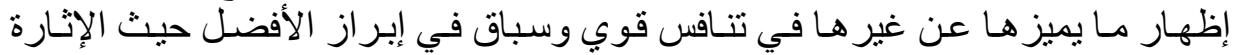

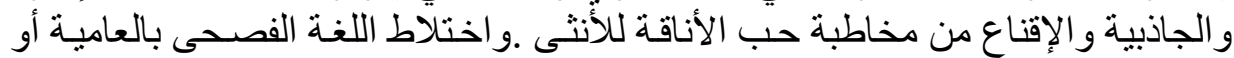

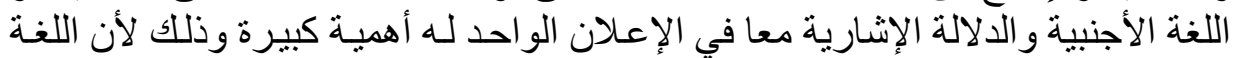

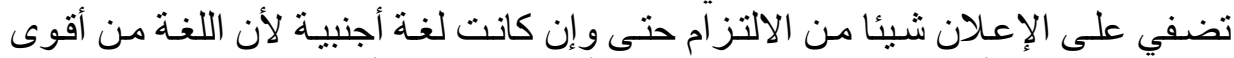

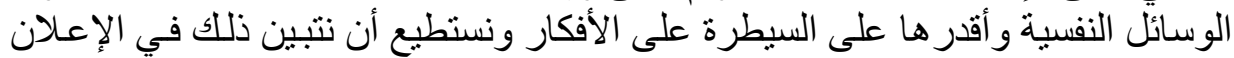

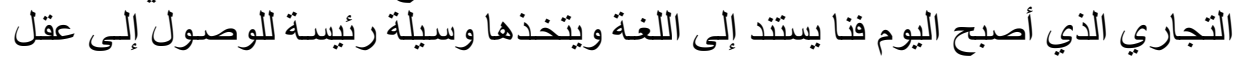

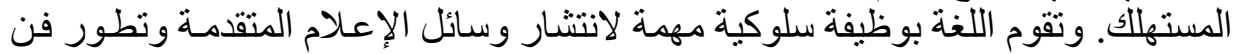

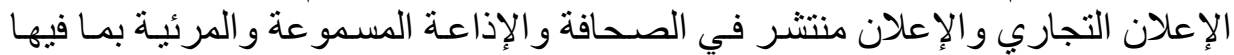

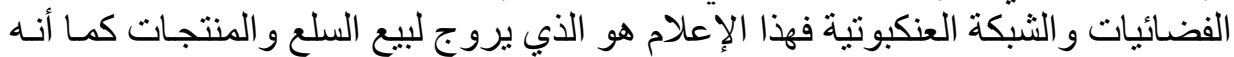

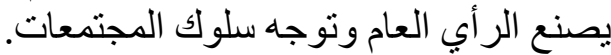

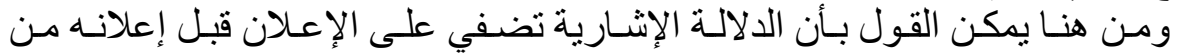

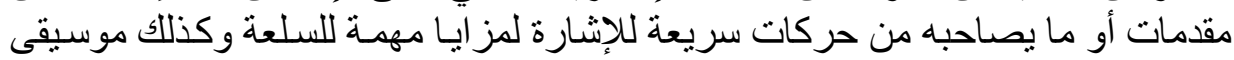

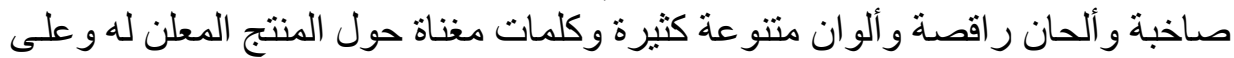

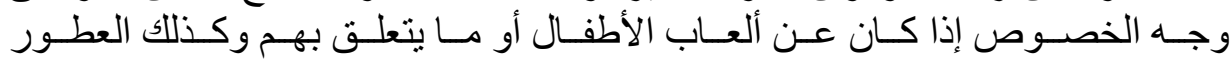

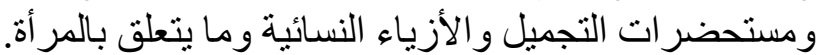

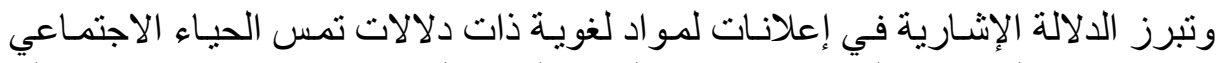

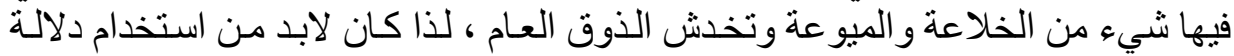

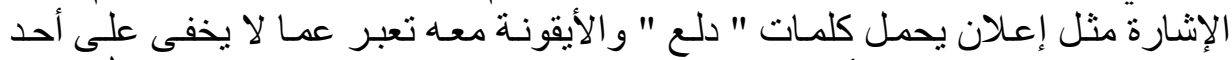

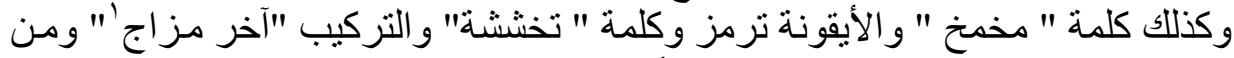

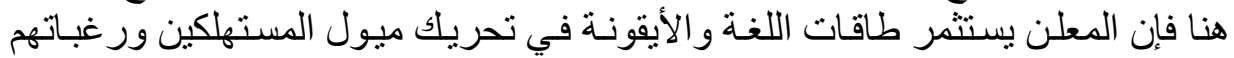

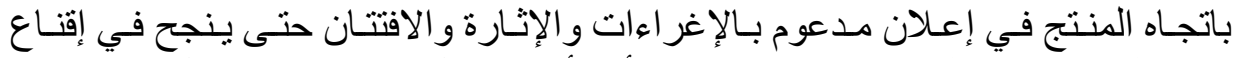

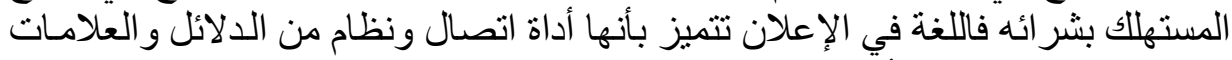

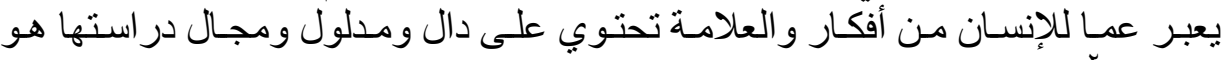

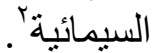
وتشكل اللغة في الإعلان وحدة قائمة بذاتها لها أصولها ومو ادها وفنها و أسسـها وهي

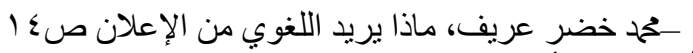

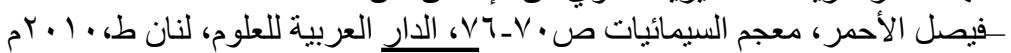




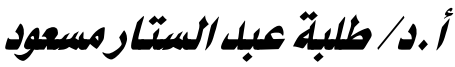

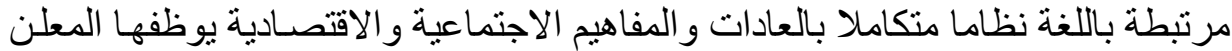

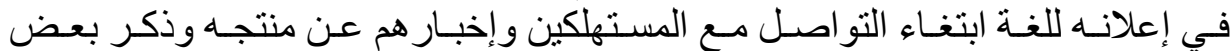

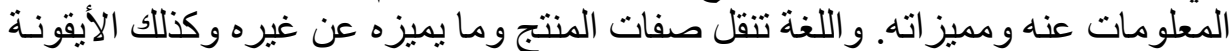

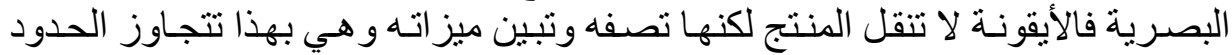

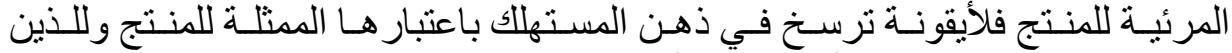

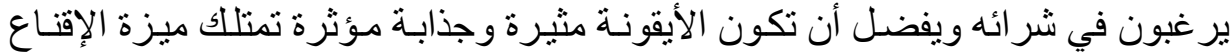

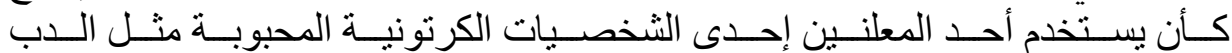
(winny)

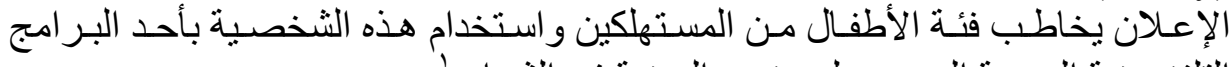

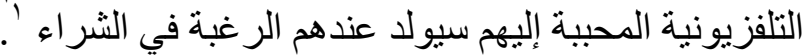

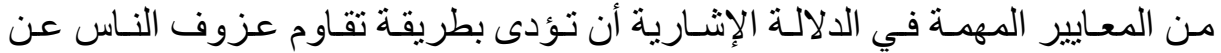

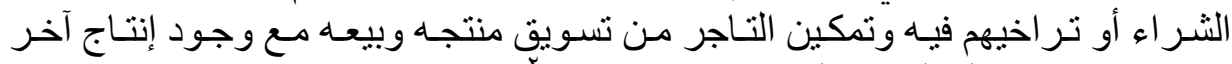

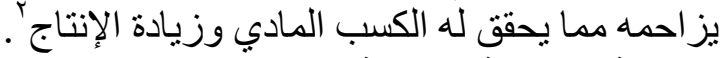

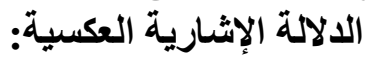

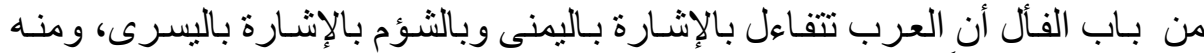

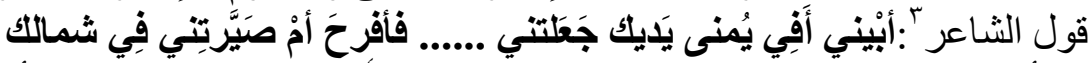

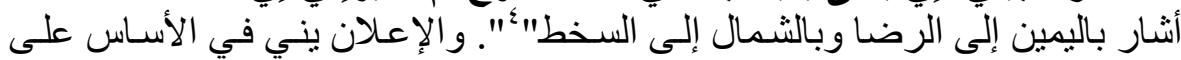

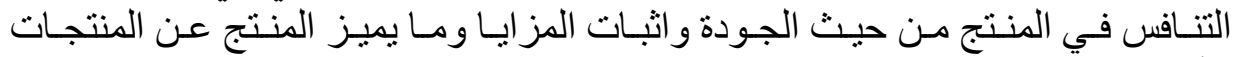

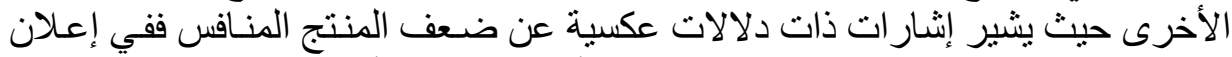

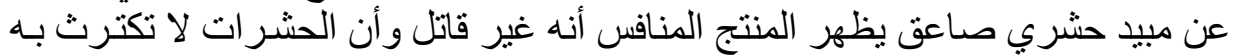

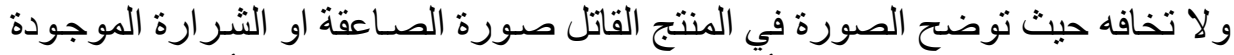

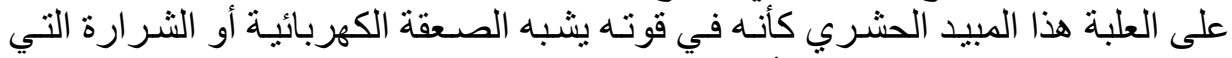

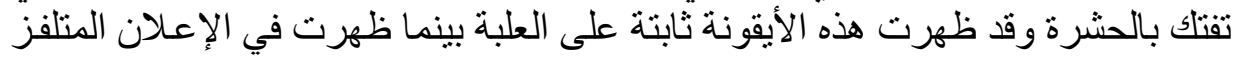

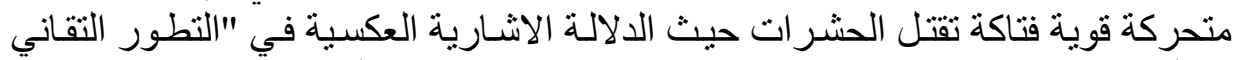

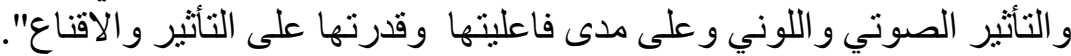

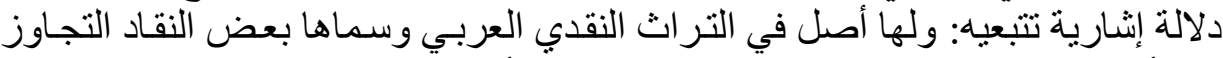

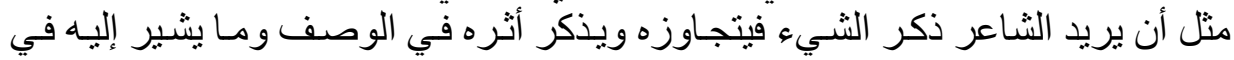

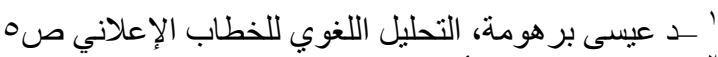

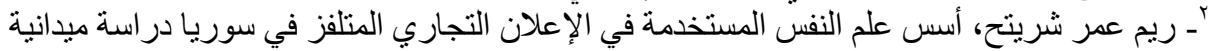

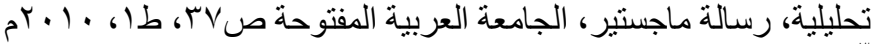

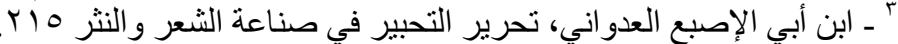

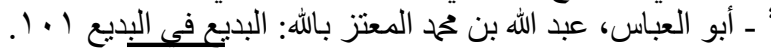




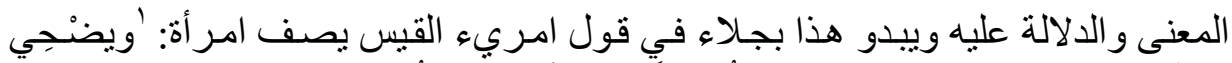

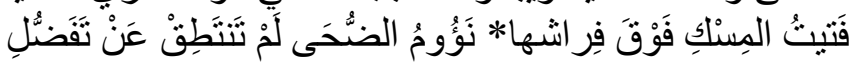

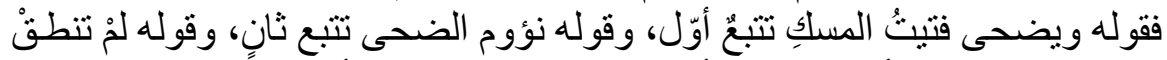

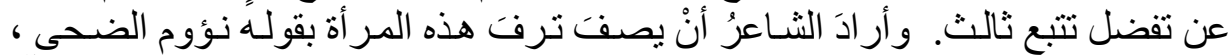

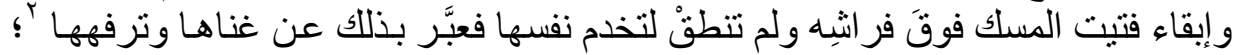

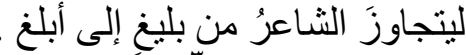

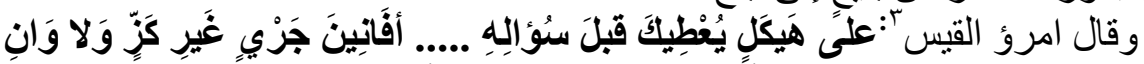

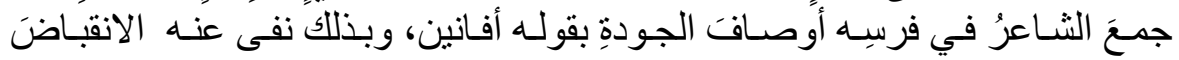

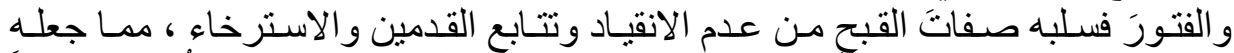

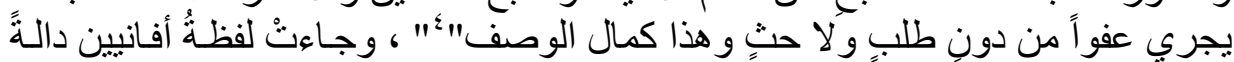

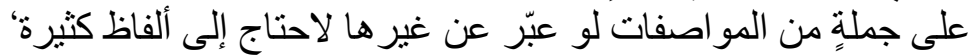

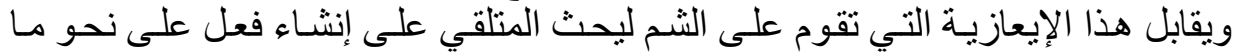

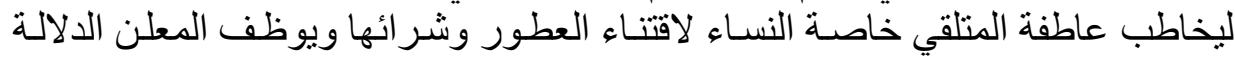

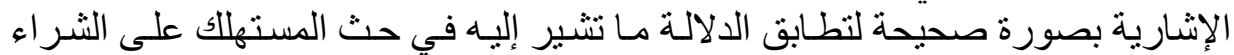

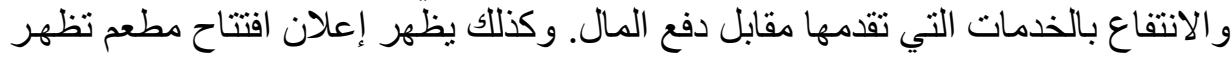

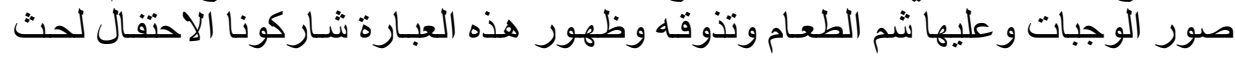

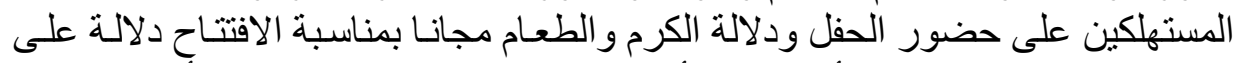

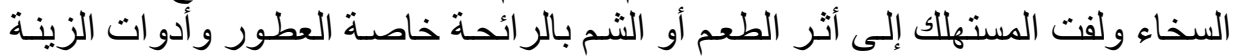

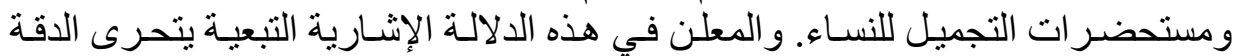

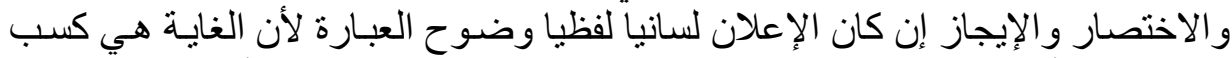

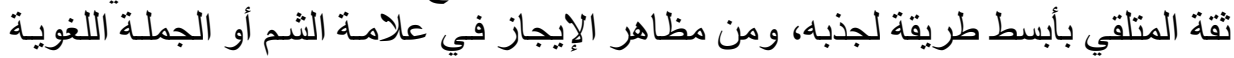

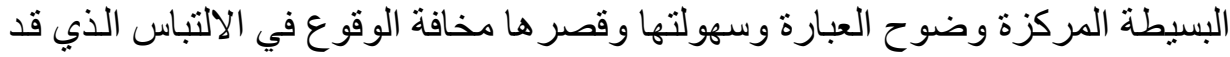

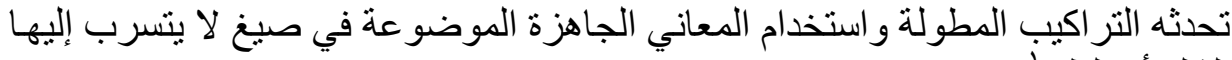

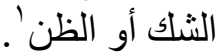
الالالة الإشـارية بالمغايرة: المغايرة" هي مدح الثـيء بعد ذمـه، أو عكسـه " ()، ومنهـ

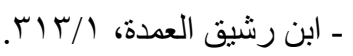

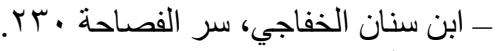

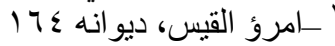

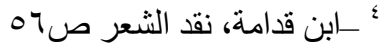

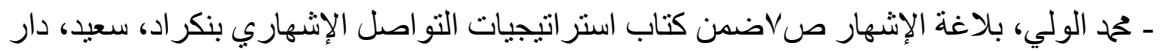

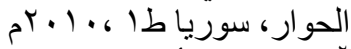

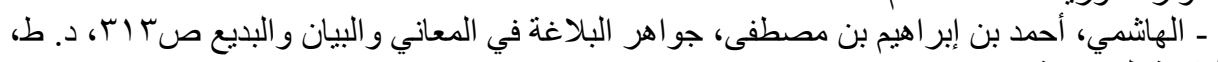




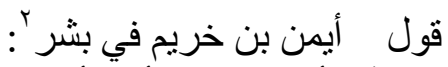

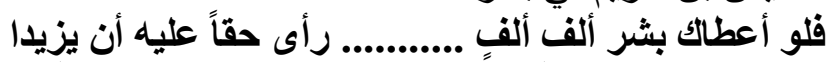

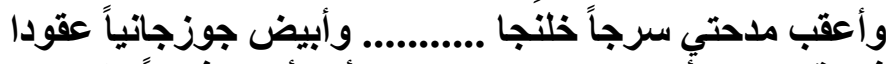

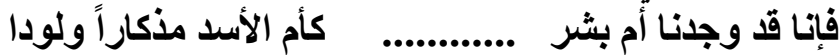

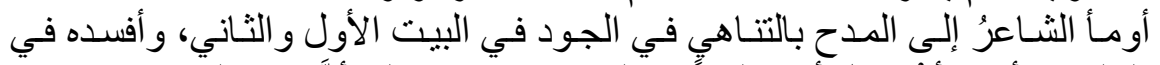

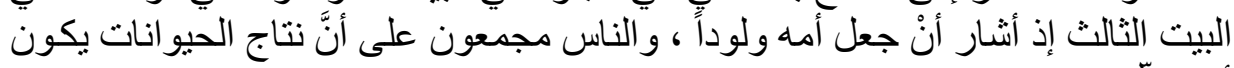

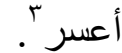

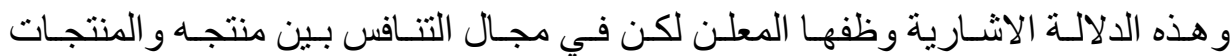

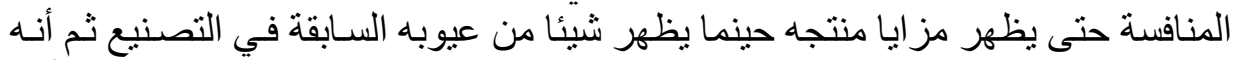

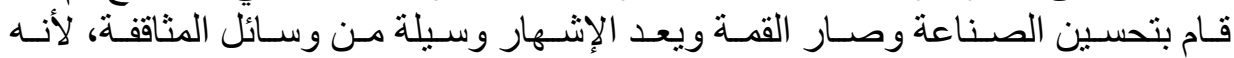

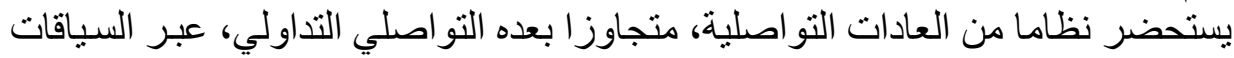

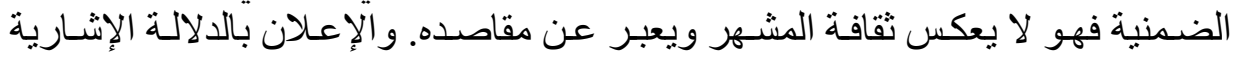

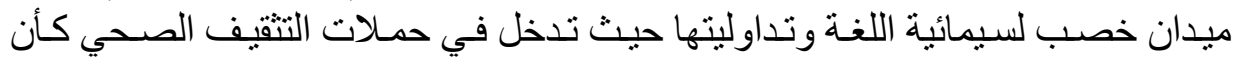

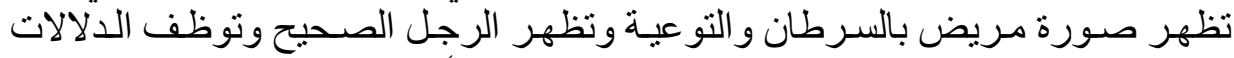

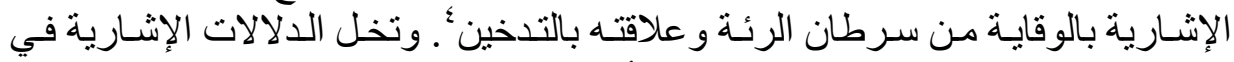

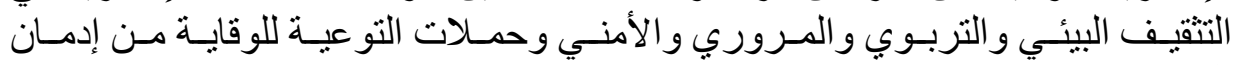

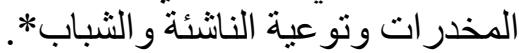

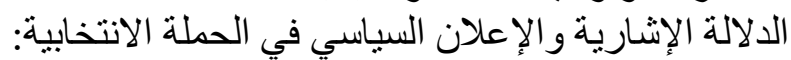

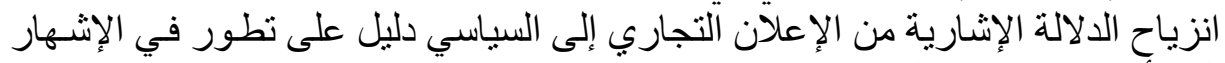

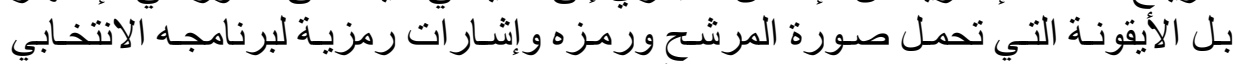

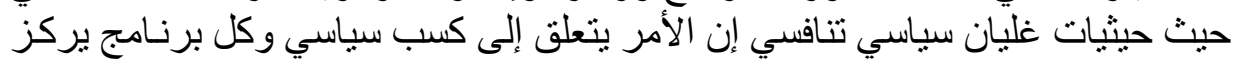

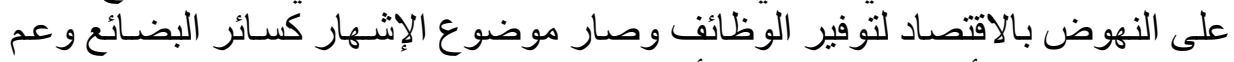

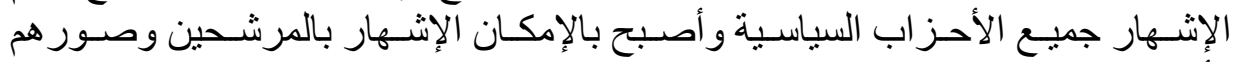

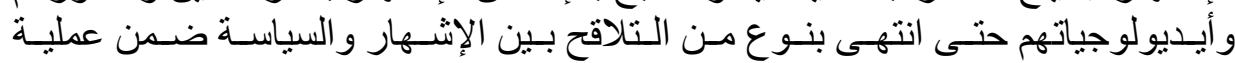

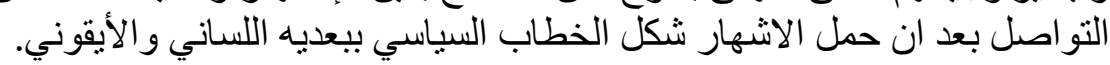

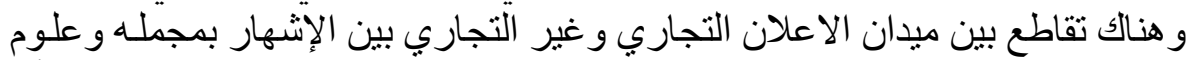

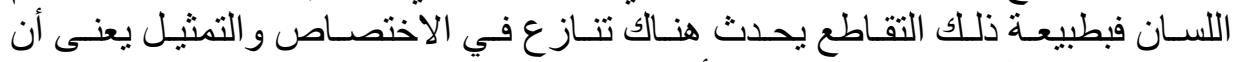

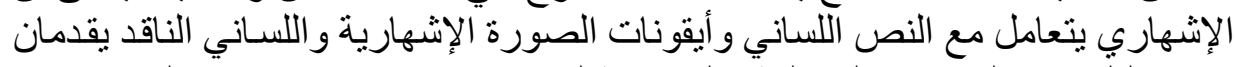

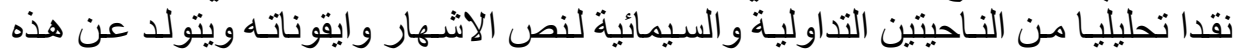

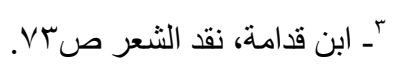

- هذه الإعلانات مأخوذة من المركز الطبي الجامعى، مكة المكرمة. 


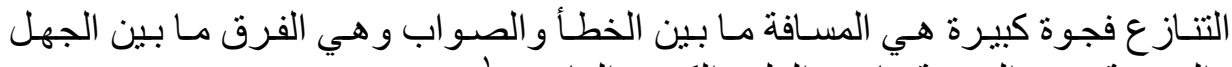

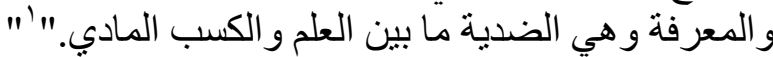

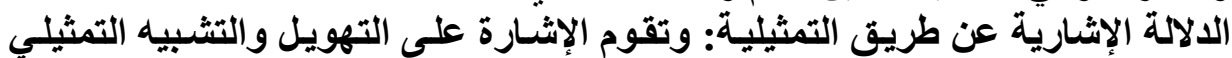

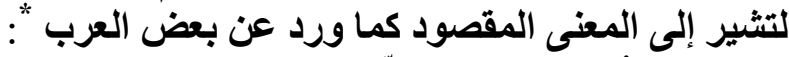

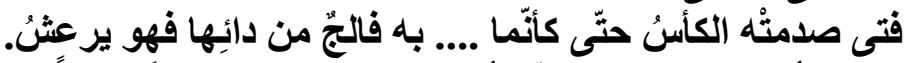

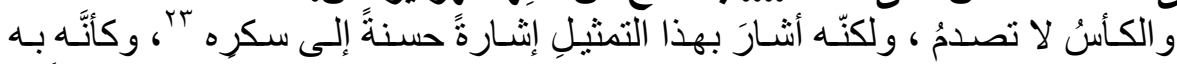

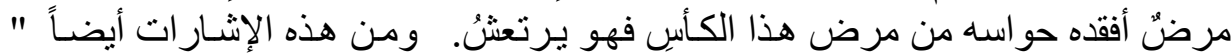

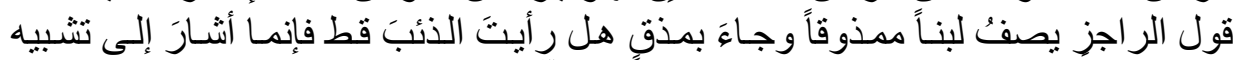

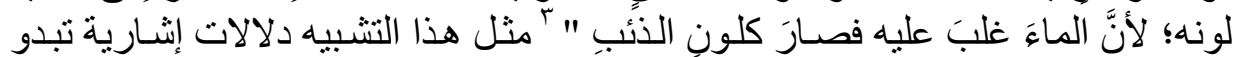

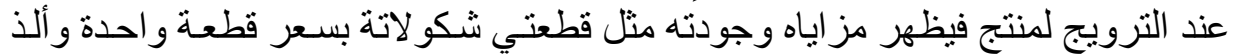

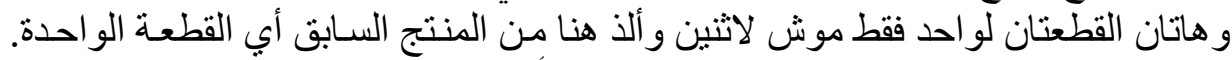

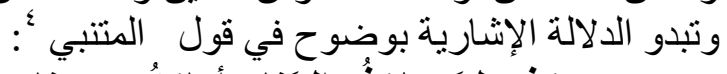

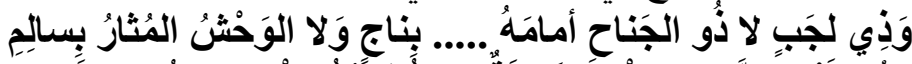

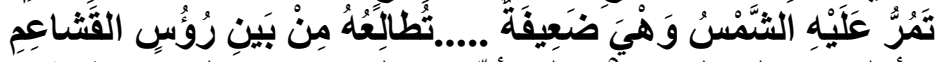

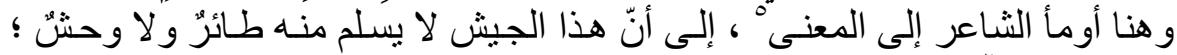

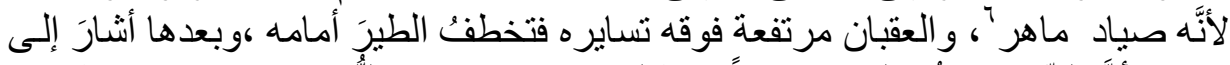

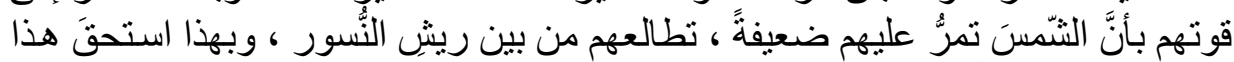

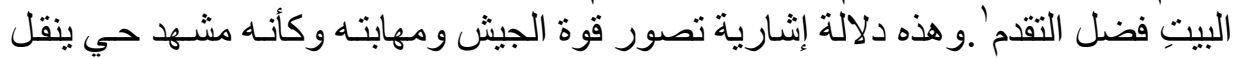

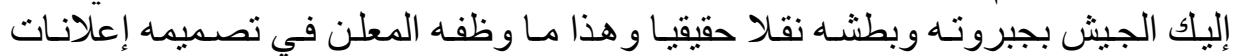

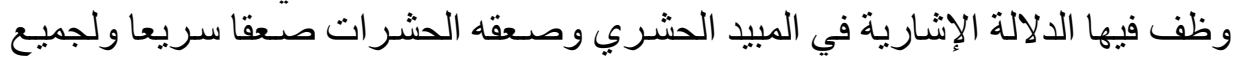

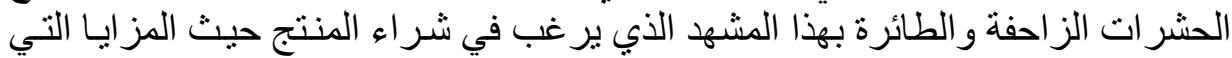

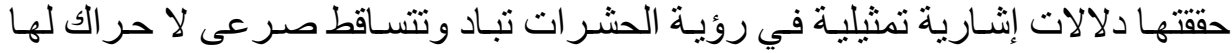

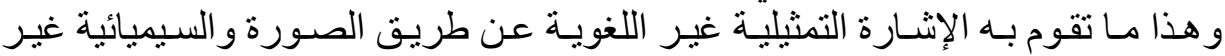

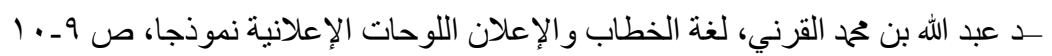

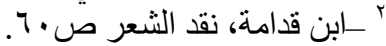

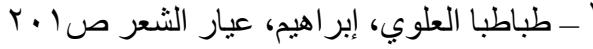

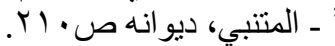

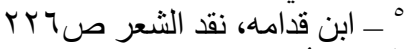

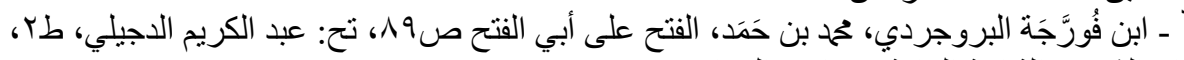

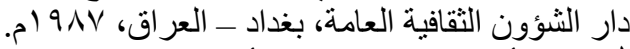

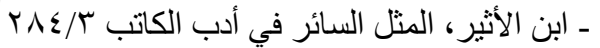




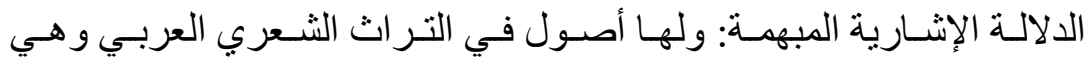

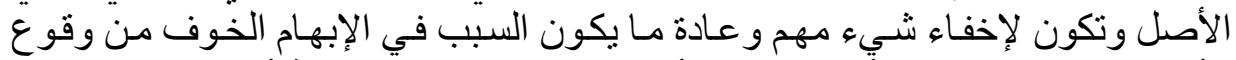

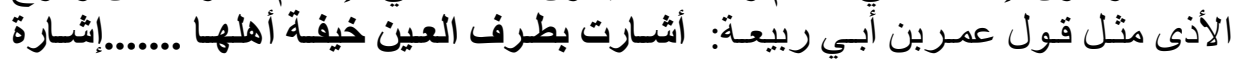

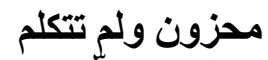

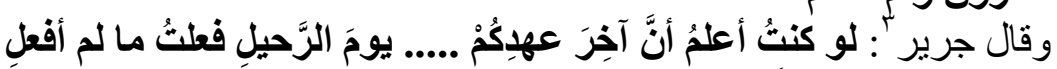

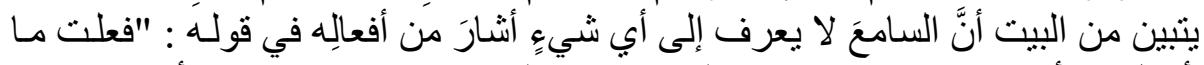

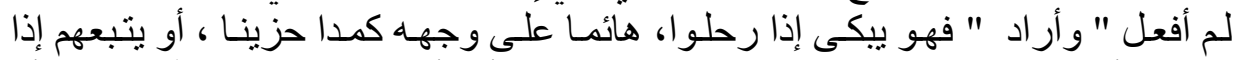

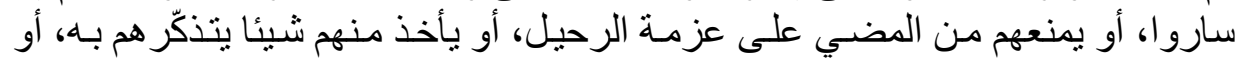

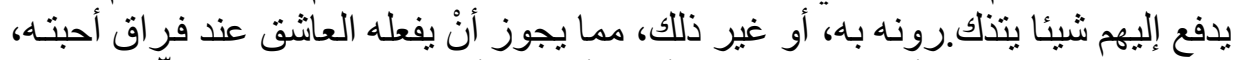

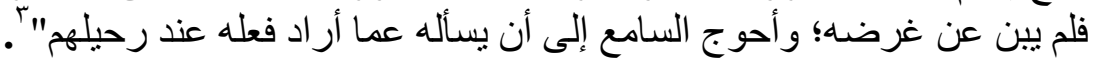

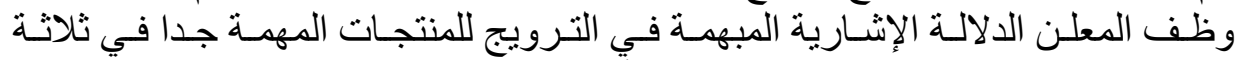

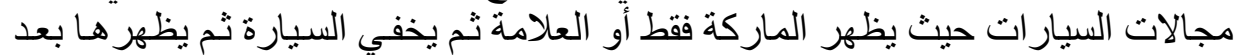

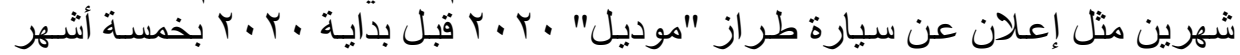

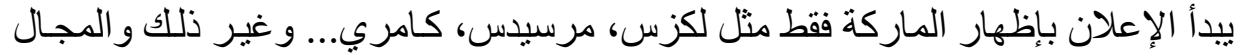

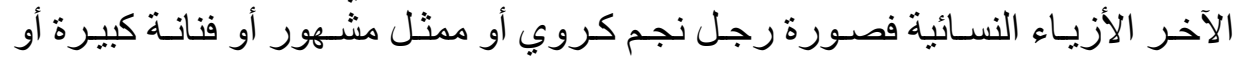

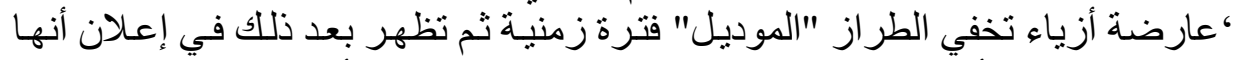

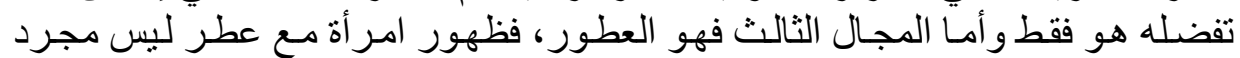

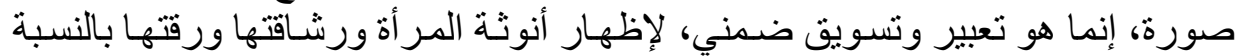

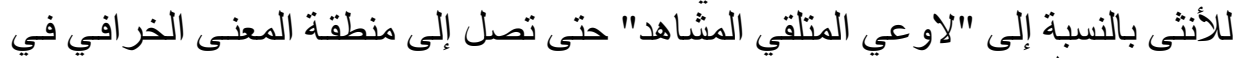

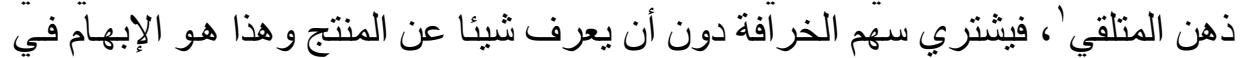

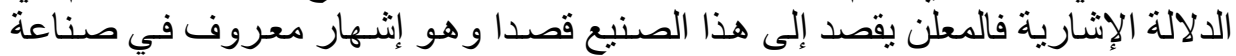

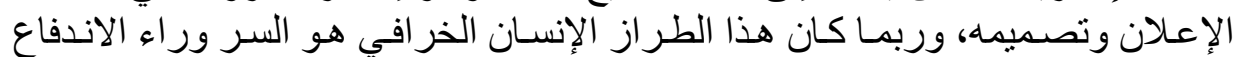

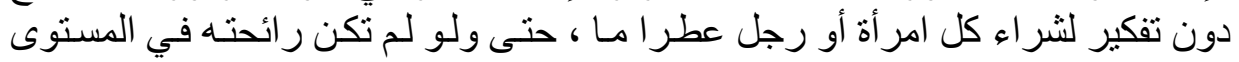

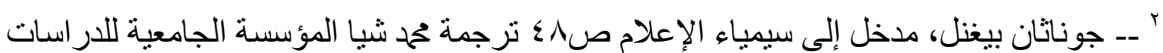

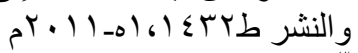

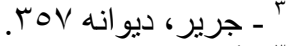

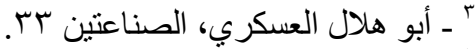

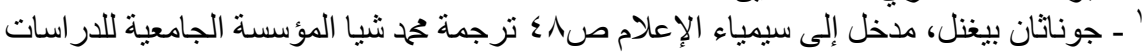

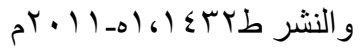




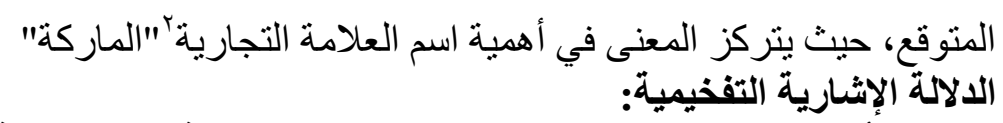

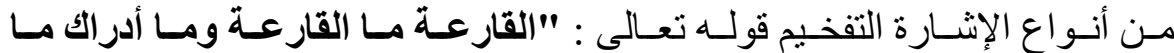

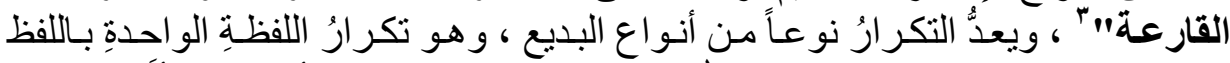

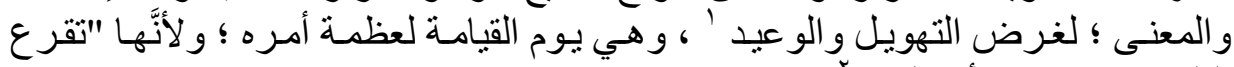

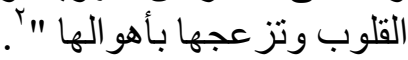

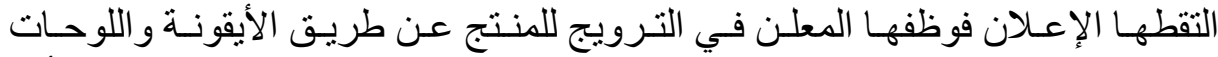

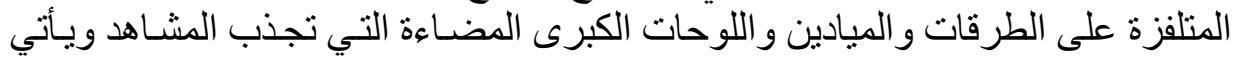

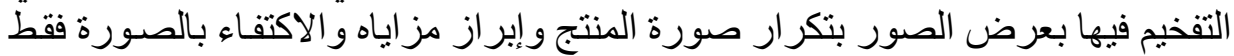

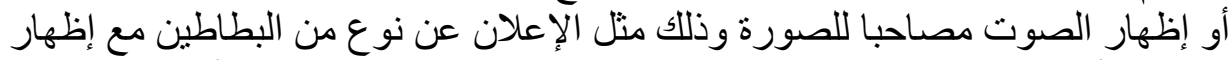

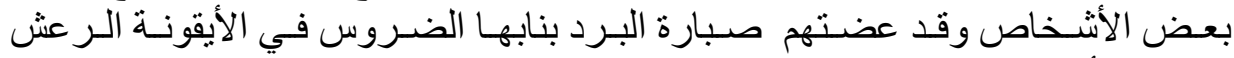

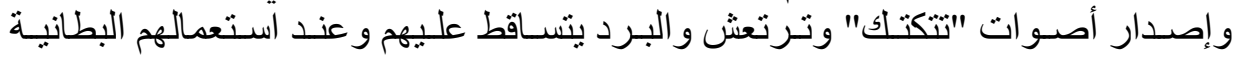

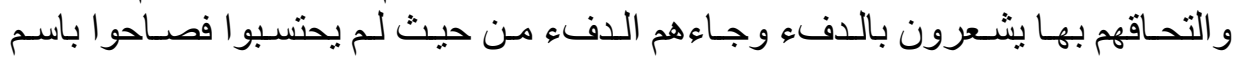

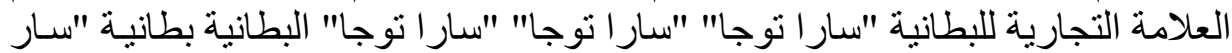

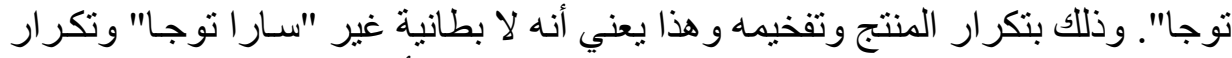

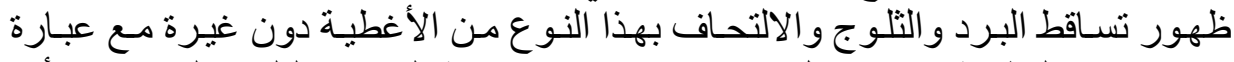

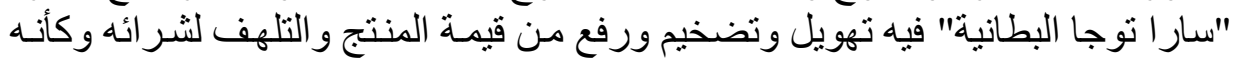

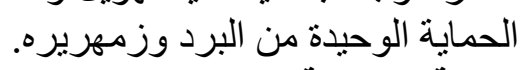

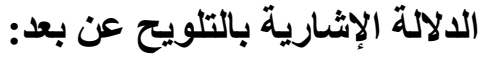

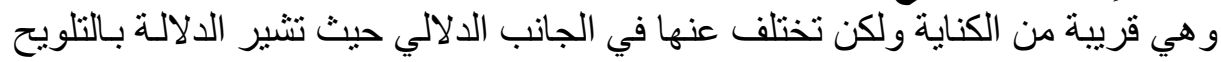

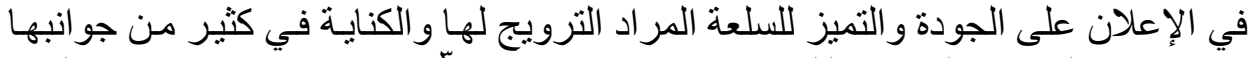

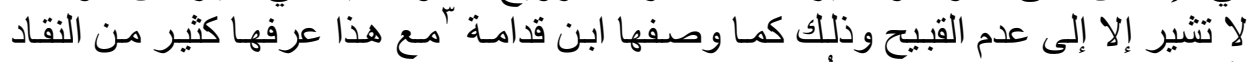

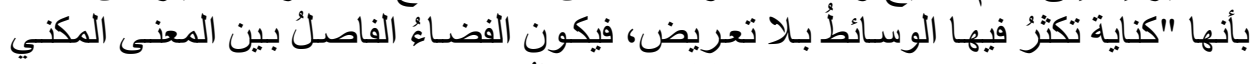

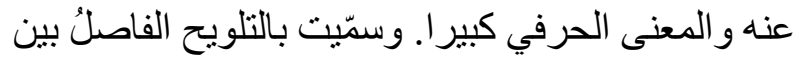

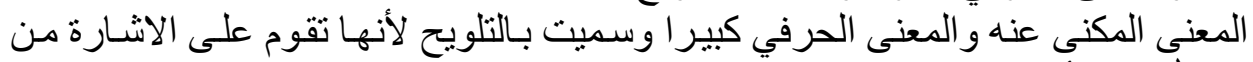

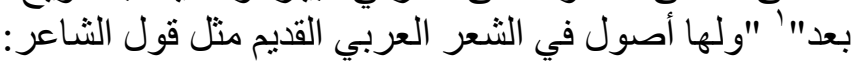

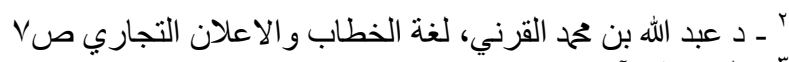

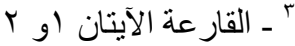

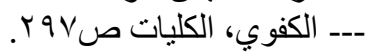

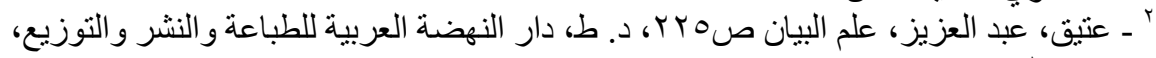

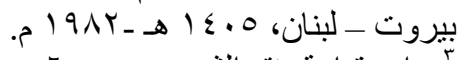

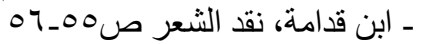

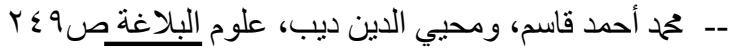




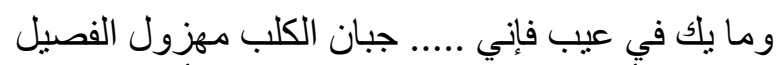

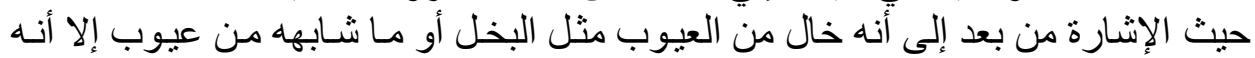

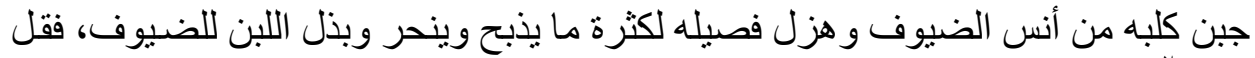

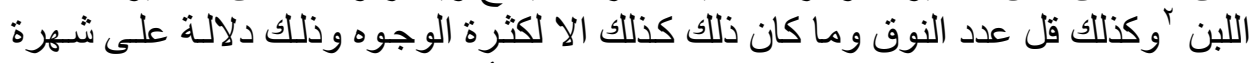

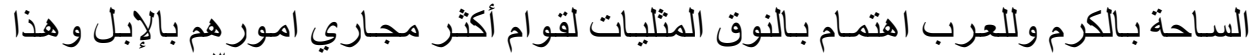

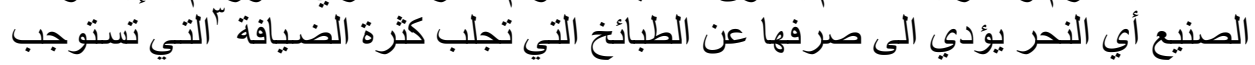

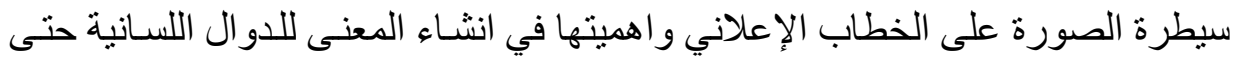

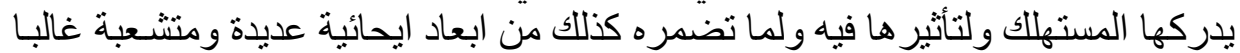

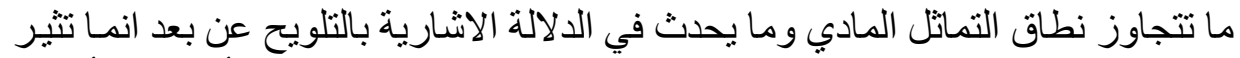

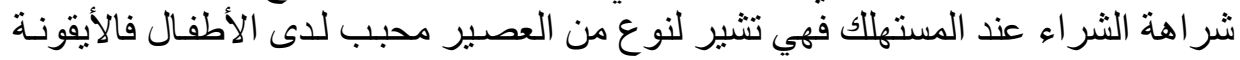

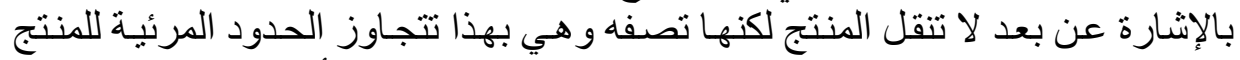

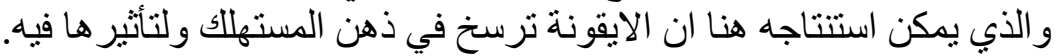

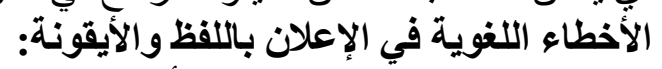

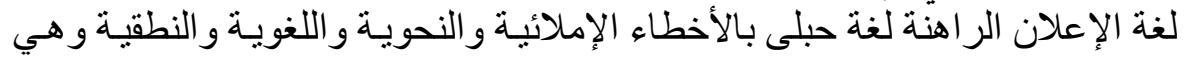

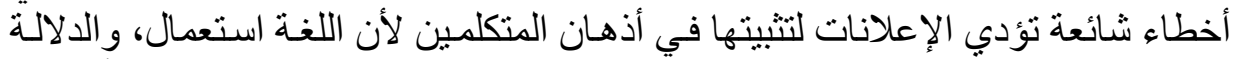

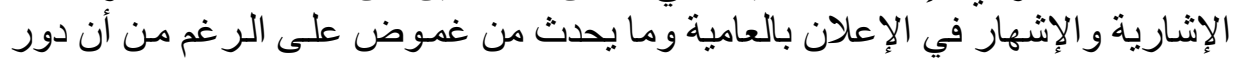

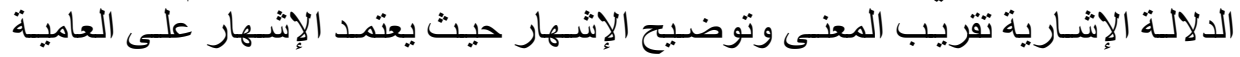

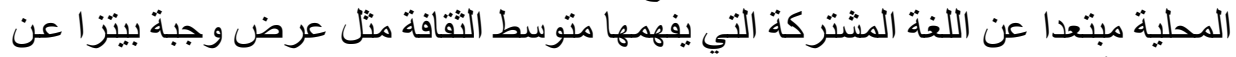

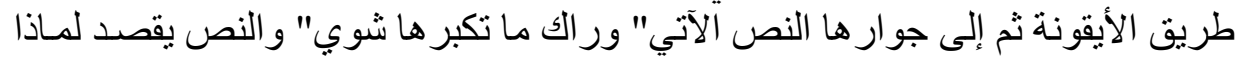

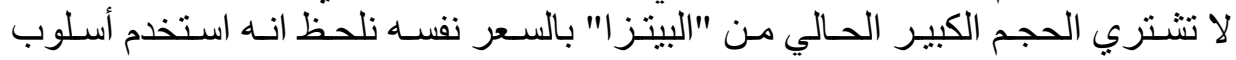

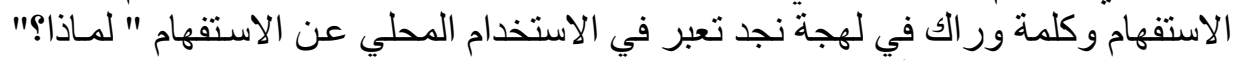

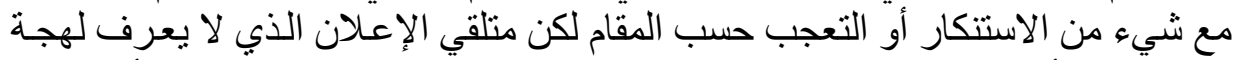

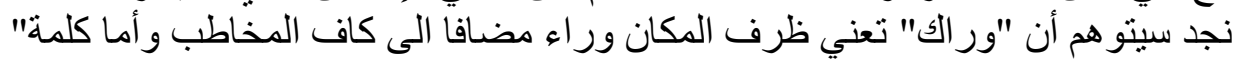

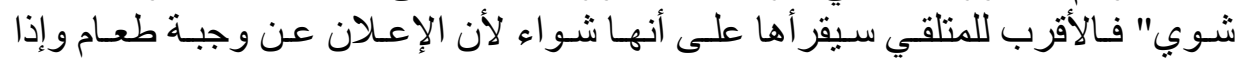

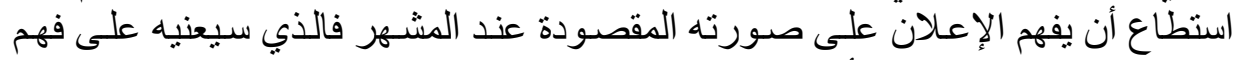

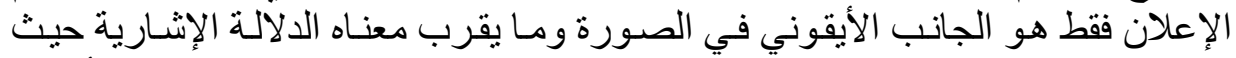

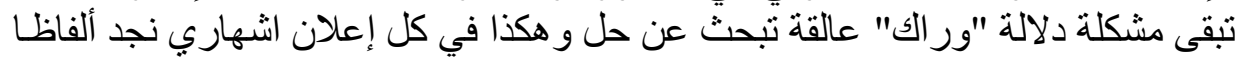

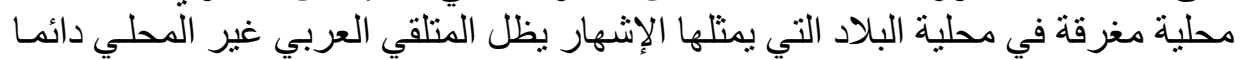

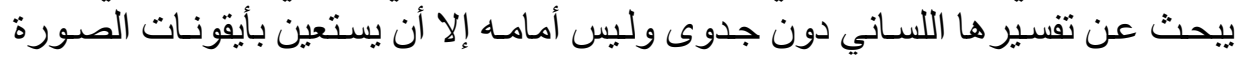


لتقسير الدلالة المستغلقة في بلده العربي أو في بلد عربي آخر.

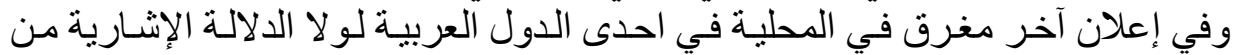

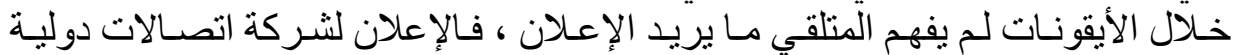

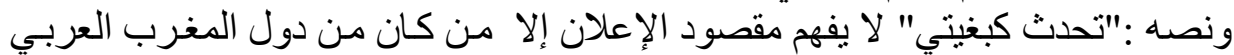

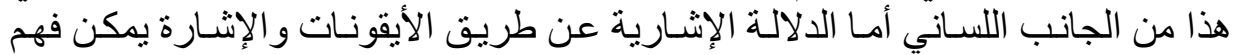

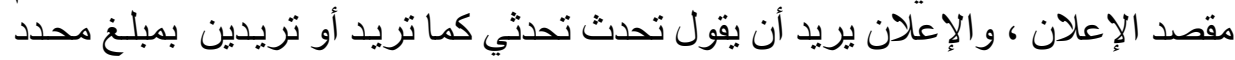

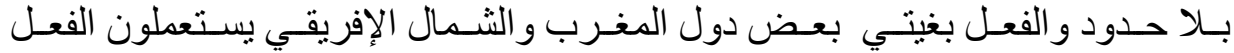

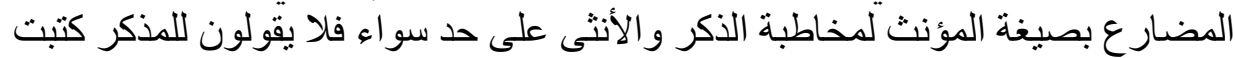

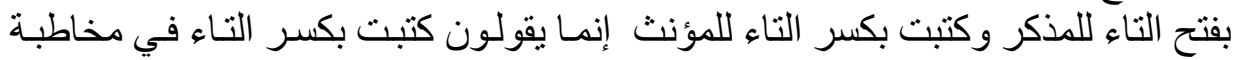

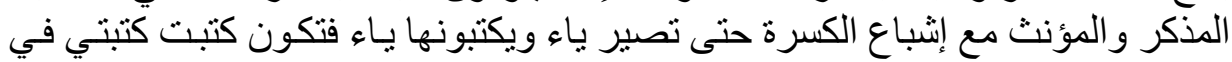

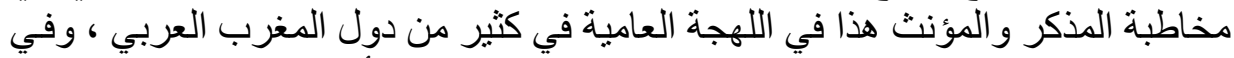

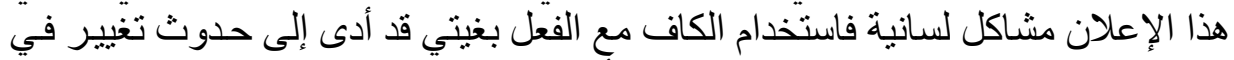

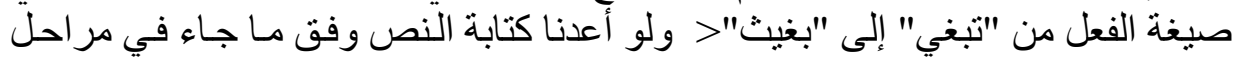

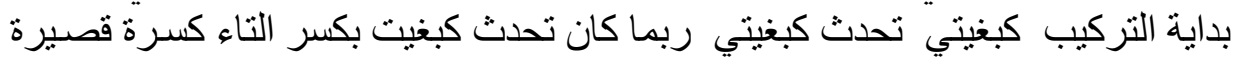

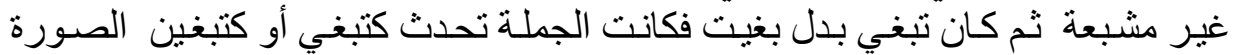

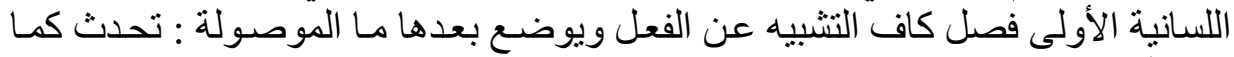

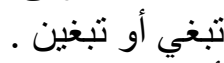

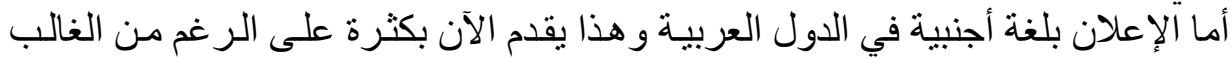

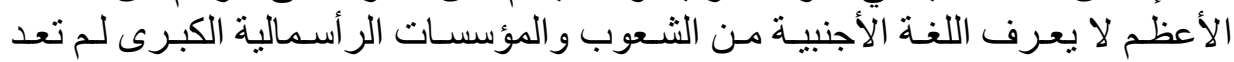

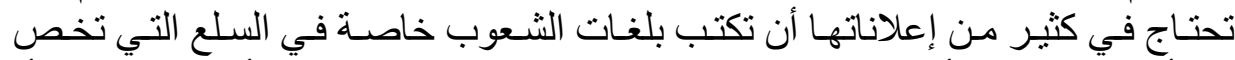

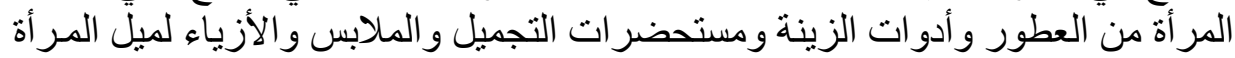

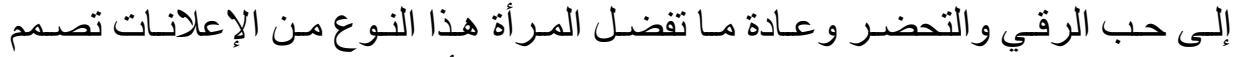

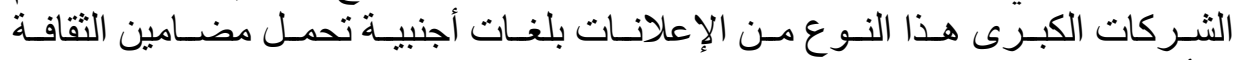

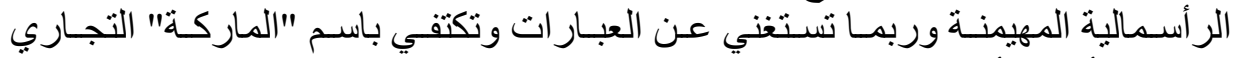

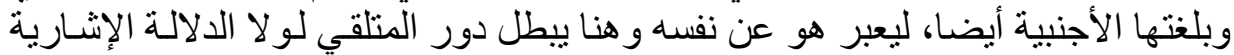

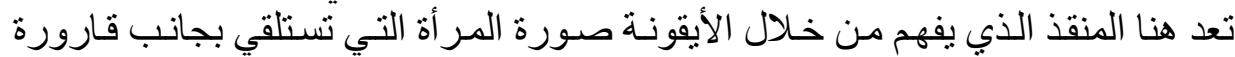

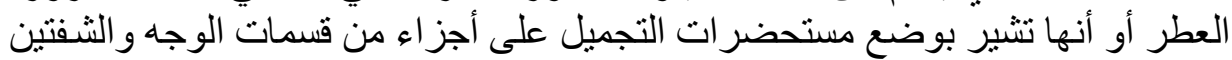

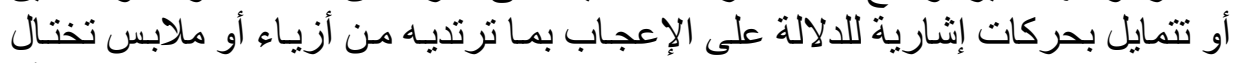

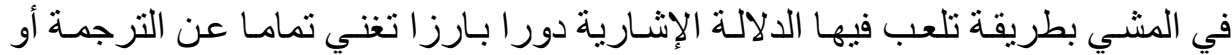

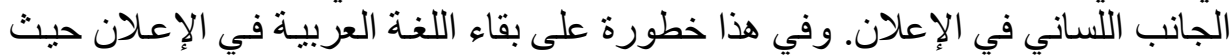

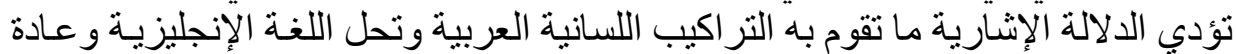

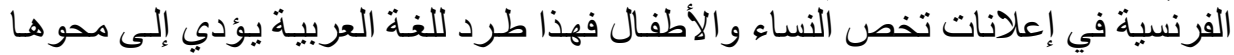

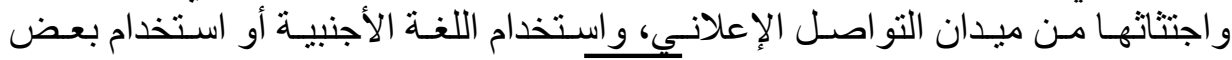




\section{أ.د/ طلبة عبل الستارمسعود}

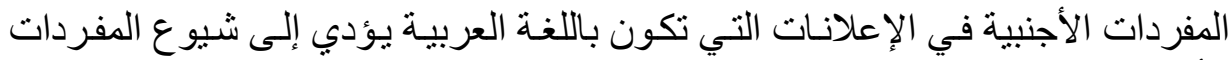

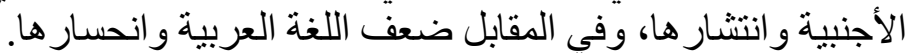

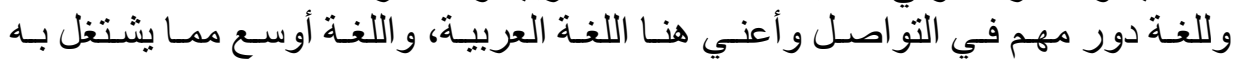

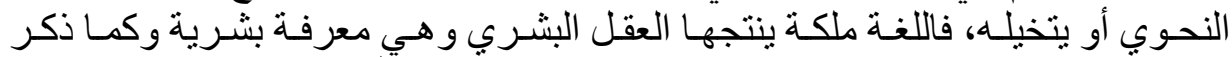

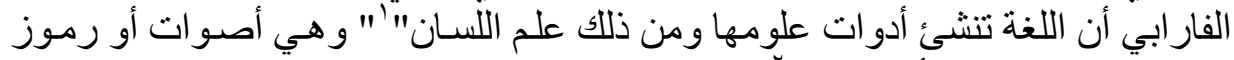

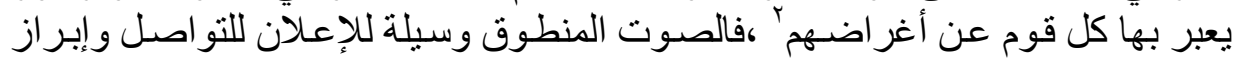

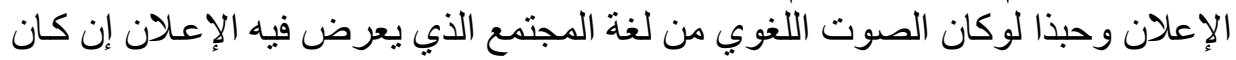

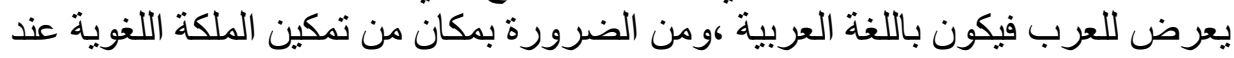

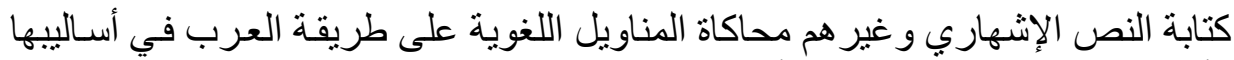

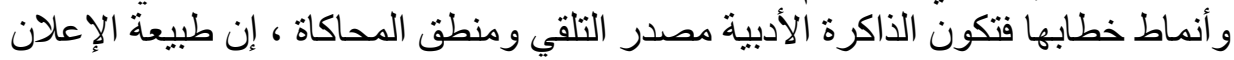

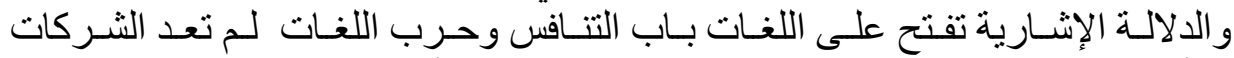

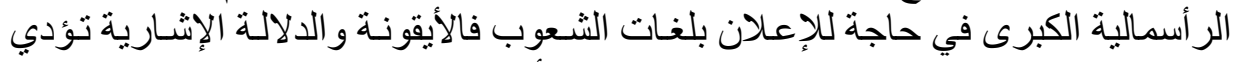

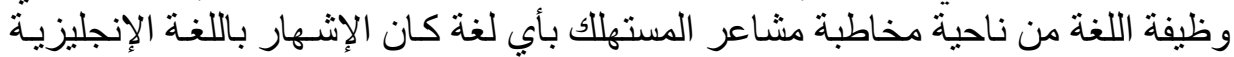

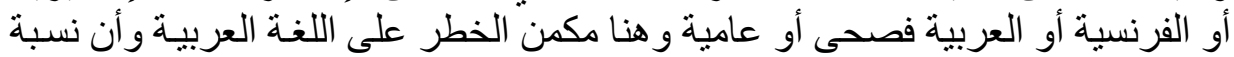

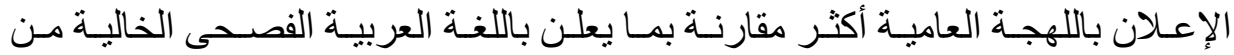
الأخطاء.

الأخطاء في الإعلاء بأن بالعامية: حيث العبارة في الإعلان (بدك تكون فظيع خليك على طبيعتلك) يقصد المعلن التأثلثير في

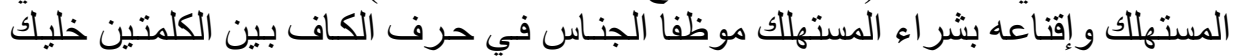

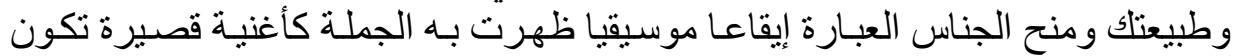

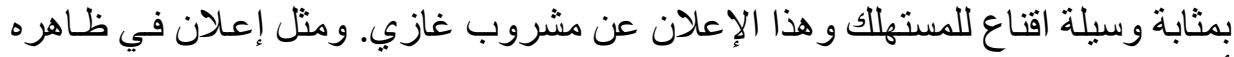

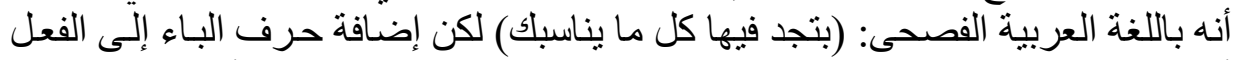

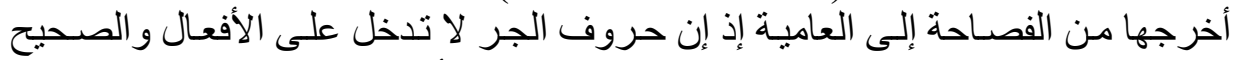

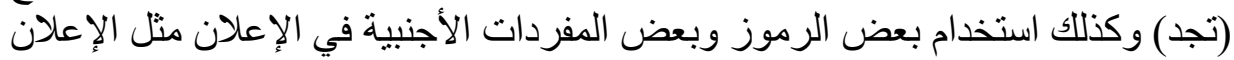

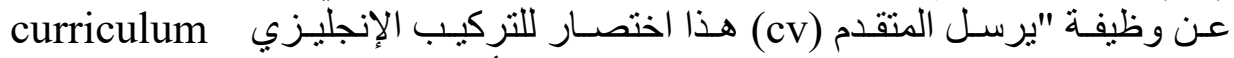

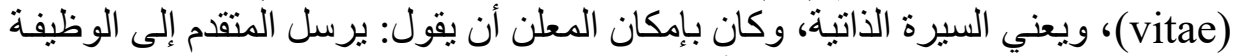

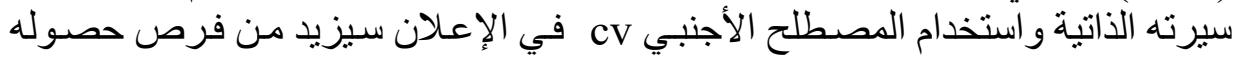

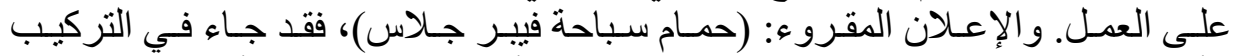

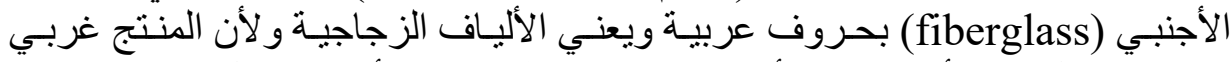

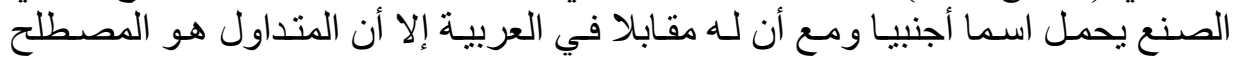

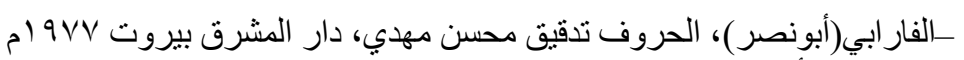

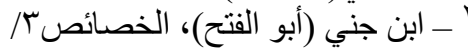




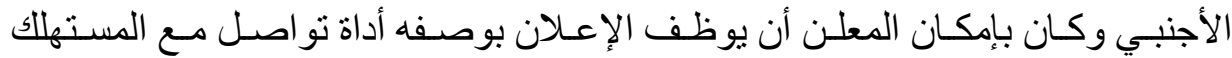

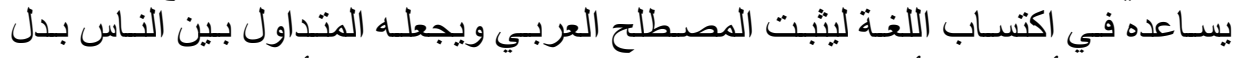

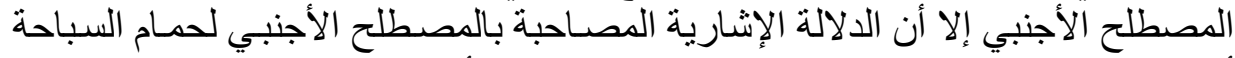

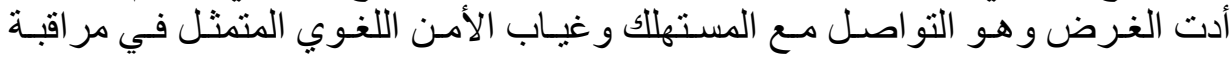

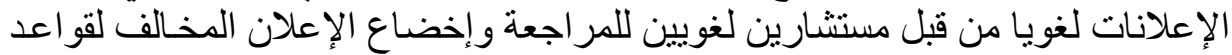

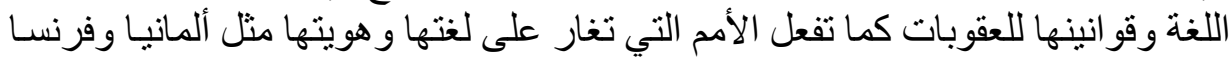
واسبانيا و اليابان.

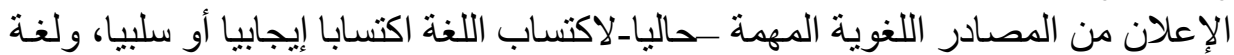

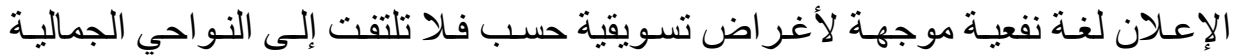

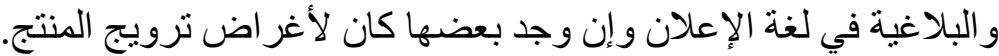

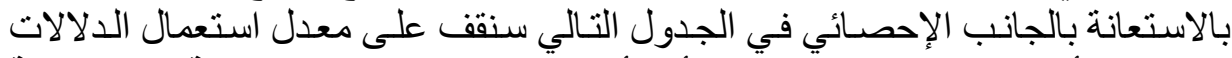

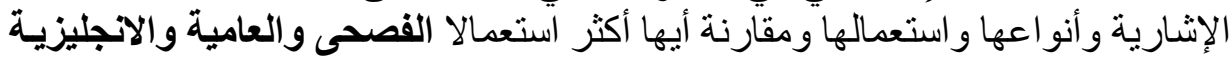

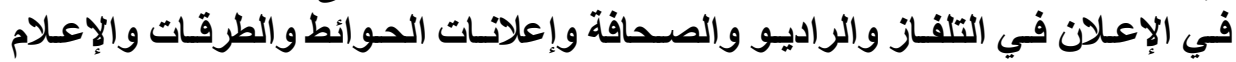
الثبكي فيس بوتك وتويتر ويوتيوب:

\begin{tabular}{|c|c|c|c|c|c|c|}
\hline 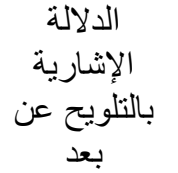 & الإلثارية & الإشثارية الإلة & الإشارية الالية & الإشـارية الدلة & الإلثشارية الإلة & نوع الإعلان \\
\hline $1 \cdot 1$ & Tו & 10 & 11 & 19. & 9. & 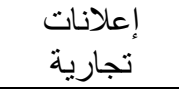 \\
\hline$\% \leq V$ & $\% 9$ & $\% \circ \mathrm{V}$ & $\% \vee$ & $\% \vee$. & \% & ملابس نسائية \\
\hline$\% 0 \leq$ & $\% 7$ & $\%$ rq & $\% 1$ & $\% \leqslant V$ & $\%$ & وألغاب الأطفال \\
\hline$\ldots . . \% \leqslant 0 \ldots$ & $\% 11$ & $\%) \mathrm{V}$ & $\%$. & $\% \wedge \vee$ & $\%$ \%० & الشكو لاتة \\
\hline$\% r$ & $\% r$ & $\% \circ$ & $\% 7$ & $\% \wedge \varepsilon$ & v. & المثبيدات \\
\hline$\% r v$ & $\% 11$ & \%) & $\% \wedge \vee$ & $\% 9$ & $\% \leqslant 0$ & أدوية الضعف \\
\hline
\end{tabular}

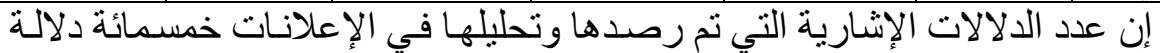

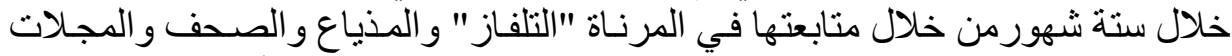
ولوحات إعلانات الطرق في القاهرة و الإسكندرية وجدة ولناة الرياض ولناض والأعلام الثبكي. 


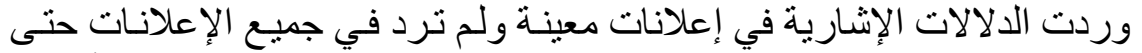

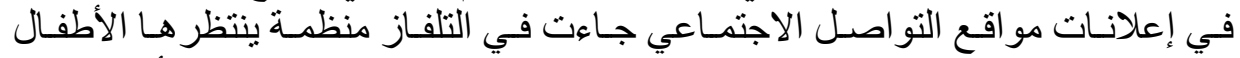

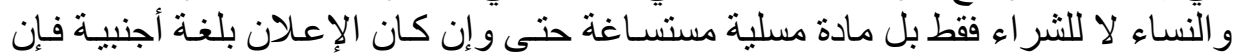

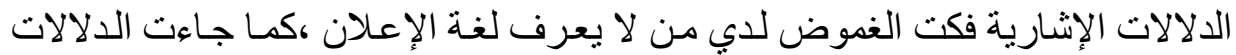

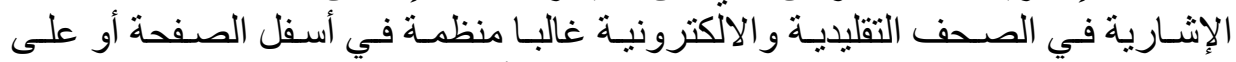

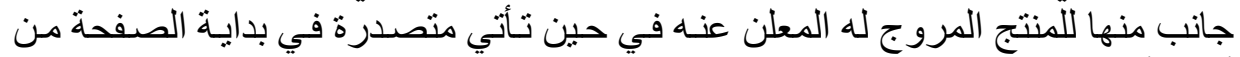

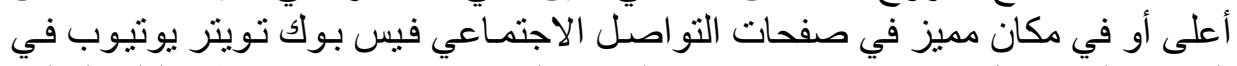

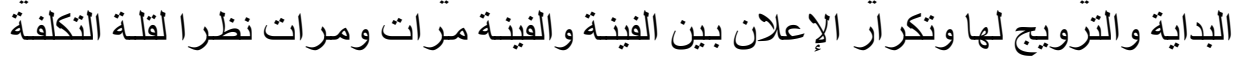

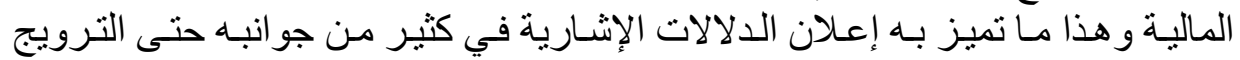

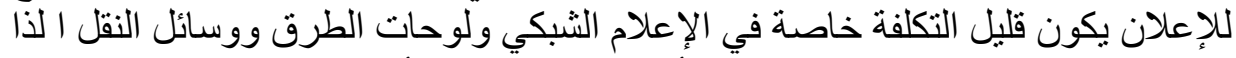

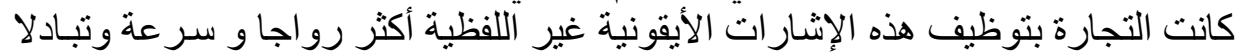

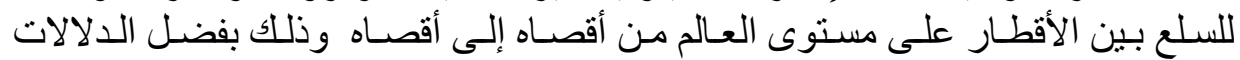

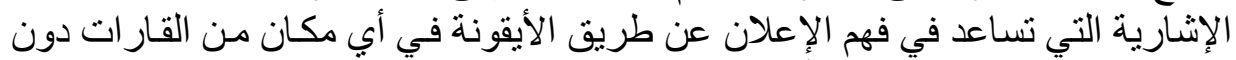
الحاجة للغات بيسر دون تعقيد أو حو ائل .

كثف التحليل الإحصائي للإعلانات المستخدمة للالالات الإشارية أنها تشكل خطر الإنة الإنها

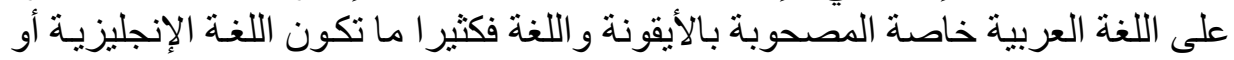

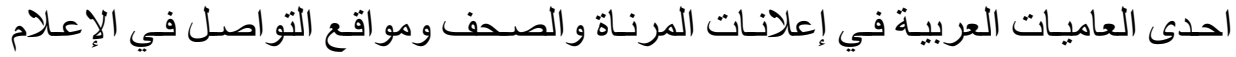

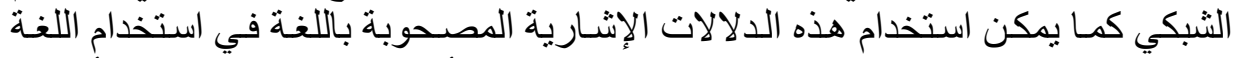

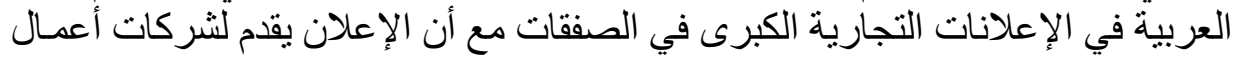

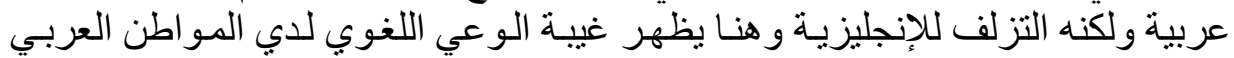
وكذلك غياب فكرة الأمن اللغوي للحفاظ على الهوية.

\section{الخاتمة وإلنتائج : الإلت الإنار}

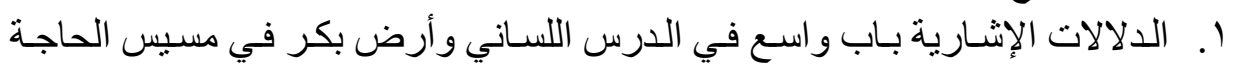

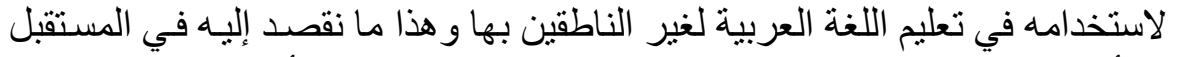

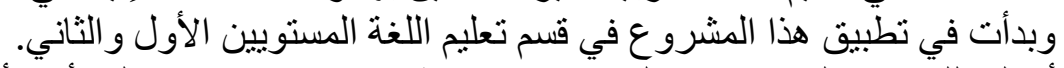

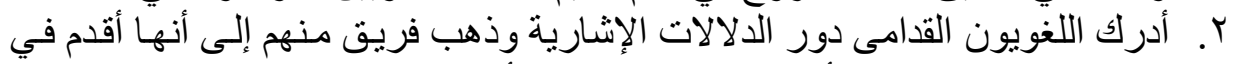

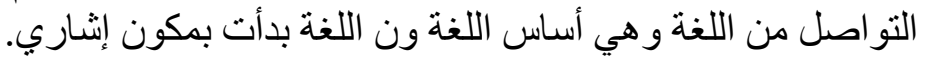

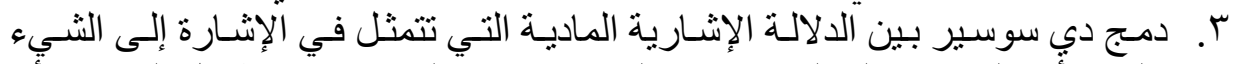

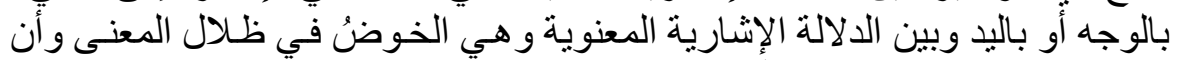

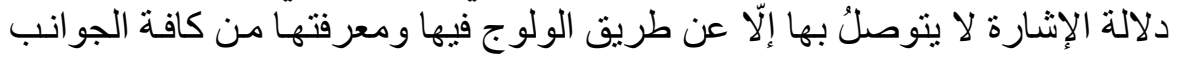




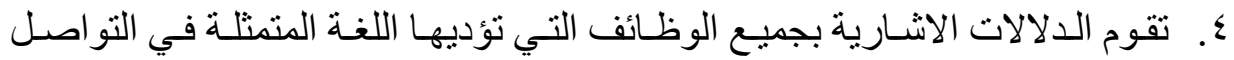

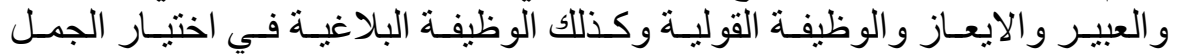

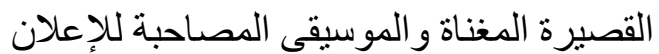

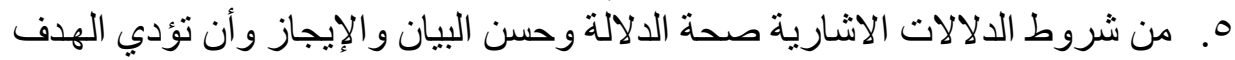

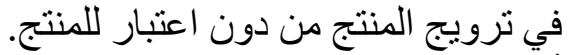

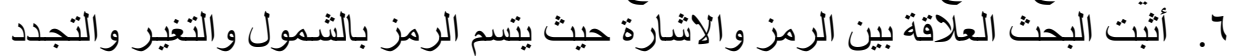

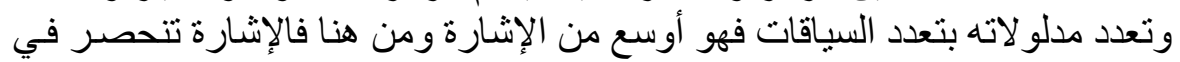

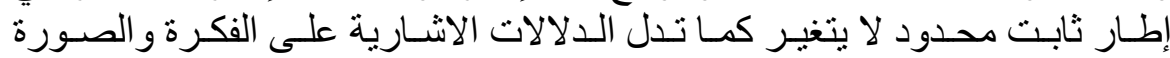
الصوتية.

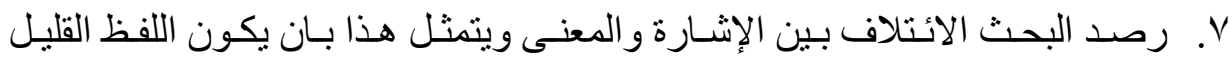

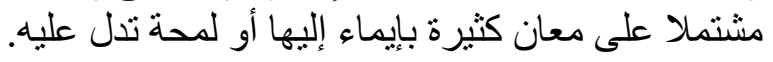

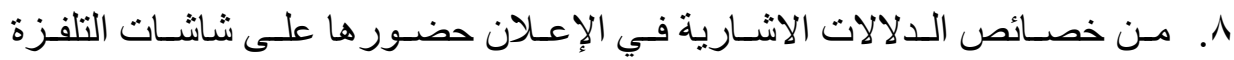

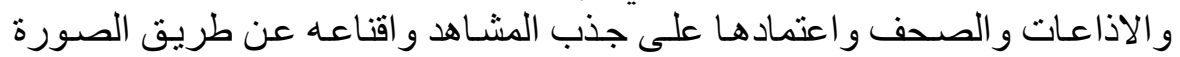
و الحركة و اللون.

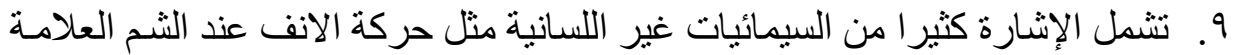

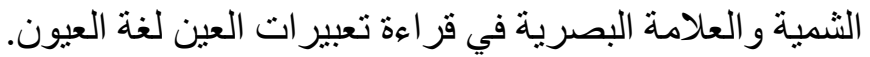

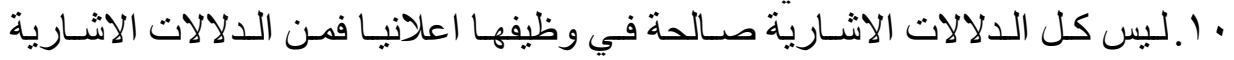

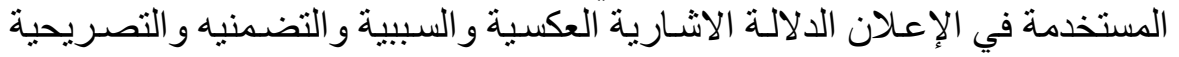

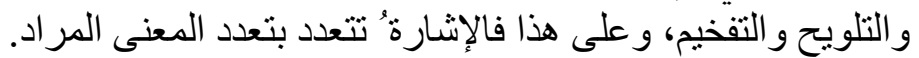

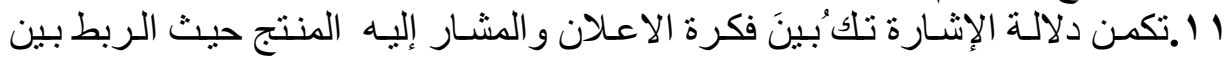

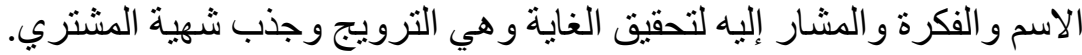

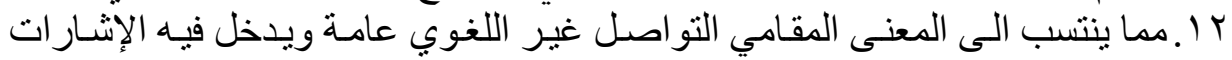

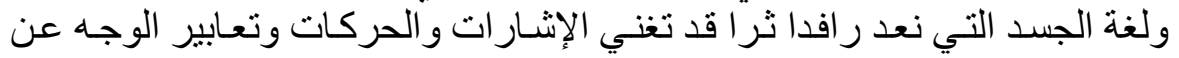
الجانب اللساني.

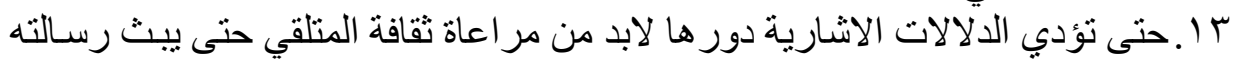

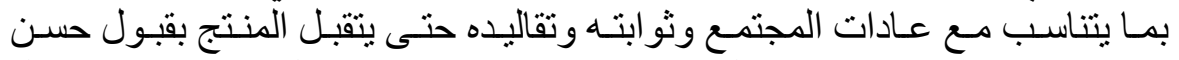

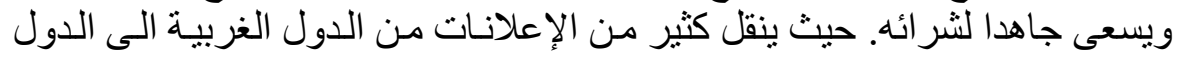

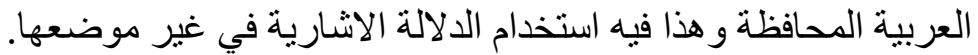

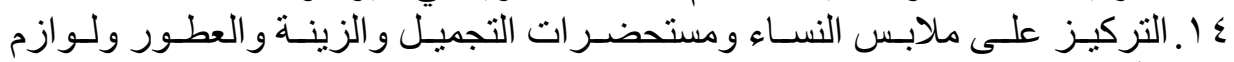

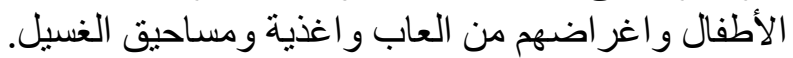

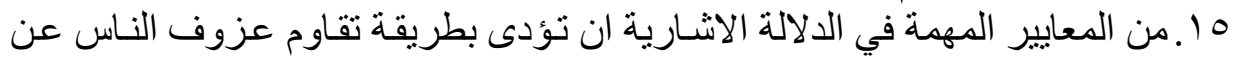


7 ا ـتقوم الإشارة الدلاليـة بدور ها مـع اللغـة الفصحى او العامية او الإنجليزيـة او بدونها

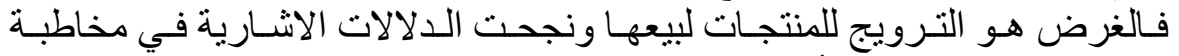

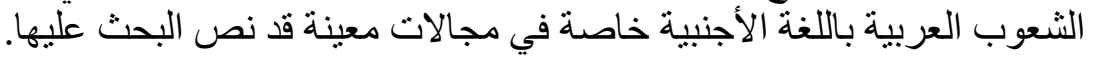

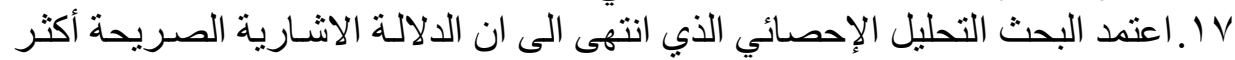

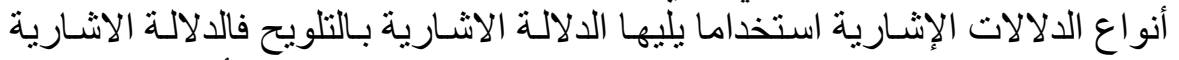

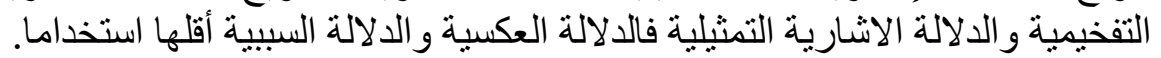

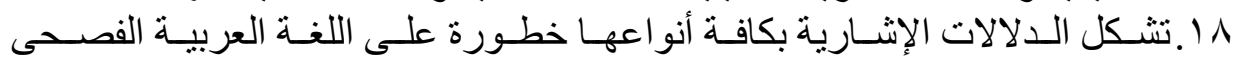

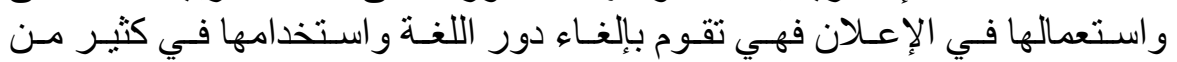
الإعلانات.

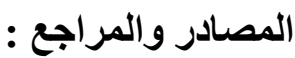

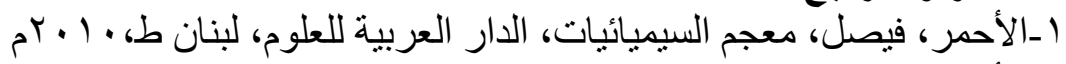

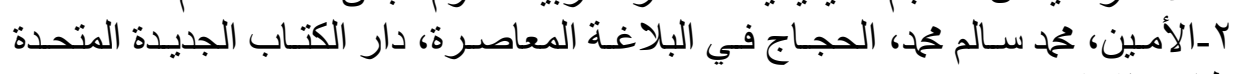

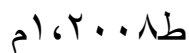

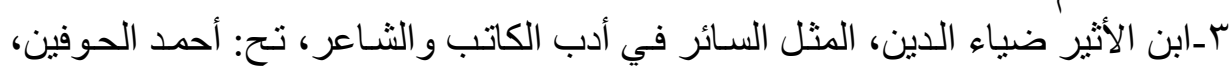

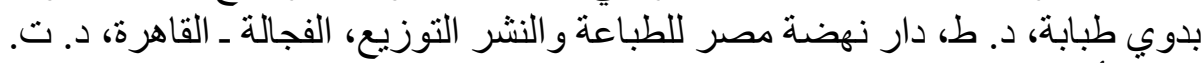

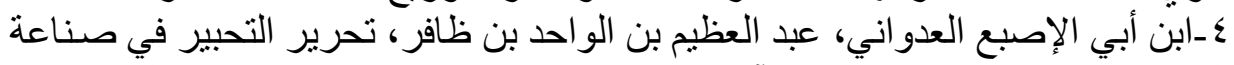

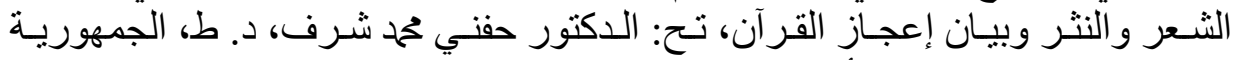

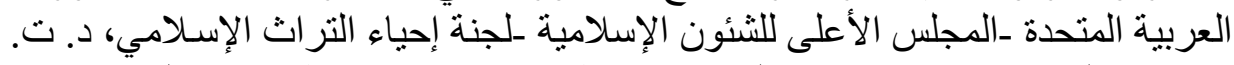

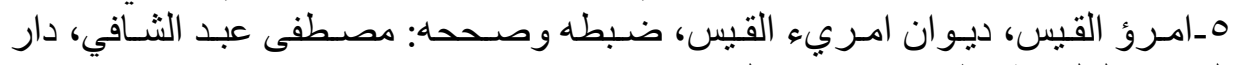

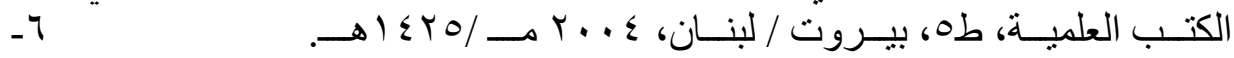

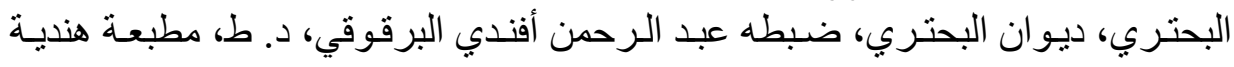

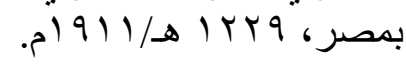

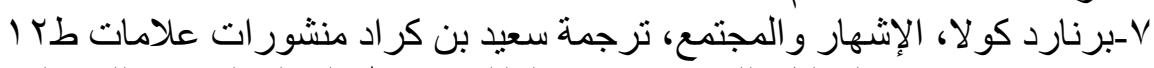

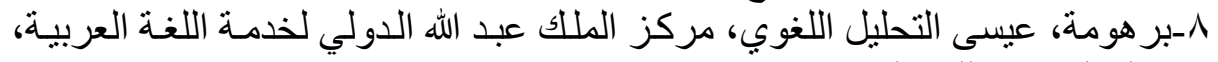

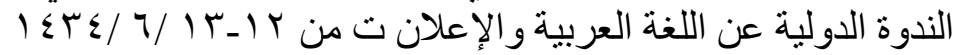

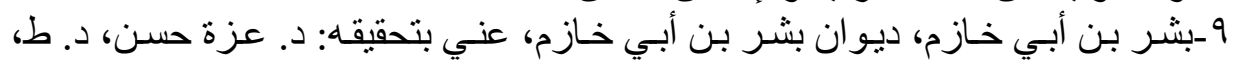

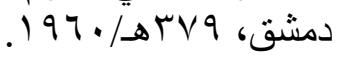

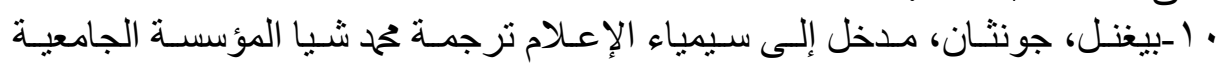

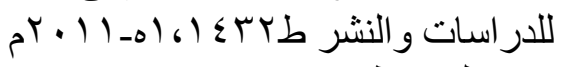

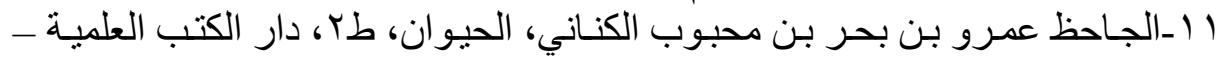

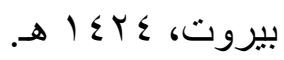


Y ا -جبار ، سعيد، التخييل وبناء الأنسـاق الدلاليـة د سعيد جبار ، التخييل وبنـاء الأنسـاق

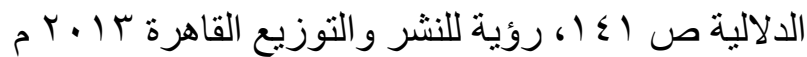

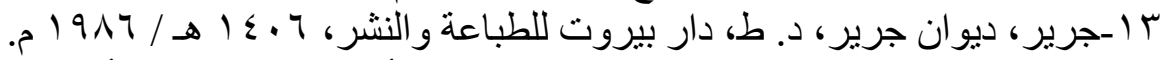

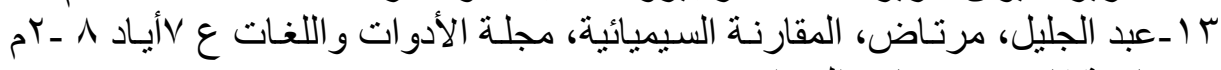

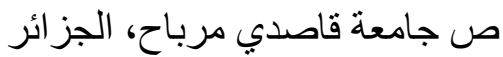

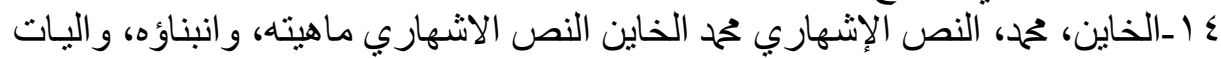

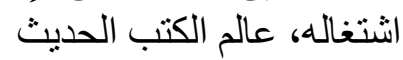

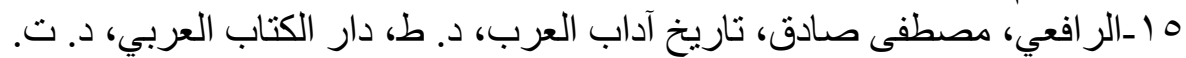

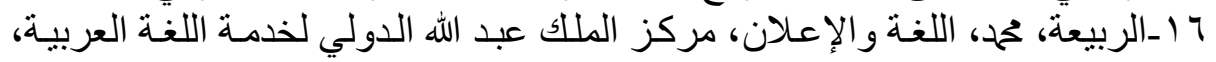

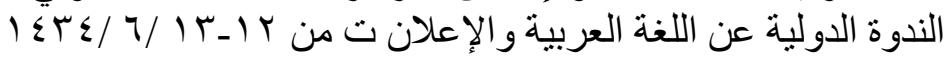

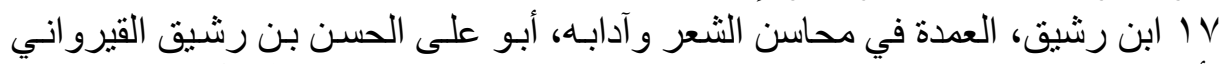

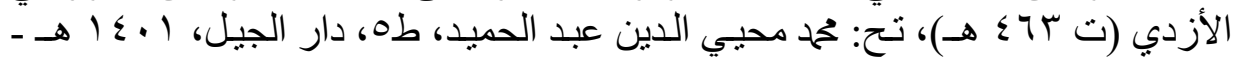
1 1 ـالسعدي، إسر اء عامر شمس الدين، الحجاج في الصورة الأيقونيـة، مجلة سيمائيات،

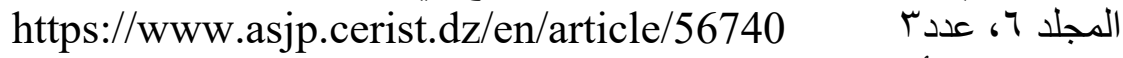

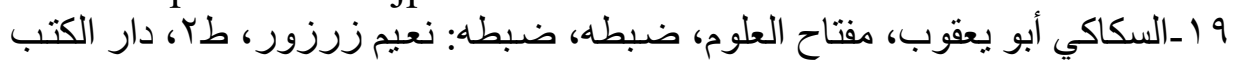

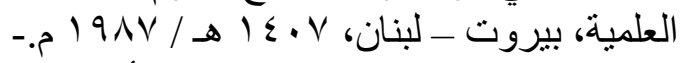

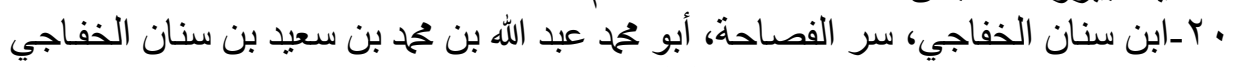

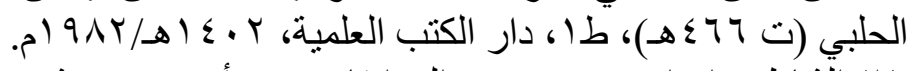

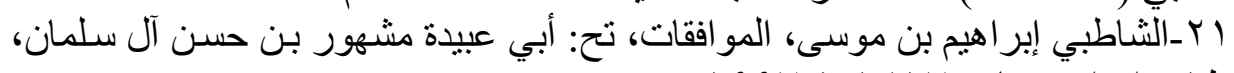

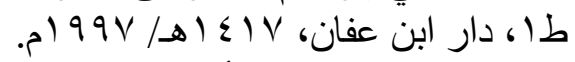

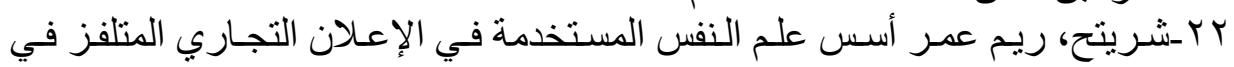

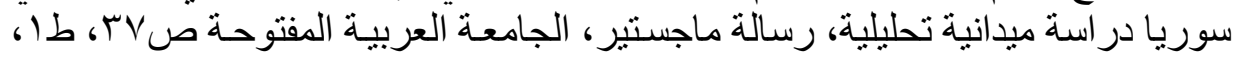

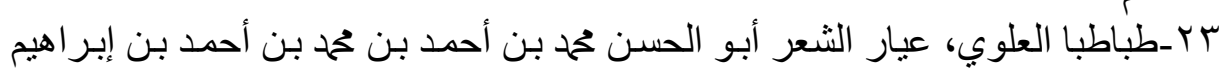

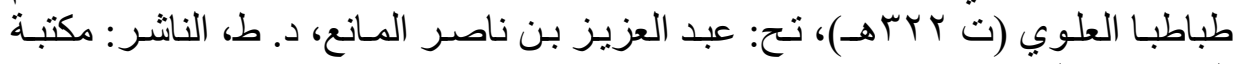

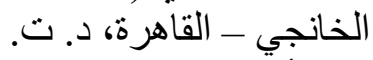

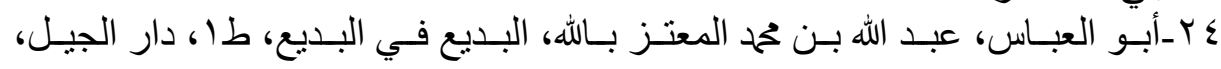

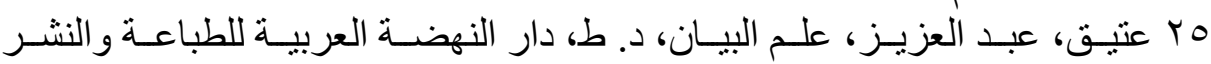

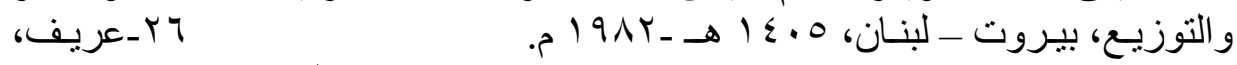

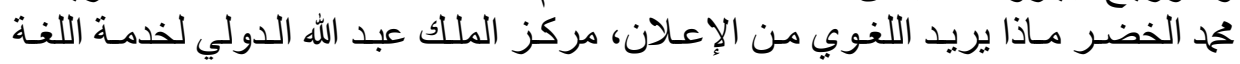

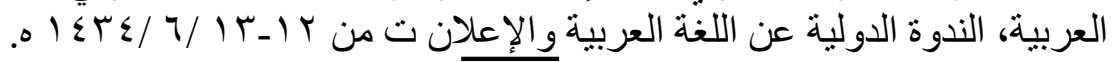
$11 \mathrm{~V}$ 


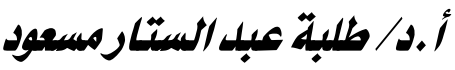

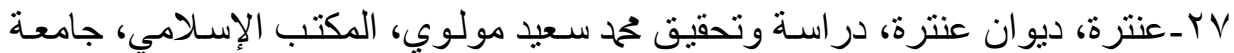

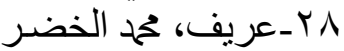

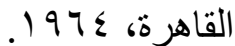

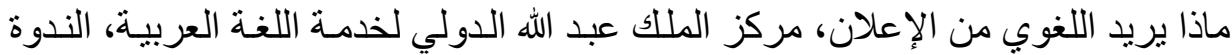

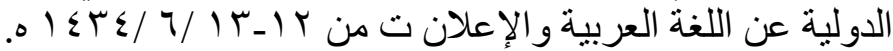

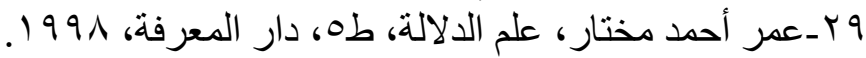

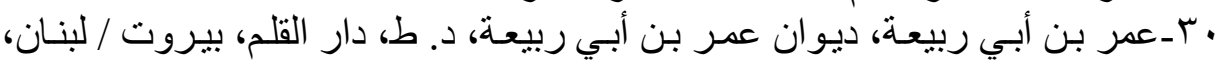

اســغدويس، و غروست، لغة الجسد ترجمة هيلانـة صـالح شقير نشر دار علاء الدين

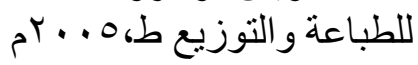

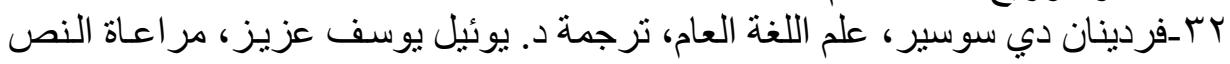

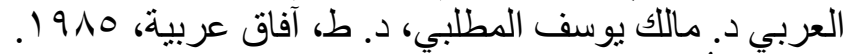

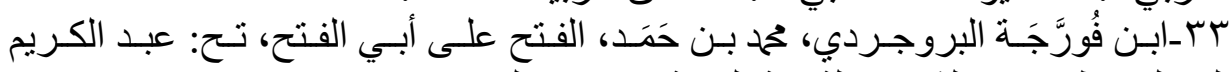

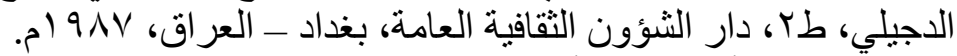

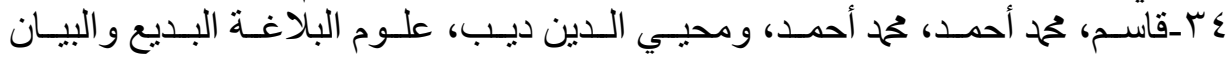

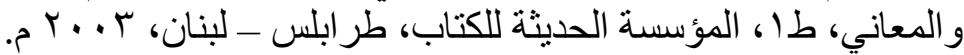

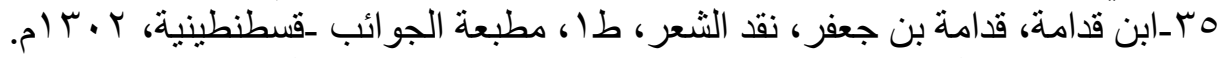

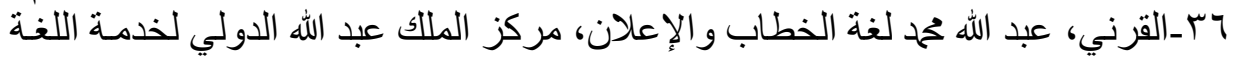

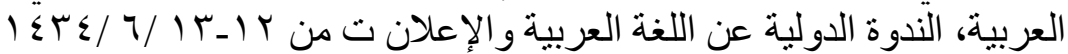

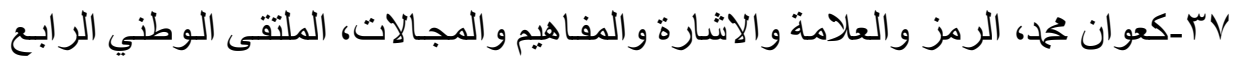

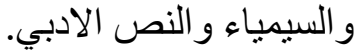
^זـالكفوي أيوب بن موسى أبو البقاء الحنفي، الكليات معجم في المصطلحات و الفروق

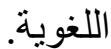

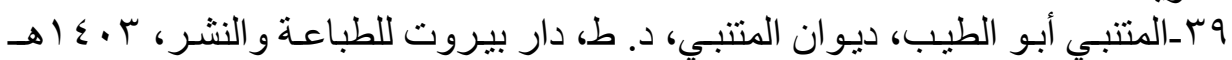

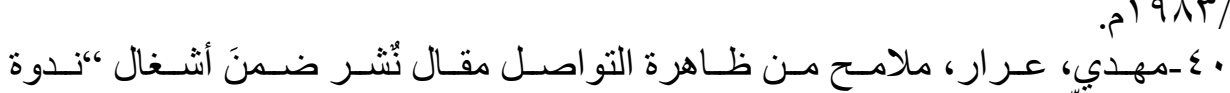

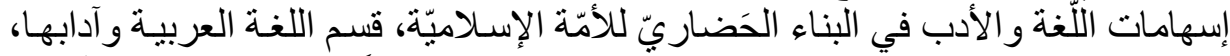

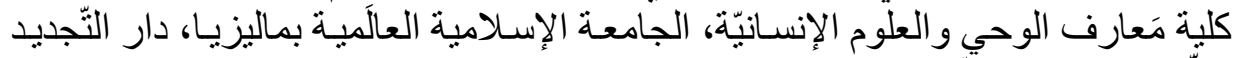

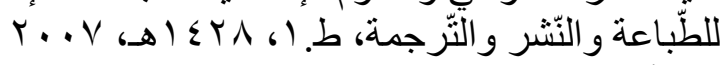

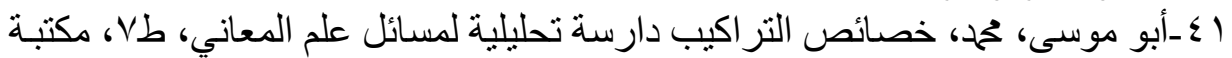

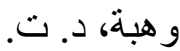
، ك ـالنابغة، ديوان النابغة الذبياني، شرح وتعليق: د. حنا نصر ، طا ، دار الكتاب العربي

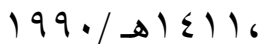




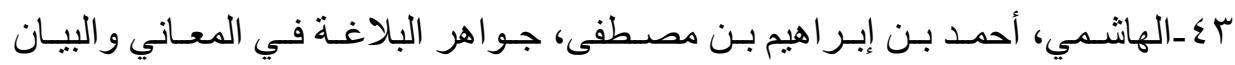

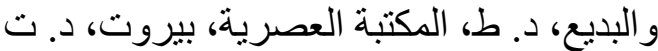

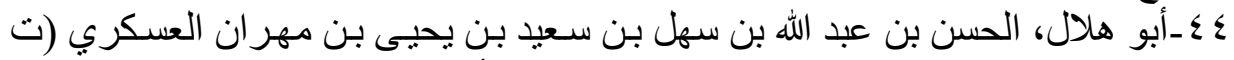

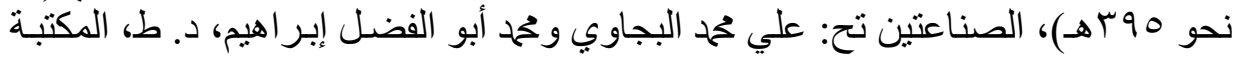

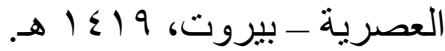

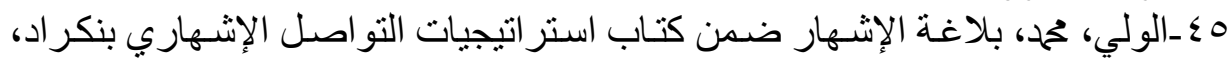

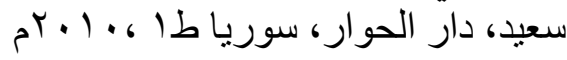


أ. د/ طلبة عبل الستارمسعود

$\Gamma$ 